\title{
Cognitive Mechanisms Behind the Memory- Undermining Effect of Feigned Crime-Related Amnesia
}

Citation for published version (APA):

Mangiulli, I. (2018). Cognitive Mechanisms Behind the Memory-Undermining Effect of Feigned CrimeRelated Amnesia. [Doctoral Thesis, Maastricht University, Univ Bari Aldo Moro, University of Bari]. Maastricht University. https://doi.org/10.26481/dis.20180913im

Document status and date:

Published: 01/01/2018

DOI:

10.26481/dis.20180913im

Document Version:

Publisher's PDF, also known as Version of record

\section{Please check the document version of this publication:}

- A submitted manuscript is the version of the article upon submission and before peer-review. There can be important differences between the submitted version and the official published version of record.

People interested in the research are advised to contact the author for the final version of the publication, or visit the DOI to the publisher's website.

- The final author version and the galley proof are versions of the publication after peer review.

- The final published version features the final layout of the paper including the volume, issue and page numbers.

Link to publication

\footnotetext{
General rights rights.

- You may freely distribute the URL identifying the publication in the public portal. please follow below link for the End User Agreement:

www.umlib.nl/taverne-license

Take down policy

If you believe that this document breaches copyright please contact us at:

repository@maastrichtuniversity.nl

providing details and we will investigate your claim.
}

Copyright and moral rights for the publications made accessible in the public portal are retained by the authors and/or other copyright owners and it is a condition of accessing publications that users recognise and abide by the legal requirements associated with these

- Users may download and print one copy of any publication from the public portal for the purpose of private study or research.

- You may not further distribute the material or use it for any profit-making activity or commercial gain

If the publication is distributed under the terms of Article $25 \mathrm{fa}$ of the Dutch Copyright Act, indicated by the "Taverne" license above, 
Cognitive Mechanisms Behind the Memory-Undermining Effect of Feigned Crime-Related Amnesia

\author{
Ivan Mangiulli
}





\title{
Cognitive Mechanisms Behind the Memory-Undermining Effect of Feigned Crime-Related Amnesia
}

\begin{abstract}
Dissertation
To obtain the degree of Doctor of Philosophy from the University of Bari A. Moro on the authority of Rector Magnificus Prof. dr. Antonio F. Uricchio, and the degree of Doctor at Maastricht University on the authority of Rector Magnificus Prof. dr. Rianne M. Letschert, according to the decision of the Board of Deans, to be defended in public on Thursday the $13^{\text {th }}$ of September 2018 at 10.00 hours in Maastricht
\end{abstract}

by

Ivan Mangiulli 


\section{Supervisor}

Prof. dr. M. Jelicic

\section{Co-supervisors}

Dr. A. Curci, University of Bari

Dr. K. van Oorsouw

\section{Defence Committee}

Prof. dr. P.E.H.M. Muris (Chair)

Dr. H. Otgaar

Prof. dr. E. Rassin, Erasmus University Rotterdam

Prof. dr. G. Sartori, University of Padua

Dr. V. van de Ven 






\section{Content}

$\begin{array}{lll}\text { Chapter } 1 \quad \text { General Introduction } & 11\end{array}$

Introduction $\quad 12$

Relevance of Crime-Related Amnesia in the Legal System 15

The Memory-Undermining Effect of Feigning Amnesia 16

Aims and Outline of the Dissertation 20

Chapter 2 Do Visual and Verbal Reminders of the Crime Reverse

the Memory-Undermining Effect of Simulating Amnesia? 23

Abstract $\quad 24$

Introduction $\quad 25$

Study $1 \quad 28$

Method $\quad 28$

Results $\quad 31$

Discussion $\quad 35$

Study 2

$\begin{array}{ll}\text { Method } & 37\end{array}$

Results $\quad 38$

Discussion $\quad 41$

General Discussion $\quad 41$

Chapter 3 Feigning Amnesia Moderately

$\begin{array}{ll}\text { Abstract } & 48\end{array}$

Introduction $\quad 49$

Method $\quad 52$

Results $\quad 55$

$\begin{array}{ll}\text { Discussion } & 60\end{array}$

Chapter 4 Can Implicit Measures

Detect Source Information in Crime-Related Amnesia? 65

Abstract $\quad 66$

Introduction $\quad 67$

$\begin{array}{ll}\text { Method } & 72\end{array}$

$\begin{array}{ll}\text { Results } & 78\end{array}$

$\begin{array}{ll}\text { Discussion } & 81\end{array}$ 
Chapter 5 Retrieval-Induced Forgetting in

Feigning Amnesia for a Crime Paradigm

$\begin{array}{lc}\text { Abstract } & 88\end{array}$

Introduction $\quad 89$

Method $\quad 91$

Results $\quad 94$

Discussion $\quad 100$

Appendixes 103

$\begin{array}{lll}\text { Chapter } 6 & \text { General Discussion } & 107\end{array}$

Introduction $\quad 108$

Cognitive Memory-Undermining Mechanisms 108

Theoretical and Practical Implications 112

Directions for Future Studies $\quad 114$

$\begin{array}{ll}\text { Final Remarks } & 117\end{array}$

$\begin{array}{ll}\text { References } & 119\end{array}$

$\begin{array}{ll}\text { Summary } & 137\end{array}$

$\begin{array}{ll}\text { Sommario } & 141\end{array}$

$\begin{array}{lr}\text { Valorisation Addendum } & 145\end{array}$

$\begin{array}{lr}\text { Acknowledgments } & 149\end{array}$

$\begin{array}{ll}\text { Curriculum Vitae } & 151\end{array}$ 


Chapter 1

General Introduction 


\section{Introduction}

"I woke up close to the corpse, both times, I do not remember that I killed them, but I do not exclude it. The nights before I was with them, I remember I slept but when I woke up, I was in a blood lake. We had oral intercourse. Then, I fell asleep. It seemed like hours had passed and when I woke up I was entirely covered in blood".

This is not science fiction. ${ }^{1}$ Those words were reported by N.I., a 52 year old man sentenced to life imprisonment for having tortured and killed two prostitutes in a small city nearby Naples, Italy. N.I., also known as "the good giant", is a divorced upholsterer without a previous criminal record, who got caught after five years of police investigation. In 2015, after his arrest, N.I. denied remembering anything related to the crimes he was suspected of. He claimed having a "black hole" in his memory, an amnesic gap for events pertaining to the crimes. According to the prosecutor, on the $13^{\text {th }}$ of February 2010, N.I. murdered S.R., a 63 year old prostitute, by strangling the woman in her house using a rope, and then torturing her with a pair of scissors. Four years later, on the $30^{\text {th }}$ of May 2014, the second murder took place in the victim's place: M.A. was a 74 year old prostitute. Police investigators found her corpse. Her rib cage was broken and one of the bed's feet was stuck in her throat. A psychiatric and psychological evaluation was requested by the Court in order to assess the defendant's mental health at the moment of both brutal, excessive murders. The man never explicitly confessed to the crimes, neither did he entirely explain the evidence held against him. He claimed he only had memories of meeting the two women, without lucidly remembering whether or not he murdered them. Even though mental health problems were not ruled out by the experts who evaluated him, the man received life imprisonment after the first judgment in 2015 . However, as requested by his attorney, the case was recently reopened. N.I. was examined again in 2017 by three specialists in psychiatry and psychology. Although his attorney claimed the defendant was insane, N.I. was found to be fully capable of understanding and controlling his actions at the moment of the crimes. On the $12^{\text {th }}$ of February 2018, the appeal court confirmed the life imprisonment sentence for "the good giant".

Even though the case-report depicted above might appear as uncommon, offenders frequently claim amnesia for their deeds (Bourget \& Whitehurst, 2007; Cima, Merckelbach, Nijman, Knauer, \& Hollnack, 2002; Cima, Nijman, Merckelbach, Kremer, \& Hollnack, 2004; Pyszora, Barker, \& Kopelman, 2003; Pyszora, Fahy, \& Kopelman, 2014). Those who claim memory loss for their crimes may share certain traits, such as a low intelligence quotient (IQ), depressed mood, and

1 This case-report is based on an actual Italian case. See:

http://napoli.repubblica.it/cronaca/2015/05/19/news/nocera_inferiore_arrestato_il_serial_killer_dell e_prostitute-114747481/ 
manipulative behaviour (e.g., Cima et al., 2004). Moreover, crime-related amnesia often occurs during intense arousal, during so-called crimes of passion and/or when perpetrators have been intoxicated with drugs and/or alcohol (e.g., Pyszora et al., 2014). Because genuine amnesia for a crime is relatively uncommon, pretending to have memory loss (i.e., malingering) might account for most of the cases (Jelicic, Merckelbach, \& Van Bergen, 2004). When determining the veracity of a claim of crime-related amnesia, it is important to investigate possible organic or psychological causes of the reported memory loss, and assess the likelihood of malingering.

\section{Types of Amnesia}

Looking into the literature, several taxonomies have been proposed to distinguish between different types of amnesia (Kopelman, 1995; Schacter, 1986). A number of authors have defined two forms of amnesia: organic and dissociative amnesia, also named functional or psychogenic amnesia. Organic amnesia is, by definition, caused by a neurological deficit which can be either structural, for instance as a result of brain injury, or momentary, such as in the case of alcohol or drug intoxication (Bourget \& Whitehurst, 2007; Van Oorsouw \& Merckelbach, 2012). Note that amnesic gaps because of brain injury or intoxication tend to shrink as time passes. This phenomenon was first described in the $19^{\text {th }}$ century by French psychologist Théodule Ribot and is now known as the "law of Ribot". However, in most cases the amnesia will not dissipate completely, meaning that the person involved will have a permanent gap in his/her memory lasting a few minutes (Van Oorsouw, Merckelbach, Ravelli, Nijman, \& Pompen, 2004).

Permanent organic amnesia often is due to structural damage to (a) the hippocampus and surrounding areas or (b) the thalamus. Milner, Corkin, and Teuber (1968) described the famous case of H.M. He suffered from a profound memory loss after having his hippocampus removed in an attempt to treat his epileptic seizures. Essentially, the man was unable to both remember events that occurred 1 to 3 years before the surgery and store any type of new information. An inability to access memories that were created before the injury is termed retrograde amnesia. A failure to store new information in memory, resulting in an inability to recollect the recent past, is labelled anterograde amnesia.

Dissociative amnesia is not caused by a neurological deficit, but has psychological origins. It may occur in the so-called fugue state: This is a rare condition defined by the loss of autobiographical memory and sense of personal identity (Swihart, Yuille \& Porter, 1999). In a fugue state, the usually integrated memory and consciousness functions are compromised, leading to a lack of memory of a person's identity or behaviour. Furthermore, according to some authors, it would be possible to have dissociative amnesia for crime-related events. Many violent crimes are committed by perpetrators who are in a state of rage. When a person is in state of extreme arousal, 
information is encoded and stored in a specific way (in the context of strong emotions). Later, when this individual has "cooled down", there would be a mismatch in his/her emotional state between the learning and the retrieval phase. This mismatch could result in amnesia for criminal events (Bourget \& Whitehurst, 2007; Kopelman, 2002; Porter, Birt, Yuille, \& Herve, 2001; Pyszora et al., 2014; Swihart et al., 1999). Although it cannot be completely excluded that genuine amnesia occurs as a result of extreme emotional arousal, dissociative amnesia, especially for criminal events, is believed to be quite rare. In support of this, research has shown that people are in general well capable of remembering their own actions (Engelkamp \& Zimmer, 1994; Symons \& Johnson, 1997), and that emotional or traumatic events are even better recalled than neutral ones (McGaugh, 2006; McNally, 2005). Therefore, it is not surprising that, in absence of an organic cause, the authenticity of crime-related amnesia is often questioned (Centor, 1982; Jelicic \& Merckelbach, 2007; Liepmann, 2002; Marshall, Serran, Marshall \& Fernandez, 2005; Ornish, 2001).

There is reason to believe that many offenders who claim crime-related amnesia are feigning their memory loss (Centor, 1982; Cima et al., 2002; Marshall et al., 2005). With the term of "feigned crime-related amnesia", forensic mental health experts refer to deliberate simulation of memory problems following a criminal act. Offenders have different reasons to feign memory loss for an offence (Jelicic, Merckelbach \& Boskovic, 2017). Some of them pretend to have amnesia to obstruct police investigations, others hope that simulating memory loss will be beneficial to the outcome of their trial. Moreover, some offenders may feign amnesia as an attempt to prevent endless conversations about the crime in the course of psychiatric treatment (e.g., Cima et al., 2002). In closing, the prevalence of feigned crime-related amnesia is nontrivial and the practical consequences are far from irrelevant in the legal arena (Christianson \& Merckelbach, 2004; Smith \& Resnick, 2007; Van Oorsouw \& Merckelbach, 2010). For example, the high occurrence of amnesia claims can mislead both the general public and legal professionals into believing that amnesia is a frequent and reasonable phenomenon resulting from traumatic episodes such as crimes (Cima et al., 2002). 


\section{Relevance of Crime-Related Amnesia in the Legal System}

For the legal system, crime-related amnesia presents a serious concern because, as noted above, a certain number of defendants claim total or partial amnesia for actions pertaining to their crime. Although the exact number of such cases is unknown, approximately a third of violent offenders claim memory loss (e.g., Cima et al., 2002). Forensic psychiatrists and psychologists are well aware of this issue. Leitch (1948), for instance, pointed out that the $31 \%$ of manslaughter or murder convicts claimed amnesia following a crime. In a same vein, O'Connell (1960) found that $40 \%$ of homicide defendants reported memory loss. And Kopelman (1995) noted that 25-45\% of individuals found guilty of homicide stated to have amnesia for their deeds. A similar percentage has been found in German forensic psychiatric inpatients (24\%, Cima, Merckelbach, Hollnack, \& Knauer, 2003) and in a Dutch sample (25\%, Cima et al., 2004). Moreover, Pyszora, Barker, and Kopelman (2003) found that $29 \%$ of a 1 -year cohort of individuals sentenced to life imprisonment claimed memory loss for their offence ( $31.4 \%$ of those were convicted of homicide).

Even though a number of jurisdictions articulated that crime-related amnesia per se (i.e., automatic) is not a bar to an individual's competency to stand trial (i.e., CTS), such claim in court does raise both doctrinal and practical issues (e.g., Tysee, 2005; Tysse \& Hafemeister, 2006). The two most influential arguments pertaining to why, at least to some extent, amnesia should be considered relevant to CTS consist of (1) the ability of the defendant to consult with his/her attorney and (2) the accused's right to a fair trial. These two arguments are, indeed, conceptually related to each other. To begin with, some authors (e.g., Slobogin \& Smith, 1982) have suggested that a lack of memory for criminal events jeopardizes the defendant's capability to communicate with his/her counsel. Temporary or permanent amnesia may interfere with the preparation of the defendant's defense, suggesting that the accused should be found incompetent to stand trial (Konson \& Robey, 1973). Due to the accused's inability to cooperate with an attorney, consequently, it has been questioned whether or not this leads to a violation of due process (Hermann, 1986). If the defendant can neither inform his/her attorney about the circumstances of the alleged crime, nor distinguish or challenge misleading or false accusations related to his/her own case, the right to a fair trial might be violated and therefore denied. Roesch and Golding (1986) illustrated the potential relevance of amnesia to CTS. An offender who claimed amnesia following sexual assault and capital murder was given the death penalty. However, after several sessions with psychologists, it appeared that the defendant was capable of remembering some details that led the sexual assault to be dropped from the accusations. Indeed, sexual assault had not taken place, since he had paid the victim for sex and murdered her after having had an intense argument. Finally, the man pled guilty to second degree murder and avoided the capital sentence. Although quite unique, 
this scenario highlights why courts should consider amnesia as a possible obstacle to a fair trial, and emphasizes the importance of information gathering from defendant in high-stake cases.

Undoubtedly, courts are skeptical about claims of crime-related amnesia because of the remarkable high rate of such claims and the fact that memory loss can easily be feigned. However, distinguishing genuine amnesia from feigned memory loss can be quite difficult and this may hamper CTS determination (Tysee, 2005; Tysse \& Hafemeister, 2006). Evidence suggests that the intentional simulation of amnesia might impair actual memory for criminal acts (e.g., Christianson \& Bylin 1999; Van Oorsouw \& Merckelbach, 2004). Indeed, perpetrators who falsely claimed amnesia of the act may later encounter actual problems in retrieving crime-related information. While in real-life cases what defendants truly remember may differ from what they actually decide to disclose in an attempt to affect the outcome of their trial, the scientific literature provides several hints of a detrimental effect of feigning amnesia on perpetrators' memory (i.e., the memoryundermining effect of feigning amnesia; Christianson \& Bylin, 1999).

\section{The Memory-Undermining Effect of Feigning Amnesia}

Over the past decades, research has shown that motivated forgetting of unwanted memories may sometimes take place in individuals (e.g., Anderson \& Hanslmayr, 2014). And although feigned amnesia is a recurring behaviour among offenders of violent homicide and sexual assaults (Bourget \& Whitehurst, 2007; Cima, et al., 2002; Cima, et al., 2004; Pyszora, et al., 2003; Pyszora, et al., 2014), relatively little is known about the consequences of deliberate simulation on later memory of the criminal act.

Several studies have investigated the negative consequences of feigning amnesia on the actual memory for a crime (See Table 1; Bylin, 2002; Bylin \& Christianson, 2002; Christianson \& Bylin 1999; Sun, Punjabi, Greenberg, \& Seamon, 2009; Van Oorsouw \& Merckelbach, 2004, 2006). The typical procedure to explore the memory-undermining effect of feigning crime-related amnesia is as follows: To begin with, individuals are usually exposed to a written/narrative script about a crime. They are furthermore instructed to identify themselves with the offender or asked to commit a mock crime. Next, participants are distributed to one of the two (or three) conditions: Some participants are asked to collaborate with the police by reporting as accurately as possible all information they remember about the crime (i.e., confessor group); others are instructed to minimize or evade their responsibility for the crime by simulating lack of memory for the criminal event (i.e., simulator group; Bylin, 2002; Christianson \& Bylin 1999; Van Oorsouw \& Merckelbach, 2006). Sometimes, a third condition is included consisting of participants who do not receive any instruction, and who serve as a delayed test-only control condition (i.e., control group; Bylin \& Christianson, 2002; Sun 
et al., 2009; Van Oorsouw \& Merckelbach, 2004). During the first memory phase, participants in the first two conditions (confessors vs. simulators) are given a free and cued recall test pertaining to the crime. One week later, during the second memory phase, all participants of the two (or three) conditions are requested to genuinely account for the crime event, through the same free and cued recall test.

Table 1. Summary of major research in the feigning amnesia for a crime field. Authors, number of participants included, type of crime stimulus used, instruction given to simulating amnesia condition, $p$ value for simulating amnesia effect, and presence of the delayed test-only control group, are displayed for each study.

\begin{tabular}{|c|c|c|c|c|c|c|}
\hline \multirow[t]{2}{*}{ Authors } & \multirow[t]{2}{*}{ Sample } & \multirow[t]{2}{*}{$\begin{array}{c}\text { Crime } \\
\text { Stimulus }\end{array}$} & \multirow[t]{2}{*}{$\begin{array}{l}\text { Instruction } \\
\text { Given }\end{array}$} & \multicolumn{2}{|c|}{$\begin{array}{l}\text { Feigning } \\
\text { Amnesia }\end{array}$} & \multirow[t]{2}{*}{$\begin{array}{l}\text { Control } \\
\text { Group }\end{array}$} \\
\hline & & & & $p$ & $d$ & \\
\hline $\begin{array}{c}\text { Christianson \& } \\
\text { Bylin, } 1999\end{array}$ & 54 & $\begin{array}{l}\text { Narrative } \\
\text { story }\end{array}$ & $\begin{array}{l}\text { Evading } \\
\text { responsibility }\end{array}$ & .05 & - & $\mathrm{x}$ \\
\hline \multirow[t]{2}{*}{ Bylin, 2002* } & \multirow[t]{2}{*}{55} & \multirow[t]{2}{*}{$\begin{array}{l}\text { Narrative } \\
\text { story }\end{array}$} & \multirow[t]{2}{*}{$\begin{array}{l}\text { Evading } \\
\text { responsibility }\end{array}$} & $<.001$ & 1.27 & \multirow[t]{2}{*}{$\mathrm{x}$} \\
\hline & & & & $<.001$ & 1.28 & \\
\hline $\begin{array}{c}\text { Bylin \& } \\
\text { Christianson, } 2002\end{array}$ & 79 & $\begin{array}{l}\text { Narrative } \\
\text { story }\end{array}$ & $\begin{array}{l}\text { Appearing not } \\
\text { guilty }\end{array}$ & $<.05$ & .98 & n.s \\
\hline $\begin{array}{c}\text { Van Oorsouw \& } \\
\text { Merckelbach, } 2004\end{array}$ & 61 & Mock crime & $\begin{array}{l}\text { Minimizing } \\
\text { responsibility }\end{array}$ & $<.05$ & .77 & n.s \\
\hline $\begin{array}{c}\text { Van Oorsouw \& } \\
\text { Merckelbach, } 2006\end{array}$ & 60 & Mock crime & $\begin{array}{l}\text { Evading } \\
\text { responsibility }\end{array}$ & $<.05$ & 1.27 & $\mathrm{x}$ \\
\hline $\begin{array}{l}\text { Sun, Punjabi, } \\
\text { Greenberg, \& } \\
\text { Seamon, 2009 }\end{array}$ & 106 & $\begin{array}{l}\text { Narrative } \\
\text { stories }\end{array}$ & $\begin{array}{l}\text { Evading } \\
\text { responsibility }\end{array}$ & $\begin{array}{l}<.0001 \\
<.0001\end{array}$ & - & n.s \\
\hline
\end{tabular}

"Bylin's study (2002) involved two simulation groups: 18 non-repeat simulation (i.e., SIM 1) and 19 repeat simulation (i.e., SIM 2), first two lines of the corresponding row, respectively.

'Sun and colleagues' study (2009) consisted in two experiments: 60 and 46 participants included, first two lines of the corresponding row, respectively.

Note: $p$ and Cohen's $d$ values for feigning amnesia referred to the difference between confessor and simulator groups only for free recall outcome for each research. Instead, the last column (Control Group) concerns the comparison between simulators and controls groups in which non-significant (n.s.), significant differences $(p<.05)$, and absence of control group condition (x), are reported.

Typically, when simulators are asked to give up their role as a feigner, they exhibit a weaker memory for the mock crime or the crime narrative than those who are not asked to feign memory loss (Bylin, 2002; Bylin \& Christianson, 2002; Christianson \& Bylin, 1999; Sun et al., 2009; Van 
Oorsouw \& Merckelbach, 2004). Relatedly, it is commonly noticed that feigning participants comply with their instructions by withholding, distorting, and introducing new information (i.e., commission errors) on the initial memory test (Bylin, 2002; Bylin \& Christianson, 2002; Van Oorsouw \& Merckelbach, 2004, 2006). It seems that simulating participants use laypeople's ideas about how memory loss works (Bylin, 2002). Therefore, it is not surprising that many of them come up with a personal, self-generated story of the crime (i.e., simulated version of the crime). Creating a "new version" of the act not only impairs participants' memory for the crime (e.g., Christianson \& Bylin, 1999; Van Oorsouw \& Merckelbach, 2004), but also, as some authors pointed out, increases the recall errors over time, as a result of an elaborative cognitive processing (Van Oorsouw \& Giesbrecht, 2008).

Taken together, research on simulating amnesia suggests that feigning memory loss leads to impairment of actual memory for a crime and, to some extent, increases the number of errors over time (e.g., Bylin, 2002; Christianson \& Bylin 1999; Van Oorsouw \& Giesbrecht 2008; Van Oorsouw \& Merckelbach, 2004). However, the underlying mechanism of memory detriments after feigning amnesia yet has to be identified. Christianson and Bylin (1999) proposed three possible cognitive explanations for why, at least to some degree, feigning amnesia would undermine actual memory for a criminal event: (1) lack of rehearsal, (2) source monitoring confusion, and (3) retrieval-induced forgetting.

\section{Lack of Rehearsal}

As said above, several authors have included a delayed testing-only control group in the experimental design in order to test the underlying mechanism of feigning amnesia (e.g., Bylin \& Christianson, 2002; Sun, et al., 2009; Van Oorsouw \& Merckelbach, 2004). Contrary to significant differences in delayed memory recall between simulating participants and those who reported honestly during both memory phases (i.e., confessors), no differences emerged on this memory measure between simulators and controls (i.e., participants who did not initially recall the crime stimulus and reported honestly for the same event only at the second memory phase). That is, in contrast to confessors, simulators and controls did not have to provide details of the crime after watching the crime stimulus. In other words, both groups did not elaborately engage in rehearsal of the crime. This lack of rehearsal, thus, might explain the memory-undermining effect of feigning amnesia (e.g., Van Oorsouw \& Merckelbach, 2004). Alternatively, Sun and colleagues (2009) stated that "there is no feigned amnesia effect other than differential practice at recall" (p. 89). They argued that there is nothing unique about the cognitive processes involved in pretending to suffer from memory loss. The memory-undermining effect of feigning amnesia would not take place because its detrimental consequence on the memory for the criminal experience simply 
reflects a variation in the opportunity to practice the crime stimulus (e.g., Bornstein, Liebel, \& Scarberry, 1998; Sun et al., 2009).

\section{Source Monitoring Confusion}

Another possible account for the memory undermining effect of feigned amnesia for a mock crime or narrative story has to do with the source monitoring framework (SMF; Johnson, Hashtroudi, \& Lindsay, 1993; Mitchell \& Johnson, 2009). The SMF refers to the processes needed to distinguish memories belonging to different sources (e.g., reality vs. imagination). The SMF suggests that memories for experienced events involve more contextual (e.g., spatial and temporal), perceptual (e.g., sound and color) and affective (e.g., emotions) details than memories for imagined events. Source monitoring errors, therefore, take place when memory for an imagined event contains the same contextual, perceptual and affective details as a memory for a perceived event.

Drawing on the SMF, Christianson and Bylin (1999) suggested that when feigners simulate memory loss, they oftentimes come up with a different, self-generated version of the crime which might be confused with the original experience causing source monitoring errors. Such source monitoring misattribution, thus, may lead feigners to incorporate some of that distorted information into their actual memory, thereby undermining the entire memory for original experience. So far, the SMF appears to be an unlikely explanation for the feigning amnesia effect. If source monitoring confusion was the mechanism behind the feigning amnesia effect, some repetition of memory errors during the second memory phase - when participants were instructed to honestly report the crime would have been observed. Yet, some studies found no link between the number of errors made by feigners in the initial memory phase and errors provided during the second memory phase (e.g., Van Oorsouw \& Merckelbach, 2004, 2006). Thus, it might be that the weaker simulators' memory performance at the second session is not caused by self-generated errors.

\section{Retrieval-induced Forgetting}

Finally, Christianson \& Bylin (1999) proposed that feigners' memory detriments might be due to retrieval-induced forgetting (RIF, Anderson, 2003; Anderson, Bjork, \& Bjork, 1994; Levy \& Anderson, 2002). RIF is a memory phenomenon that takes place when selective retrieval of specific information leads to forgetting of other related details. Drawing on the inhibition-based forgetting theory, forgetting is a consequence of an inhibitory mechanism which supports selective retrieval by suppressing the conflict from related memories (e.g., Anderson, 2003; Levy \& Anderson, 2002).

By this view, simulators would tend to omit crucial crime-related information while retrieving only certain elements during the process of feigning amnesia. Therefore, those latter information 
would be strengthened in memory, while other details would be weakened, leading to impaired recall of the entire crime over time. When feigners make-up their self-generated version of the crime, thereby ignoring crucial details of the original crime, this should interfere with the retrieval of the actual experience when asked to honestly recollect on the second memory performance. However, based on the lack of differences between feigning participants and delayed testing-only control - which had not been instructed to withhold information - some authors seem to disregard retrieval-induced forgetting as driving mechanism behind the memory-undermining effect of simulation (e.g., Bylin \& Christianson, 2002; Van Oorsouw \& Merckelbach, 2004).

\section{Aims and Outline of the Thesis}

Although research has consistently shown that pretending memory loss undermines feigners' genuine memory for the criminal act, additional studies seem necessary. Specifically, the extent to which feigned crime-related amnesia may (or may not) affect perpetrators' recollection and what mechanism leads to poorer actual memory after feigning, are not entirely clear. Hence, in the following chapters, the three explicative hypotheses outlined above - why simulation impairs actual memory for a crime - are further examined.

As mentioned above, several authors think that rehearsal would be the most parsimonious explanation for the feigning amnesia effect. However, in real-life cases it might be that perpetrators who committed a crime will be triggered to "rehearse" the criminal event when they are interrogated by the police. Thus, in Chapter 2, we tried to rule out the lack of rehearsal explanation by forcing participants to rehearse the crime stimulus. Precisely, in two studies we investigated whether reminders of the crime (i.e., visual vs. verbal) would enhance memory performance of feigners, as well as confessors. Relatedly, in Chapter 3, we aimed to replicate previous research on the detrimental effect of simulating amnesia for a mock crime by adopting a mock crime video instead of a narrative story. Moreover, we extended our previous two studies by investigating whether the memory-undermining effect of feigning amnesia would be affected by inner speech activity.

Secondly, according to the source monitoring framework (SMF), the memory-undermining effect of feigning amnesia might be considered a result of misattribution of the right source of information. However, because of possible elaborative cognitive processing, one could argue that the content of self-generated information (i.e., simulated version of the crime) might be preserved and distinguished over time. Chapter 4 addresses the question whether or not individuals are still capable to identify the right source of information (i.e., feigned story vs. original story) despite previously simulating amnesia of original event. 
Thirdly, although retrieval-induced forgetting (RIF) has been often excluded as possible account for the feigning amnesia effect, Chapter 5 represents the very first attempt to adapt the RIF procedure to the feigning amnesia for a crime paradigm. That is, we sought to examine whether requesting feigning participants to retrieve certain information of the crime, would lead them to forget other parts of the offence.

Finally, the main findings of the previous chapters are reviewed and discussed in Chapter 6. Overall conclusions are drawn and implications for legal practice and recommendations for future studies are given. 



\section{Chapter 2}

\section{Do Visual and Verbal Reminders of the Crime Reverse the Memory-Undermining Effect of Simulating Amnesia?}

This chapter is based on:

Mangiulli, I., Lanciano, T., Van Oorsouw, K., Jelicic, M., \& Curci, A. (2018). Do visual and verbal reminders of the crime reverse the memory-undermining effect of simulating amnesia?. Manuscript under review. 


\begin{abstract}
Research has shown that simulating amnesia impairs actual memory for a mock crime. Lack of rehearsal has been suggested as the most likely explanation for this finding because feigning amnesia is linked to reduced thinking about the offence. We investigated whether reminders about the crime could reverse the memory-undermining effect of simulation. In two studies, participants watched a video of a violent crime. After, they were asked to either simulate amnesia or confess the crime. During the week between the first and second memory test phase, participants were provided with reminders of the crime in two different modalities. In study 1, participants received visual cues related to the video. Findings showed that visual reminders did not enhance exsimulators' memory. In study 2, verbal cues were adopted, and this led to improved memory for the offence in simulators. Practical implications of our findings for the legal field are discussed.
\end{abstract}

Keywords: simulating amnesia; malingering; rehearsal; visual vs. verbal reminders; mock crime 


\section{Introduction}

In the literature there is debate about the existence of bona fide crime-related amnesia. Some authors argue that crime-related amnesia is due to a mismatch in an offender's emotional state between the time of the crime and the moment he/she is interrogated by the police (e.g., Kopelman, 1995). Because criminal acts are encoded in an intense emotional state, they would be difficult to access in a more calm state (Bourget \& Whitehurst, 2007; Porter, Birt, Yuille, \& Herve, 2001). Indeed, amnesia is often reported by people who committed violent and passionate crimes (Pyszora, Fahy, \& Kopelman, 2014). However, other authors reason that crime-related amnesia is an improbable outcome (e.g., Christianson \& Merckelbach, 2004), because overall people are well capable to remember their own actions. For instance, participants better recalled statements that were enacted than statements that were only heard (action superiority effect; Engelkamp \& Zimmer, 1994). In a related vein, it has been shown that remembering personal acts is far better than remembering witnessed acts (self-reference effect; Symons \& Johnson, 1997). Moreover, emotional or traumatic events are better recalled than neutral ones (e.g., McGaugh, 2006).

So far, the veracity of claims of crime-related amnesia without an organic cause has been often queried, rendering fabrication of such condition (i.e., malingering) a possible explanation as to why a person would claim memory loss after committing a crime (Jelicic \& Merckelbach, 2007; Liepmann, 2002; Marshall, Serran, Marshall, \& Fernandez, 2005; Ornish, 2001). Indeed, Pyszora, Barker, and Kopelman (2003) noticed that $29 \%$ of a 1-year cohort of people sentenced to life imprisonment claimed amnesia surrounding their crime (31.4\% of those convicted of homicide). By feigning a memory deficit, moreover, offenders might try to obstruct police investigation and/or interfere with the trial proceedings (Cima, Merckelbach, Nijman, Knauer, \& Hollnack, 2002; Tysee, 2005; Tysse \& Hafemeister, 2006). For that reason, many criminal offenders claim memory loss for their crime (McSherry, 1998; Porter, Birt, Yuille, \& Herve, 2001; Schacter, 1986).

Furthermore, when defendants claim memory loss surrounding their criminal act crucial crime-related information might be forgotten. Several researches, indeed, have observed that feigning amnesia might have a memory-undermining effect (e.g., Bylin \& Christianson, 2002; Christianson \& Bylin 1999; Sun, Punjabi, Greenberg, \& Seamon, 2009; Van Oorsouw \& Merckelbach, 2004; 2006). That is, when one week later participants were asked to genuinely account for the crime experience, individuals who had initially been instructed to feign amnesia for the same target event (i.e., further referred to as simulators) had poorer memory than those who were instructed to truthfully recall the crime both times (i.e., further referred to as confessors). Relatedly, some studies have found that participants initially asked to pretend memory loss for the criminal experience increased the number of memory errors over time (e.g., van Oorsouw and 
Giesbrecht, 2008). Albeit claims of crime-related amnesia might mostly lead to omissions (e.g., Christianson and Bylin, 1999; van Oorsouw and Merckelbach, 2004), in some circumstances the act of feigning amnesia might even imply distorting and/or fabricating new information on the initial memory test (see also Otgaar \& Baker, 2017). Thus, it is quiet common that feigning participants report more errors over time as compared with genuinely responding participants (i.e., confessors).

To test the memory-undermining effect of feigning amnesia, several studies have included a delayed testing-only control condition (e.g., Bylin \& Christianson, 2002; Sun et al., 2009; Van Oorsouw \& Merckelbach, 2004). On the delayed recall, participants who had initially feigned amnesia performed similar to the delayed testing-only group (i.e., further referred to as controls). Given that both simulators and controls did not actually rehearse the crime as compared with confessors during the first memory phase, this lack of rehearsal might explain the memoryundermining effect in simulating participants. Albeit lack of rehearsal has been considered as the best account for the memory-undermining effect of simulated amnesia (e.g., Van Oorsouw \& Merckelbach, 2004), Sun and colleagues (2009) stated that "there is no feigned amnesia effect other than differential practice at recall" (p. 89). According to these authors, a simulating amnesia effect would not take place because simulators - equally to controls - would just have less occasions to rehearse the crime, rendering the memory-undermining effect of feigned amnesia as nothing more than a mere differential practice at recall.

However, one could argue that in a real life situation offenders who committed a crime may have several opportunities to "rehearse" the experience. For instance, they might think about how they came to their criminal acts, how they could have prevented the offence, or perhaps even develop unwanted intrusions or flashbacks of the crime (e.g., Evans, 2006; Evans, Ehlers, Mezey, \& Clark, 2007a; 2007b). Generally speaking, rehearsal can enhance memory consolidation (Anderson, Bjork, \& Bjork, 1994; Glover, 1989), and improve memory for facts, such as spatial and temporal details, and activity components of the events (Marsh, Tversky, \& Hutson, 2005). Furthermore, offenders who claimed amnesia surrounding their crime might even individually rehearse what they experienced in order to be consistent with their feigned story during police interrogations. Consequently, this "self-rehearsal practice" might lead offenders to not easily forget the crime.

\section{Overview and Hypotheses}

The main goal of the present research was to determine whether the lack of rehearsal could explain the memory-undermining effect of feigned amnesia. Specifically, we aimed to investigate whether feigners who are prompted to think about the crime no longer demonstrate the memoryundermining effect of feigning compared with feigners who are not prompted. We showed 
participants a mock crime video and we asked them to either feign amnesia (simulator group) or to confess (confessor group) when asked about their involvement in the crime during a first memory test phase (T1). In order to induce participants to rehearse the crime event, we manipulated rehearsal in two studies giving half of the participants either visual (study 1) or verbal (study 2) reminder cues about the crime. In both studies, a delayed-testing only group (i.e., controls) was included to empirically test the lack of rehearsal effect. We anticipated that simulating amnesia would undermine memory for the mock crime regardless of rehearsal induction (hypothesis 1). However, we also expected that visual and verbal cues would increase simulators' performance over time, leading ex-feigners to recollect as many correct details as confessors (hypothesis 2). Relatedly, simulators who received the rehearsal induction would recall more correct crime information than those who did not get the rehearsal induction (hypothesis 3). Moreover, we predicted that both confessors and simulators who were given reminders to rehearse would recall more correct crime details than a delayed-testing only control group (hypothesis 4). Finally, we expected that simulators would make more errors than confessors at the second memory test phase (hypothesis 5), and reasoned that simulators who received the rehearsal inductions would report fewer errors than simulators who did not get the rehearsal inductions (hypothesis 6). 


\section{Study 1}

\section{Method}

\section{Participants and Design}

A total of 90 undergraduate students (65\% women; $\left.M_{\text {age }}=22.58 ; S D=3.19\right)$ were evenly distributed over the three conditions - simulators $(N=30)$, confessors $(N=30)$, and controls $(N=$ 30). Participants were rewarded with one course credit hour. The study adopted a $3 \times 2 \times 2$ mixed model design with condition (simulators vs. confessors vs. controls) and rehearsal induction (reminder vs. no reminder) as between subjects variables, and memory test-retest (T1 vs. T2) as a within subjects repeated measure variable. The dependent variable was the correctness of memory calculated as free and cued recall scores. Additionally, we calculated free and cued error scores.

\section{Measures and Procedure}

Pre-experimental phase. The study consisted of two phases, both conducted in a quiet test room. Participants were randomly assigned to one of three conditions. During the screening phase, each participant was asked to fill out the Structured Inventory of Malingered Symptomatology (SIMS; La Marca, Rigoni, Sartori, \& Lo Priore, 2011; Smith \& Burger, 1997) in order to exclude individual differences in terms of malingering tendency before the experimental phase. The SIMS ${ }^{2}$ is a self-report screening instrument for malingering and it consists of a 75 item true-false questions. It contains bizarre items that pertain to bizarre or atypical symptoms (e.g. "Sometimes my muscles go limp for no apparent reason so that my arms and legs feel as though they weigh a ton"). The items are divided into five subscales (affective disorders; amnestic disorders; low intelligence; neurological impairment; psychosis). Answers indicative of malingering are summed to obtain a total SIMS score $(\alpha=.85)$.

Mock crime event. After the pre-experimental phase, participants were presented a short video lasting approximately 2.30 minutes. Other than a brief dialogue between two characters in the beginning, the mock crime video is mainly accompanied by background music. Participants were asked to pay attention to the mock crime movie and to identify themselves with the character that showed up first on the scene (the offender). The video contained a violent scene depicting a fight between two armed men. The scene ended with one of the men being strangled by the other.

${ }^{2}$ The SIMS (Smith \& Burger, 1997) includes five subscales which were not directly relevant for our purposes. Participants were not found to differ in their malingering tendency before the memory test phase $(p>.05)$. 
After the video, there was a 10 min interval during which participants performed a filler task (puzzle).

Memory test phase (T1). After completing the filler task, participants received the following instruction: "Remember the crime you just watched. Imagine that you are under arrest because you are the prime suspect of the murder. A witness saw you with the victim and a policeman asks you to report every detail you can remember about the crime". While doing so, simulators were instructed to simulate amnesia to evade punishment. They were instructed to describe the events pertaining to the murder in such a way as if they had great difficulties remembering them. Confessors, on the other hand, were requested to collaborate with the police and to honestly report as many details as possible about the murder. Immediately after this free recall, simulators and confessors were asked to answer 14 cued recall questions about the mock crime event and were requested to adhere to the previously given instruction about the role they were playing (i.e., simulating or confessing). The controls did not receive any instruction, which means they were not tested during the first memory phase. Finally, participants were scheduled for a new session one week later.

Rehearsal induction. During the week between the presentation of the video clip and the retest phase, a random half ${ }^{3}$ of the entire sample (including the three conditions: simulators, confessors, and controls) received video frames about the crime on their smartphones (via WhatsApp) three times in different daytime hours (rehearsal induction). Nine frames were directly extracted from the video and reported the crucial scenes of the mock crime. Each frame was followed by a "reminder" of the meeting scheduled for the second experimental memory session. Each condition (simulators vs. confessors vs. control) received the same number of visual cues. The other half of the sample did not receive any reminders during the week.

Memory retest phase (T2). One week after the first memory phase, all participants of each condition (simulators vs. confessors vs. control) returned to the testing room and all were asked to honestly respond to the free and cued recall tasks. This time, in contrast to the instructions given at $\mathrm{T} 1$, simulators were requested to describe what they remembered from the mock crime movie, thus giving up feigning amnesia. Confessors again received the instruction to report what they remembered about the crime. Controls were asked to report as many details as possible about the video clip of the mock crime that they had watched one week earlier. In the cued recall task, all participants were asked to honestly respond to the same 14 questions as presented one week earlier. Once participants finished the second session, they were debriefed and thanked individually.

${ }^{3}$ The messages were randomly sent to participants. Neither particular sampling design nor specifics criteria were followed. 


\section{Memory Test-Retest Scoring}

Free recall. The mock crime video was divided into 50 critical information units by the first author. Participants earned 1 point for every correct unit reported (maximum $=50$ ). A critical information unit was defined as a significant fragment of the video clip relevant for the whole story (e.g., "I had pointed the gun at the back of the victim's head"). Instead, a partial correct answer was assigned half point (e.g., "I had pointed the gun at the victim"). The correct score was transformed into proportions (range $=0-1$ ) by dividing the number of information units correctly reported by each respondent by the maximum obtainable score of 50. Additionally, the number of errors (i.e., introduction of new information which was not part of the mock crime event such as "That day, I was not alone" or distorted information such as "I strangled the victim with my hands") were identified. Free recall outcomes were scored by the first author and two student assistants who were blind to condition. The Interclass Correlation Coefficient (ICC) average measure for the number of correct free recall information was .977 with a $95 \%$ confidence interval from .97 to $.98, F(88,17)=45.28, p<.001$. The ICC average measure for the errors was .75 with a $95 \%$ confidence interval from .54 to $.83, F(88,17)=5.29, p<.001$.

Cued recall. Seven of the 14 cued recall items referred to central details (i.e., weapon or blood), while seven other items referred to peripheral details (i.e., characters' clothing, details about the location and the surroundings). To calculate cued recall scores, 1 point was given for each correct answer (e.g., Question: "Was the victim armed?" "Yes, he had a weapon and a knife”), while half a point was given for a partial correct answer (e.g., "Yes, he had a weapon"). When participants did not provide any detail, they did not receive points (e.g. "I do not remember"). The maximum obtainable score was 14. Then, in order to obtain a correctness score, proportions (range $=0-1$ ) were calculated by dividing the score obtained in the questionnaire by the maximum obtainable score. Additionally, also for the cued recall, the number of errors was identified (e.g., "The victim had a rifle"). The ICC average measure for the number of correct cued recall information was .94 with a $95 \%$ confidence interval from .92 to $.96, F(88,17)=20.28, p<.001$. Instead, the ICC average measure of the errors for cued recall was .82 with a $95 \%$ confidence interval from .68 to $.89, F(88,17)=6.94, p<.001$. 


\section{Results}

\section{Free Recall - Correctness Score}

Correct free recall scores were entered in a $2 \times 2 \times 2$ repeated measures ANOVA with condition (simulators vs. confessors) and rehearsal induction (reminder vs. no reminder) as between subjects factors and memory test-retest (T1 vs. T2) as a within subjects factor. Control participants were not included in this analysis since they did not provide memory accounts during the first session. Significant main effects were found for condition, $F(1,56)=159.00, p<.001, \eta_{p}{ }^{2}=.74$, and test-retest, $F(1,56)=94.52, p<.001, \eta_{p}{ }^{2}=.63$. Moreover, significant interaction effects of condition by test-retest and condition by rehearsal were found, $F(1,56)=89.71, p<.001, \eta_{p}^{2}=.62$, and $F(1,56)=12.48, p=.001, \eta_{p}{ }^{2}=.18$, respectively. No other significant main or interaction effects reached the significance level, $F \mathrm{~s}(1,56)<1.50, p>.22$. Given that simulators were instructed to come up with a feigned story of the crime, we expected that, in line with their instructions, they would perform better at $\mathrm{T} 2$ than $\mathrm{T} 1$. The condition by test-retest interaction effect showed indeed that, in contrast to confessors, only simulators significantly improved their recall over time $\left(M_{\text {simulators T1 }}=.02, S D=.03 ; M_{\text {simulators T2 }}=.20, S D=.06\right), F(1,58)=169.92, p<.001$, $\eta_{p}{ }^{2}=.74$. Following this interaction, overall confessors reported more correct information than simulators at T2 $\left(M_{\text {confessors T2 }}=.26, S D=.06\right), F(1,58)=11.19, p=.001, \eta_{p}{ }^{2}=.16$. However, the analysis of the simple effects for the condition by rehearsal interaction highlighted that only confessors who received the rehearsal induction outperformed simulators, and both groups recollected the same amount of information when participants did not have any opportunity to rehearse the crime through the visual cues, $F(1,57)=19.68, p<.001, \eta_{p}{ }^{2}=.26$, and $F(1,57)=.31$, $p=.58$, respectively (see Table 1 ). These results seem to be in contrast with the hypothesis that simulating amnesia undermines memory for the crime (Hp 1), but they nonetheless suggest that the visual rehearsal manipulation was not successful at improving memory in simulators (Hp 2). Furthermore, against our expectation, simulators who were given visual reminders did not report more correct information than those who did not receive reminders $(\mathrm{Hp} 3), F(1,58)=1.11, p=.30$, $\eta_{p}{ }^{2}=.02$ (see Table 1). By contrast, confessors who received the visual reminders remembered more correct information than those who did not get reminders, $F(1,58)=5.97, p=.02, \eta_{p}{ }^{2}=.09$ (see Table 1).

In order to investigate potential differences in memory recall between simulators, confessors and controls, a 3 condition (simulators vs. confessors vs. controls) x 2 rehearsal induction (reminder vs. no reminder) between subjects ANOVA was run only for the memory retest phase (T2). This suggested a significant main effect of condition, $F(2,83)=17.74, p<.001, \eta_{p}{ }^{2}=.30$, and a 
condition by rehearsal interaction, $F(2,83)=3.36, p=.04, \eta_{p}^{2}=.07$. The main effect of the rehearsal induction did not reach the significance level, $F(1,83)<1.82, p>.18$. Among participants who received the visual rehearsal induction, we expected that both confessors and simulators would recall more correct information than controls. Only confessors reported more correct details than the control group, $F(1,86)=16.12, p<.001, \eta_{p}^{2}=.16$ (see Table 1). Simulators and controls performed at a similar level, $F(1,86)=.63, p=.43, \eta_{p}{ }^{2}=.00$ (see Table 1). Thus, the visual rehearsal induction did not have the same consequences for the confessor and simulator group, thereby only partially supporting our hypothesis ( $\mathrm{Hp} \mathrm{4).} \mathrm{However,} \mathrm{both} \mathrm{confessors}$ and simulators recalled more correct information than controls without reminders, $F(1,86)=9.41$, $p=.003, \eta_{p}^{2}=.10$, and $F(1,86)=6.77, p=.011, \eta_{p}^{2}=.07$, respectively (see Table 1$)$.

\section{Free Recall - Error Scores}

For errors the same $2 \times 2 \times 2$ repeated measures ANOVA with condition (simulators vs. confessors) and rehearsal induction (reminder vs. no reminder) as between subjects factors and memory test-retest (T1 vs. T2) as a within subjects factor was conducted. Significant main effects were found for condition, $F(1,56)=32.27, p<.001, \eta_{p}{ }^{2}=.37$, and memory test-retest, $F(1,56)=$ $95.43, p<.001, \eta_{p}{ }^{2}=.63$. The interactions of condition by memory test-retest and condition by rehearsal induction were also significant, $F(1,56)=90.86, p<.001, \eta_{p}{ }^{2}=.62$, and $F(1,56)=5.51$, $p=.02, \eta_{p}{ }^{2}=.09$, respectively. Neither other main nor interaction effects reached significance, $F \mathrm{~s}$ $(1,56)<2.55, p>.11$. Following condition by memory test-retest interaction, simulators committed more errors than confessors during T1 $\left(M_{\text {simulators } 11}=7.13, S D=2.73 ; M\right.$ confessors T1 $=1.66, S D=$ $2.50), F(1,58)=64.98, p<.001, \eta_{p}{ }^{2}=.53$, but the simulators' errors number drastically decreased at T2 $\left(M_{\text {simulators } 22=1.70, S D=1.29}\right), F(1,56)=178.83, p<.001, \eta_{p}{ }^{2}=.75$. However, against our hypothesis (Hp 5), simulators did not report more errors than confessors at T2 $(M$ confessors T2 $=1.60$, $S D=2.25), F(1,58)=.04, p=.83$. Thus, only previous simulators significantly reduced their errors over sessions, and confessors did not. Against our prediction ( $\mathrm{Hp} 6)$, a condition by rehearsal interaction shows that simulators who received the visual reminder did not report fewer errors at $\mathrm{T} 2$ than those who did not get reminders, $F(1,58)=1.72, p=.19$ (see Table 1). Yet, no significant difference was found for the error rate between confessors who received the visual induction and those who did not, $F(1,58)=1.01, p=.32($ see Table 1$)$.

Finally, to compare participants' error rates with delayed tested-only participants during the memory retest phase (T2) a 3 condition (simulators vs. confessors vs. controls) x 2 rehearsal induction (reminder vs. no reminder) between subjects ANOVA was entered on the free recall 
errors. Neither main nor interaction effects reached significance, $F \mathrm{~S}(2,83)=2.14, p=.12$. Controls did not differ from the others two groups, $F_{\mathrm{s}}(1,86)<.33, p>.56$.

\section{Cued Recall - Correctness Score}

For cued recall, identical analyses to the free recall were run. Against our assumption (Hp 1, and Hp 2), overall findings showed no significant differences between simulators and confessors at $\mathrm{T} 2\left(M_{\text {simulators T2 }}=.50, S D=.12 ; M\right.$ confessors T2 $\left.=.52, S D=.11\right), F(1,58)=.26, p=.61$. Yet, simulators who received visual reminders performed similar to those who did not against our expectation $(\mathrm{Hp} 3), F(1,58)=.15, p,=.70$ (see Table 1). However, in support of our prediction (Hp 4), both simulators and confessors who were given visual cues appeared to be more correct than controls at T2, $F(1,86)=16.25, p<.001, \eta_{p}{ }^{2}=.16$, and $F(1,86)=20.37, p<.001, \eta_{p}{ }^{2}=.19$, respectively (see Table 1). Finally, regardless of rehearsal induction both simulators and confessors continued to outperformed controls, $F(1,86)=11.23, p=.001, \eta_{p}{ }^{2}=.11$, and $F(1,86)=8.74, p$ $=.004, \eta_{p}{ }^{2}=.10$, respectively (see Table 1$)$.

\section{Cued Recall - Error Scores}

In line with the free recall errors, a similar pattern of results was observed for cued recall error scores. Against our prediction (Hp 5), simulators did not differ from confessors in cued recall errors at T2 $\left(M_{\text {simulators T2 }}=1.47, S D=1.28 ; M_{\text {confessors T2 }}=1.23, S D=1.01\right), F(1,58)=.62, p=.44$. Again, not in line with our expectation ( $\mathrm{Hp} 6$ ), simulators who received the visual reminders did not make fewer errors than those who did not receive the induction, $F(1,58)=9.37, p=.003, \eta_{p}^{2}=.14$, (see Table 1). 
Table 1. Free and cued recall proportions for each condition during the first (T1) and the second (T2) memory phase (Study 1).

FREE RECALL

\begin{tabular}{|c|c|c|c|c|c|c|c|c|c|c|}
\hline \multirow{3}{*}{$\begin{array}{l}\begin{array}{l}\text { Memory } \\
\text { phase }\end{array} \\
\text { Reminder } \\
\text { (visual) }\end{array}$} & \multicolumn{4}{|c|}{ Simulators } & \multicolumn{4}{|c|}{ Confessors } & \multirow{2}{*}{\multicolumn{2}{|c|}{$\begin{array}{l}\text { Controls } \\
\text { T2 }\end{array}$}} \\
\hline & \multicolumn{2}{|c|}{$\mathrm{T} 1$} & \multicolumn{2}{|c|}{$\mathrm{T} 2$} & \multicolumn{2}{|c|}{$\mathrm{T} 1$} & \multicolumn{2}{|c|}{$\mathrm{T} 2$} & & \\
\hline & Yes & No & Yes & No & Yes & No & Yes & No & Yes & No \\
\hline Correct & $\begin{array}{c}.01 \\
(.01)\end{array}$ & $\begin{array}{c}.03 \\
(.02)\end{array}$ & $\begin{array}{l}.19^{\mathrm{a}} \\
(.05)\end{array}$ & $\begin{array}{l}.22^{\mathrm{c}} \\
(.06)\end{array}$ & $\begin{array}{c}.28 \\
(.06)\end{array}$ & $\begin{array}{c}.23 \\
(.08)\end{array}$ & $\begin{array}{l}.29^{\mathrm{a}, \mathrm{b}} \\
(.05)\end{array}$ & $\begin{array}{l}.23^{\mathrm{d}} \\
(.06)\end{array}$ & $\begin{array}{l}.17^{b} \\
(.08)\end{array}$ & $\begin{array}{l}.15^{\mathrm{c}, \mathrm{d}} \\
(.04)\end{array}$ \\
\hline Errors & $\begin{array}{c}8.40 \\
(2.87)\end{array}$ & $\begin{array}{c}5.86 \\
(1.95)\end{array}$ & $\begin{array}{c}2.13 \\
(1.50)\end{array}$ & $\begin{array}{l}1.26 \\
(.88)\end{array}$ & $\begin{array}{c}1.40 \\
(2.26)\end{array}$ & $\begin{array}{c}1.93 \\
(2.78)\end{array}$ & $\begin{array}{c}1.26 \\
(1.83)\end{array}$ & $\begin{array}{c}1.93 \\
(2.63)\end{array}$ & $\begin{array}{c}1.86 \\
(1.18)\end{array}$ & $\begin{array}{c}1.00 \\
(1.24)\end{array}$ \\
\hline
\end{tabular}

CUED RECALL

Simulators

Memory

phase
T1
Confessors

Controls

\begin{tabular}{lcccccccccc}
\hline $\begin{array}{l}\text { Reminder } \\
\text { (visual) }\end{array}$ & Yes & No & Yes & No & Yes & No & Yes & No & Yes & No \\
\hline Correct & .22 & .21 & $.49^{\mathrm{a}}$ & $.50^{\mathrm{b}}$ & .56 & .51 & $.53^{\mathrm{c}}$ & $.49^{\mathrm{d}}$ & $.39^{\mathrm{a}, \mathrm{c}}$ & $.34^{\mathrm{b}, \mathrm{d}}$ \\
& $(.11)$ & $(.10)$ & $(.13)$ & $(.11)$ & $(.11)$ & $(.09)$ & $(.12)$ & $(.08)$ & $(.15)$ & $(.10)$ \\
& & & & & & & & & & \\
Errors & 3.53 & 1.93 & 2.06 & 0.86 & 1.53 & 1.53 & 1.26 & 1.20 & 2.00 & 1.92 \\
& $(1.95)$ & $(1.09)$ & $(1.38)$ & $(0.83)$ & $(.91)$ & $(1.06)$ & $(1.22)$ & $(.77)$ & $(1.00)$ & $(1.26)$ \\
\hline
\end{tabular}

Note: Table 1 displays proportions split by visual rehearsal induction (reminder vs. no reminder). Standard deviations are shown between parentheses. Errors are reported in absolute numbers. Same letters within the same row indicate significant differences across groups. All significant differences are at $p<.05$. 


\section{Discussion}

Although there is a substantial body of research on the nature of visual rehearsal and its contribution in storing information in memory (e.g., Watkins, Peynircioĝlu, \& Brems, 1984; Shaffer \& Shiffrin, 1972), our visual rehearsal manipulation was not successful at reaching the purpose of study 1 . To begin with, reminders had no beneficial effect on simulators' memory performance (i.e., more correct recall and fewer errors) as compared with no simulators who did not receive reminders, whereas for confessors a beneficial effect was found. That is, although visual reminders appeared to improve confessors' memory since they outperformed both those who did not receive cues and simulators who were provided with frames of the crime event, the rehearsal induction did not increase simulators' memory over time. There are several possible explanations for these findings. First of all, it might be possible that participants might passively have looked at the WhatsApp reminders and did not rehearse the content of images or simply may have ignored them since there was no incentive for superior performance. It could be that, participants were just triggered by the "reminders" of the meeting scheduled for the second session without receiving any further instruction regarding the crime frames. Perhaps, confessors were more motivated to stick with the instruction received during the first memory phase in contrast to simulators. It remains speculative why confessors benefitted from rehearsal and simulators did not. Yet, it sounds plausible that the memory of confessors, who told the truth at the first recall test, was triggered by the frames to a greater extent than that of simulators who in the role of simulators might not. Thus, it is likely that the way in which both groups engaged with the visual cues had a crucial role in increasing or not participants' memory.

More importantly, simulating amnesia appeared to undermine ex-feigners' memory over time by taking together the overall participants' performance (i.e., collapsing the data of reminder vs no reminder). However, this effect was caused by the improved performance of confessors. At the baseline condition (no reminder), the memory undermining effect of feigning amnesia was not present. That is, both simulators and confessors who did not receive visual reminders performed at a similar level. Arguably, the low sample size due to rehearsal induction partition (i.e., 15 simulators no reminder vs. 15 confessors no reminder) did not guarantee in our study the previously found simulating amnesia effect (Bylin \& Christianson, 2002; Christianson \& Bylin 1999; Van Oorsouw \& Merckelbach, 2004; 2006). Of importance, however, simulators in the present study did recall more correct information than controls, regardless of rehearsal induction, thereby supporting our idea that some rehearsal is present at $\mathrm{T} 1$ when simulators are asked to recall the crime while role-playing amnesia. This rehearsal was obviously not present in the delayed-onlytesting group. That is, even while feigning memory problems, they rehearsed the actual crime while 
attempting to provide a convincing amnesia story. Therefore, it is conceivable that the real rehearsal occurred while simulators were tested in the first memory test phase and not by mock crime frames sent via WhatsApp. To further test this idea, and to force participants to actually interact with the reminders, a second study was conducted. In study 2 , we assessed whether active rehearsal through verbalization instead of merely observing the images would improve memory after simulating amnesia.

\section{Study 2}

A further consideration on the rehearsal effect led us to slightly modify the procedure in designing the second study. In study 1, the delayed-testing only control group was given the rehearsal induction, so that this design allowed us to evaluate the effects of rehearsal induction upon crime recall of groups instructed to either simulate or confess as compared with participants who recalled the crime after a one-week delay. However, in study 2 , the control condition was excluded from the rehearsal induction. This methodological choice answered the practical concern to have a condition approaching as much as possible the naturalistic situation of individuals not involved in legal procedures and simply lead to reiterate their experience after some time.

The procedure of study 1 was followed although the rehearsal induction phase was slightly modified. This time, verbal cues were used. We believe these more closely resemble a real life situation where an offender who feigns amnesia might actually mentally reiterate the crime when he is not interrogated. Additionally, a larger sample of participants was recruited. In line with study 1, we anticipated simulating amnesia would undermine memory (hypothesis 1) but because of the rehearsal induction, simulators would perform at a similar level to confessors (hypothesis 2). Additionally, simulators who received the rehearsal induction would be more correct in their memories than those who did not (hypothesis 3). Moreover, we again predicted both simulators and confessors (no reminder condition) would remember more correct crime information than controls (hypothesis 4). Finally, we expected that simulators would commit more errors than confessors (hypothesis 5) but those who involved in the rehearsal inductions would report fewer errors than simulators who did not (hypothesis 6). 


\section{Method}

\section{Participants and Design}

In this second study, 125 undergraduate students ( $82 \%$ women; $M_{\text {age }}=19.96 ; S D=2.70$ ) were recruited and rewarded with a course credit hour - simulators $(N=50)$, and confessors $(N=$ 50) randomly divided over reminder vs. no reminder condition, and controls $(N=25)$ no reminder induction. The study adopted a $2 \times 2 \times 2$ mixed model design with condition (simulators vs. confessors) and rehearsal induction (reminder vs. no reminder) as between subjects variables, and memory test-retest (T1 vs. T2) as a within subjects variable. The dependent variables were identical to those in study 1 .

\section{Measures and Procedure}

The materials and measures were identical to those used in study $1^{4}$. Only the rehearsal induction differed from the one adopted in study 1. That is, in order to force simulators and confessors to rehearse the video clip of the mock crime, we manipulated rehearsal in a verbal way. We transcribed the whole video, dividing it into 18 sentences. These sentences were put together on a table in a wrong temporal order. With regard to the rehearsal induction, we asked to half of simulators and confessors to put the sentences in the right order from the first temporal event to the last. This manipulation was repeated twice during the week between the memory test (T1) and retest phase (T2) by asking participants to come to the lab to complete the task. In contrast to study 1, the control group did not undergo the rehearsal induction phase. The controls were tested only during the memory retest phase (T2).

Similar to study 1, both free and cued recall scores were transformed into proportions. Additionally, the number of errors was identified. Free and cued recall outcomes were scored by the first author and by two student assistants. The ICC average measure of the number of correct free recall information was .97 with a $95 \%$ confidence interval from .95 to $.98, F(99,20)=31.57, p$ $<.001$. The ICC average measure of the free recall errors was .83 with a $95 \%$ confidence interval from .76 to $.88, F(99,19)=6.03, p<.001$. Instead, the ICC average measure of the number of correct cued recall information was .73 with a $95 \%$ confidence interval from .61 to $.83, F(99,19)=$ $4.06, p<.001$. Finally, the ICC average measure of the cued recall errors was .83 with a $95 \%$ confidence interval from .76 to $.88, F(99,19)=5.95, p<.001$.

${ }^{4}$ As in study 1 , no differences in malingering tendency were found between participants of the different groups before the memory test phase $(p>.05)$. 


\section{Results}

\section{Free Recall - Correctness Scores}

A $2 \times 2 \times 2$ repeated measures ANOVA with condition (simulators vs. confessors) and rehearsal induction (reminder vs. no reminder) as between subjects factors and memory test-retest (T1 vs. T2) as a within subjects factor was conducted. There were significant main effects of condition, $F(1,96)=124.30, p<.001, \eta_{p}{ }^{2}=.57$, memory test-retest, $F(1,96)=265.33, p<.001$, $\eta_{p}{ }^{2}=.75$, and rehearsal induction, $F(1,96)=34.78, p<.001, \eta_{p}{ }^{2}=.27$. Moreover, the interaction between condition by memory test-retest, $F(1,96)=83.78, p<.001, \eta_{p}{ }^{2}=.47$, and rehearsal by memory test-retest, $F(1,96)=30.05, p<.001, \eta_{p}{ }^{2}=.24$, reached the significance level, whereas the condition by rehearsal induction did not, $F(1,96)=.47, p=.49, \eta_{p}{ }^{2}=.00$. Finally, the three-way condition by rehearsal induction by memory test-retest interaction was significant, $F(1,96)=7.96$, $p=.006, \eta_{p}^{2}=.08$.

With regards to the three-way interaction, simulators reported more correct information at T2 rather than $\mathrm{T} 1$ with or without verbal reminders, $F(1,98)=223.08, p<.001, \eta_{p}{ }^{2}=.69$, and $F(1,98)$ $=60.47, p<.001, \eta_{p}{ }^{2}=.38$, respectively (see Table 2 ). This corresponds to the standard test-retest effect that was reported earlier. At T2, in line with our hypothesis (Hp 3), simulators who were involved in the rehearsal induction outperformed simulators who were not, $F(1,98)=43.29, p$ $<.001, \eta_{p}{ }^{2}=.30$ (see Table 2). Interestingly, confessors remembered more correct information than simulators when both groups did not get the visual reminders, thereby demonstrating the standard memory-undermining effect of simulating amnesia $(\mathrm{Hp} 1), F(1,97)=8.97, p=.003, \eta_{p}^{2}$ $=.08$ (see Table 2). Yet, no significant difference was found between simulators and confessors who were given the verbal rehearsal induction at $\mathrm{T} 2, F(1,97)=.22, p=.639$. These findings indicate that the verbal rehearsal induction improved both simulators' and confessors' memory (Hp 2).

To compare groups without the rehearsal induction, a one-way ANOVA was run including all conditions (simulators vs. confessors vs. controls) only for the retest memory phase (T2). The effect of condition was found to be significant, $F(2,72)=35.00, p<.001, \eta_{p}{ }^{2}=.49$. As expected, and in line with $\mathrm{Hp} 4$, simulators and confessors remembered more correct information than controls, $F(1,72)=14.17, p<.001, \eta_{p}{ }^{2}=.16$, and $F(1,72)=69.78, p<.001, \eta_{p}{ }^{2}=.49$, respectively (see Table 2). 


\section{Free Recall - Error Scores}

A $2 \times 2 \times 2$ repeated measures ANOVA with condition (simulators vs. confessors) and rehearsal induction (reminder vs. no reminder) as between subjects factors and memory test-retest (T1 vs. T2) as a within subjects factor was run. Significant effects of condition, $F(1,96)=10.07, p$ $=.002, \eta_{p}{ }^{2}=.09$, memory test-retest, $F(1,96)=32.39, p<.001, \eta_{p}{ }^{2}=.25$, and condition by memory test-retest interaction were found, $F(1,96)=10,65, p=.002, \eta_{p}{ }^{2}=.10$. Simulators made more errors than confessors during T1, $F(1,98)=11.40, p=.001, \eta_{p}{ }^{2}=.10$ (see Table 2 ), but their errors decreased at T2, $F(1,98)=38.81, p<.001, \eta_{p}{ }^{2}=.28$ (see Table 2). In fact, simulators performed similar to confessors at T2 $\left(M_{\text {simulators }}=2.74, S D=2.87 ; M_{\text {confessors }}=2.38, S D=3.38\right), F$ $(1,98)=.33, p=.57$. Against our hypothesis (Hp 5), simulators did not report more errors than confessors over time. Furthermore, neither condition by rehearsal interaction nor other interaction effects reached significance, $F_{\mathrm{S}}(1,96)<2.65, p>.10$. Opposite to our prediction $(\mathrm{Hp} 6)$, simulators who received the verbal rehearsal induction did not report fewer errors than those who did not. $F(1,98)=2.84, p=.09$. Moreover, no significant difference was found for errors reported between confessors who received the rehearsal manipulation and those who $\operatorname{did}$ not, $F(1,98)=$ $1.49, p=.22$.

A one-way ANOVA on free recall errors among groups (simulators vs. confessors vs. controls) for T2 was not significant, $F(2,72)=2.73, p=.08$, and no differences in the free recall errors rate were observed between controls and the others two groups, $F \mathrm{~s}(1,72)<2.66, p>.06$.

\section{Cued Recall - Correctness Scores}

On correctness cued recall scores, identical analyses to the free recall were run. In contrast to our prediction (Hp 1), simulating amnesia did not seem to undermine feigners' memory, $F(1,97)$ $=.21, p=.64$ (see Table 2). Moreover, the verbal rehearsal induction was successful at increasing both simulators and confessors memory performance since participants evenly performed at T2 (Hp 2), $F(1,97)=.08, p=.78$ (see Table 2 ). In addition, simulators who received the verbal induction recalled more correct details than those who did not, which confirmed our prediction (Hp 3), $F$ $(1,98)=8.46, p=.004, \eta_{p}{ }^{2}=.08$ (see Table 2). Finally, as for the free recall findings and in conformity with our hypothesis (Hp 4), both simulators and confessors remembered more details than controls who were assessed only in the memory retest phase, $F(1,72)=1.43, p=.001, \eta_{p}^{2}$ $=.14$, and $F(1,72)=13.41, p<.001, \eta_{p}^{2}=.16$, respectively (see Table 2 ).

\section{Cued Recall - Error Scores}

A similar pattern of results was found for cued recall error scores. Unexpectedly, simulators made fewer errors than confessors contradicting our hypothesis $(\mathrm{Hp} 5)\left(M_{\text {simulators }}=3.03, S D=\right.$ 
$\left.1.50 ; M_{\text {confessors }}=4.02, S D=1.72\right), F(1,98)=9.35, p=.003, \eta_{p}{ }^{2}=.09$. However, as predicted $(\mathrm{Hp}$ 6), simulators who received the verbal rehearsal induction performed better than those who did not, $F(1,98)=9.06, p=.003, \eta_{p}^{2}=.85($ see Table 2$)$.

Table 2. Free and cued recall proportions for each condition during the first (T1) and the second (T2) memory phase (Study 2).

\section{FREE RECALL}

\section{Simulators}

$\mathrm{T} 1$
Confessors

Controls

Memory phase

$\mathrm{T} 1$

$\mathrm{T} 2$ $\mathrm{T} 1$

$\mathrm{T} 2$

$\mathrm{T} 2$

\begin{tabular}{lccccccccc}
\hline $\begin{array}{l}\text { Reminder } \\
\text { verbal })\end{array}$ & Yes & No & Yes & No & Yes & No & Yes & No & No \\
\hline Correct & $.03^{\mathrm{a}}$ & $.03^{\mathrm{b}}$ & $.32^{\mathrm{a}, \mathrm{c}}$ & $.18^{\mathrm{b}, \mathrm{c}, \mathrm{d}, \mathrm{e}}$ & .24 & .20 & .33 & $.25^{\mathrm{d}, \mathrm{f}}$ & $.13^{\mathrm{e}, \mathrm{f}}(.05)$ \\
& $(.03)$ & $(.03)$ & $(.07)$ & $(.06)$ & $(.08)$ & $(.09)$ & $(.07)$ & $(.06)$ & \\
& & & & & & & & & \\
Errors & 12.74 & 8.52 & 2.00 & 3.48 & 5.04 & 4.00 & 2.92 & 1.84 & $3.32(3.18)$ \\
& $(15.9)$ & $(4.09)$ & $(2.36)$ & $(3.19)$ & $(5.89)$ & $(4.51)$ & $(4.54)$ & $(1.46)$ & \\
\hline
\end{tabular}

CUED RECALL

Confessors

Controls

Simulators

$\mathrm{T} 2$

$\mathrm{T} 1$

$\mathrm{T} 2$

$\mathrm{T} 2$

Memory phase

$\mathrm{T} 1$

Yes

No Yes

No

Yes

No Yes

No

No

(verbal)

\begin{tabular}{lccccccccc} 
& & .26 & $.62^{\mathrm{a}}$ & $.53^{\mathrm{a}, \mathrm{b}}$ & .60 & .54 & .63 & $.54^{\mathrm{c}}$ & $.43^{\mathrm{b}, \mathrm{c}}(0.11)$ \\
& $.25(.10)$ & $(.17)$ & $(.08)$ & $(.10)$ & $(.12)$ & $(.10)$ & $(.10)$ & $(.09)$ & \\
& & & & & & & & & \\
\multirow{3}{*}{ Corroct } & 4.48 & 5.32 & $2.34^{\mathrm{d}}$ & $3.72^{\mathrm{d}}$ & 4.24 & 4.96 & 3.60 & 4.44 & $4.08(1.63)$ \\
& $(2.75)$ & $(2.67)$ & $(1.29)$ & $(1.40)$ & $(1.58)$ & $(1.64)$ & $(1.65)$ & $(1.70)$ &
\end{tabular}

Note: Table 2 shows proportions split by verbal rehearsal induction (reminder vs. no reminder). Errors are reported in absolute numbers. Standard deviations are shown between parentheses. Same letters within the same row indicate significant differences across groups. All significant differences are at $p<.05$. 


\section{Discussion}

As predicted, simulators involved in the verbal rehearsal induction did not forget the crime even though they previously simulated amnesia at T1. As a matter of fact, simulators and confessors who received the verbal cues to rehearse the mock crime did not show differences in level of memory correctness and all benefitted from rehearsal. Contrary to study 1, participants now more actively interacted with the cues presented, providing more opportunities to rehearse the mock crime video. Moreover, verbally rehearsing seemed to help simulators to reduce errors over time and protect their memory from decay to perform at a similar level as people who told the truth repeatedly. Finally, even without memory reminders, simulators still outperformed controls, in line with study 1 . This suggests that the mere act of telling a simulated amnesia story at T1 could perhaps act as a form of rehearsal.

\section{General Discussion}

We aimed to reverse the memory undermining effect of simulated amnesia for a mock crime by inducing participants to rehearse the crime through visual and verbal cues about the event. More specifically, by trying to give them opportunities to rehearse the event, we sought to examine whether simulators who were prompted to rehearse the mock crime in two different modalities (visually vs. verbally) would keep relevant information of the event. Only the verbal rehearsal induction was successful in doing so for ex-feigners. That is, whereas in study 1 participants might have passively looked at the frames of the mock crime video sent via WhatsApp, in study 2 they more actively interacted with the reminders provided and might have rehearsed the mock crime event, leading to a more solid memory trace over time and reversal of the memory undermining effect. In fact, when participants instructed to simulate memory loss were prompted with verbal cues, they did no longer showed a memory deficit for the mock crime when they had to give up their role as a feigner. In contrast, when simulators were not encouraged to rehearse the crime, feigning amnesia did have a memory-undermining effect, at least when feigners are compared with those who confessed the crime during the free recall memory test (study 2). Interestingly, we did not observe the same memory effect on simulators' performance when using a visual rehearsal induction (study 1). Hence, we partially replicated the findings of previous studies: Research on simulated amnesia has shown that initial poor performance of simulators is due to their engagement in role playing as feigners in which a lack of rehearsal at T1 leads to some difficulties in remembering details related to the crime over time (e.g., Christianson \& Bylin, 1999; Sun et al., 2009; Van Oorsouw \& Merckelbach, 2004). In contrast, it should be noted that in the current 
studies, firstly, the memory-undermining effect of simulating amnesia appears to be less solid than it has been demonstrated in previous findings (e.g., Christianson \& Bylin, 1999; Van Oorsouw \& Merckelbach, 2004), and secondly, that a mere lack of rehearsal does not fully account for the memory detriments of simulators since these participants outperformed delayed testing-only controls regardless of rehearsal manipulation.

Of importance, by comparing simulators' performance with controls', we attempt to parse out why lack of rehearsal (e.g., Christianson \& Bylin, 1999) should be reconsidered as an explanation for the memory-undermining effect of simulating amnesia. That is, simulators could have encoded more crime-related information than controls simply because they were asked to identify themselves with the offender. This might indicate the role of engagement and active taskparticipation in memory (Nahari \& Ben-Shakhar, 2011). Thus, being tested in itself and being asked to report about the crime by claiming memory problems, could also be considered as rehearsal thereby promoting recall (Chan, 2010; Fazio, Agarwal, Marsh, \& Roediger, 2010), nevertheless contributing to less memory errors than does lack of rehearsal (i.e., control condition). While doing so, using a mock crime video rather than a narrative story seemed to strengthen participants' memory when they were requested to play a role. Alternatively, despite the fact that simulators were instructed to feign memory difficulties following the crime, they may have rehearsed the event in order to make up a simulated version of the crime (see also Van Oorsouw \& Merckelbach, 2006). Thus, simulators might have had one more opportunity to rehearse the offence and did not simply forget about the crime as compared with controls. During the first memory phase, therefore, simulating amnesia indirectly represented a way to rehearse the crime event so that it generated a significant rehearse-practice effect. This finding also entails that feigning amnesia in itself requires active cognitive processing which, even though it might protect against some memory decrements as compared with the control group (McWilliams, Goodman, Lyons, Newton, \& AvilaMora, 2014), it might have an undermining effect on the original memory. Consequently, we conclude that memory decrements for feigners possibly might be due to simulating amnesia in itself rather than lack of rehearsal (e.g., Christianson \& Bylin, 1999; Van Oorsouw \& Merckelbach, 2004).

Several limitations of our studies need to be addressed. To begin with, both our samples principally consisted of female undergraduates students. Even though we asked participants to identify themselves with the offender, it might be problematic for women to identify themselves with a male perpetrator. Although previous studies have shown that in similar paradigms participants were able to identify themselves with the main character also when using crime scripts (Christianson \& Bylin, 1999; Van Oorsouw \& Merckelbach, 2004), we did not specifically ask 
participants to rate their ability to identify with the perpetrator in the present study, which is a limitation. Nonetheless, identifying with the perpetrator might be a difficult task since undergraduate students differ on so many levels from individuals who commit severe crimes (Schacter, 1986). It is an empirical question whether the present findings might be generalized to the forensic context as is the case with other research based on mock crime. However, we believe that experimental studies based on mock crime paradigms represent a viable methodology to tap certain memory processes in individuals who feign amnesia for their offences (McWilliams et al., 2014). A second limitation of our studies is that the overall level of memory recall for the mock crime video appears to be low even though they are similar to levels already reported in the literature for mock crimes (e.g., Van Oorsouw \& Merckelbach, 2004; Van Oorsouw \& Giesbrecht, 2008). Moreover, although videos have been used in eyewitness memory and false memory research (see Loftus, 2005), previous research has not adopted videos in the simulating amnesia paradigm. Arguably, given its brief duration, our mock crime video did not display as many details as for instance in the mock crime script used by Christianson and Bylin (1999). This could explain why in the present study participants report a generally lower number of details. Finally, in study 1 , we did not observe the well-known memory-undermining effect of simulating amnesia (e.g., Christianson \& Bylin, 1999; Van Oorsouw \& Merckelbach, 2004), since ex-feigners performed similarly to confessors when they were not prompted with visual cues. In study 2 when samples sizes corresponded to those used in previous studies, the memory- undermining effect was found. In future studies, it would be wise to use a larger sample in order to further investigate whether feigning amnesia actually affects the original memory for a crime. Moreover, we do not know whether participants actually looked at the images and rehearsed them or they just ignored the reminders. Furthermore, even if participants indeed checked frames on their smartphones, it might be doubtful considering this as a form of actual rehearsal. This is notably true when compared to study 2, wherein a much stronger and active form of rehearsal was entailed. Yet, in both studies, the lack of self-report measures concerning the individual rehearsal dimension led us to raise the question of whether and how many participants did voluntarily rehearse the crime event. Rehearsal is a mental process that needs to be monitored to understand what happens in people's mind after they committed a crime. Thus, future studies could focus on the role of inner mechanisms after a crime to determine the processes involved in simulating amnesia (e.g. inner speech; Alderson-Day, McCarthy-Jones, Bedford, Collins, Dunne, Rooke \& Fernyhough, 2014).

In the legal context, for instance in plea bargaining situations, perpetrators who have previously feigned amnesia for a crime may not remember the crime very well, not because they have previously feigned, but because they have not been sufficiently encouraged to rehearse the 
actual event. Rehearsal is a simple cognitive mechanism that might stimulate offenders to think and re-think about the crime they perpetrated. If it is true that rehearsal effects increase with the number of rehearsals (Bergman \& Roediger, 1999), it would be perhaps possible to use mnemonic elicitation techniques such as cognitive cues (Meissner, Redlich, Bhatt, \& Brandon, 2012) to stimulate offenders to rehearse their criminal actions during information-gathering investigations (Memon, Meissner, \& Faser, 2010). In many cases, offender memory is crucial to reconstruct crime events. An example would be a recent case from the Netherlands in which an offender hid the victim's body and the police depended on his memory to locate the body. Previous studies have shown that when a defendant pretends to have no memory, or denies involvement he/she is oftentimes not actively rehearsing crime memories. Consequently, important details get lost from memory when offenders adopt this strategy (Christianson \& Bylin, 1999; Van Oorsouw \& Merckelbach, 2004; 2006; Sun et al., 2009). Because of the importance of disclosing crime-related information in high stake cases, a practical implication of our findings might be to find a way to increase the possibility to rehearse the criminal acts during the police interviews.

In conclusion, the present studies show that especially verbal rehearsal promotes memory for the crime of former simulators substantially and may return their mnemonic capacities to the level of a person who was interviewed repeatedly and reported honestly. Moreover, albeit feigning amnesia might jeopardize their memories, offenders who pretend to have memory loss for a crime will still recollect crime-related information better than those who are not interviewed initially. Therefore, the current findings seem also to demonstrate that feigning amnesia does not necessarily undermine memory for the crime. 


Chapter 3

Feigning Amnesia

Moderately Impairs Memory

for a Mock Crime Video

This chapter is based on:

Mangiulli I., van Oorsouw K., Curci A., Merckelbach H., \& Jelicic, M. (2018). Feigning Amnesia Moderately Impairs Memory for a Mock Crime Video. Frontiers in Psychology, 9:625. doi: 10.3389/fpsyg.2018.00625 


\begin{abstract}
Previous studies showed that feigning amnesia for a crime impairs actual memory for the target event. Lack of rehearsal has been proposed as an explanation for this memory-undermining effect of feigning. The aim of the present study was to replicate and extend previous research adopting a mock crime video instead of a narrative story. We showed participants a video of a violent crime. Next, they were requested to imagine that they had committed this offense and to either feign amnesia or confess the crime. A third condition was included: Participants in the delayed test-only control condition did not receive any instruction. On subsequent recall tests, participants in all three conditions were instructed to report as much information as possible about the offense. On the free recall test, feigning amnesia impaired memory for the video clip, but participants who were asked to feign crime-related amnesia outperformed controls. However, no differences between simulators and confessors were found on both correct cued recollection or on distortion and commission rates. We also explored whether inner speech might modulate memory for the crime. Inner speech traits were not found to be related to the simulating amnesia effect. Theoretical and practical implications of our results are discussed.
\end{abstract}

Keynote: feigning amnesia; simulation; lack of rehearsal; mock crime video; inner speech 


\section{Introduction}

Offenders in homicide and sex offense cases often claim crime-related amnesia (Bourget \& Whitehurst, 2007; Cima, Merckelbach, Nijman, Knauer, \& Hollnack, 2002; Cima, Nijman, Merckelbach, Kremer, \& Hollnack, 2004; Pyszora, Barker, \& Kopelman, 2003; Pyszora, Fahy, \& Kopelman, 2014). For instance, even though it is hard to determine to which degree defendants may intentionally feign amnesia following a crime, Pyszora and colleagues (2003) found that $29 \%$ of a 1-year cohort of individuals sentenced to life imprisonment claimed memory loss for their deeds ( $31.4 \%$ of those convicted of homicide). While it might be that the intense emotional arousal that some perpetrators experience during the crime might impair memory (e.g., Kopelman, 1995), there is also the distinct possibility that perpetrators feign memory loss (Centor, 1982; Marshall, Serran, Marshall, \& Fernandez, 2005). Although majority of jurisdictions are reluctant to equate amnesia with incompetency, claiming crime-related amnesia in court raises the question whether the defendant's ability to understand the trial proceedings or his capacity to consult with his attorney are impaired (e.g., Cima et al., 2002; Tysee, 2005; Tysse \& Hafemeister, 2006). For that reason, some individuals who are charged with serious crimes pretend to have memory loss for their offense (Christianson \& Merckelbach, 2004; Smith \& Resnick, 2007; Van Oorsouw \& Merckelbach, 2010).

Furthermore, when offenders adopt that strategy relevant information might be forgotten as it has been demonstrated that feigning amnesia has a detrimental effect on the genuine memory reported by feigners for those target events (e.g., Christianson \& Bylin 1999; Van Oorsouw \& Merckelbach, 2004, 2006). Although what perpetrators truly remember about the crime may differ from what they actually select to report or claim to remember, because of the risk of undisclosed information in high-stake cases it is crucial for the legal context to ascertain how people remember remarkable information over time despite having previously feigned amnesia (Bourget \& Whitehurst, 2007; Porter, Birt, Yuille, \& Herve, 2001).

Several studies have shown that feigning amnesia can undermine actual memory for a crime (Bylin, 2002; Bylin \& Christianson, 2002; Christianson \& Bylin 1999; Mangiulli, Lanciano, Van Oorsouw, Jelicic, \& Curci, 2018; Sun, Punjabi, Greenberg, \& Seamon, 2009; Van Oorsouw \& Merckelbach, 2004, 2006). The typical procedure to investigate the memory-undermining effect of simulating crime-related amnesia is as follows. First, participants are usually exposed to a written/narrative story about a crime and instructed to identify themselves with the perpetrator or asked to commit a mock crime. Next, participants are assigned to one of the two conditions: Some participants are asked to comply with the police by reporting as accurately as possible all information they remember about the event (i.e., further referred to as confessors); some others are 
instructed to minimize or evade their responsibility for the crime by feigning memory loss for the offense (i.e., referred to as simulators; Bylin, 2002; Christianson \& Bylin 1999; Van Oorsouw \& Merckelbach, 2006). Sometimes, a third condition is included (Bylin \& Christianson, 2002; Mangiulli et al., 2018; Sun et al., 2009; Van Oorsouw \& Merckelbach, 2004) consisting of participants who do not receive any instruction, and who serve as a delayed test-only control condition (i.e., further referred to as controls). In these studies, during the first memory phase, participants in the first two conditions (confessors vs. simulators) were given a free and cued recall test pertaining to the crime. One week later, during the second memory phase, all participants of the two (or three) conditions were requested to genuinely report about the crime event, through the same free and cued recall test. Typically, participants initially instructed to feign amnesia show a poorer memory for their crime than those who were asked to confess it (Bylin, 2002; Bylin \& Christianson, 2002; Christianson \& Bylin, 1999; Mangiulli et al., 2018; Sun et al., 2009; Van Oorsouw \& Merckelbach, 2004). Thus, research on feigning amnesia suggests that simulating memory loss impairs actual memory for a crime (e.g., Bylin, 2002; Christianson \& Bylin 1999; Van Oorsouw \& Merckelbach, 2004). Furthermore, when a delayed test-only control condition was included in the experimental design, no significant differences in memory performance were observed between controls and simulators one week after either being exposed to or committing the crime (e.g., Bylin \& Christianson, 2002; Van Oorsouw \& Merckelbach, 2004). In contrast to confessors, simulators and controls did not have to provide details of the crime just after the crime stimulus, namely they did not engage in rehearsing the crime. This lack of rehearsal, therefore, might explain the memory-undermining effect of feigning amnesia (see Van Oorsouw \& Merckelbach, 2004).

Relatedly, it is commonly observed that feigning participants comply with their instructions by withholding, distorting, and introducing new information (i.e., commission errors) on the initial memory test (Bylin, 2002; Bylin \& Christianson, 2002; Van Oorsouw \& Merckelbach, 2004, 2006). Clearly, simulating participants use laypeople's ideas about how feign amnesia works (Bylin, 2002). Thus, even though feigning amnesia might mostly lead to omissions (e.g., Christianson \& Bylin, 1999; Van Oorsouw \& Merckelbach, 2004), it is not surprising that Van Oorsouw and Giesbrecht (2008) found that participants initially instructed to minimize culpability for a mock crime increased commission errors over time, as compared with genuinely responding controls. Accordingly, the act of coming up with a personal, self-generated story of the crime (i.e., simulated version of the crime) could enhance errors, but may not affect the number of correct details provided (Ackil \& Zaragoza, 2011; Chroback \& Zaragoza, 2008, 2012; Van Oorsouw \& Giesbrecht, 2008). 
More recently, Mangiulli and co-workers (2018) explored whether confronting simulators with visual and verbal cues about a crime - by trying to induce rehearsal of details of the offenses would prevent impairments in simulators' memory. With this set-up, simulators performed on a similar level as confessors (when they were prompted with verbal cues), and interestingly they outperformed controls on a memory test for the crime regardless of a rehearsal induction. This indicates that lack of rehearsal indeed does not fully account for feigners' memory detriments. Unlike previous research in this field (e.g., Bylin \& Christianson, 2002; Sun et al., 2009), Mangiulli and colleagues used a video clip instead of a narrative story as a mock crime. They suggested that compared to a narrative story, a mock crime video was better encoded by participants engaged in role playing, such as feigners and confessors, leading to a better memory performance over time. It is well known, indeed, that visual stimuli are generally remembered better than verbal stimuli (i.e., words, narrative stories) since images are encoded into both verbal and image codes, while words are primarily coded verbally (Paivio, 1976; 1986). Moreover, images are more distinctive in their features and better evoked than words (Mintzer \& Snodgrass, 1999; Nelson, Reed, \& Walling, 1976). Thus, even though controls were exposed to the same crime material, it seems that both confessor and simulator groups actively elaborated upon the crime video so as to provide specific statements concerning their instructions, contributing to a more solid memory trace of the crime event compared with controls. The Mangiulli et al. study (2018), suggests that the memoryundermining potential of feigning amnesia is more modest and fragile than it has previously been assumed. The results of that study seem to indicate that when using a mock crime video as crime material, the phenomenon is limited to the comparison between confessors and simulators.

Following this line, the main purpose of the present study was to further investigate lack of rehearsal as the best explanation for the memory-undermining effect of simulating amnesia. We replicated the standard procedure to study feigning amnesia effects (e.g., Van Oorsouw \& Merckelbach, 2004) by using the same mock crime video employed by Mangiulli and colleagues (2018) instead of a narrative mock crime story (e.g., Bylin \& Christianson, 2002; Sun et al., 2009). We showed participants a video clip pertaining to a violent crime and asked them to either feign amnesia (simulators group) or confess the crime (confessors group) during the first memory phase. We also included a delayed test-only control group consisting of participants who did not receive any instruction. After one week, we requested all three groups to genuinely report all the information they could remember about the offense. We expected that simulators would recollect fewer correct details of the crime than confessors (hypothesis 1). However, we anticipated that both confessors and simulators would perform better than the delayed-test only control group (hypothesis 2). Finally, we predicted simulators to report more distortion and commission errors (i.e., 
introduction of new information) than confessors on the subsequent memory recall (hypothesis 3 and 4 , respectively).

Moreover, we attempted to extend the study by Mangiulli and colleagues (2018) by investigating whether the memory-undermining effect of feigning amnesia is modulated by inner speech activity. Inner speech refers to the subvocal rehearsing of personal events (Alderson-Day \& Fernyhough, 2015) and includes various characteristics such as dialogicality and condensation, the presence of other people voice and evaluative/motivational inner speech (Alderson-Day \& Fernyhough, 2015; Alderson-Day, McCarthy-Jones, Bedford, Collins, Dunne, Rooke, \& Fernyhough, 2014; McCarthy-Jones \& Fernyhough, 2011). For instance, the use of evaluative/motivational inner speech such as "I should do this", might be linked to the feigners" inclination in being consistent with their own simulated version of the crime in distinct circumstances (e.g., during preliminary investigations). Yet, perpetrators might estimate their deeds by engaging themselves in a self-evaluative-talk. Accordingly, common contents of inner speech refer to self- addressed evaluations and emotional states, in which continued inner speaking would regularly refresh experiences and maintain the corresponding memory traces in an "inner loop" (Alderson-Day \& Fernyhough, 2015). Thus, simulators might internally think of the offense they perpetrated like entailing consequences for the event. By doing so, they might feed the actual memory of the crime. If this was the case, we would expect a significant correlation between the individual inner speech traits and the memory undermining effect of feigning.

\section{Method}

\section{Participants and Design}

The present study was approved by the standing Ethical Committee of the Faculty of Psychology and Neuroscience, Maastricht University (ERCPN application - 16706052016 ). Using a snowballing sampling technique (Goodman, 1961), we tested 111 individuals who volunteered to take part in the study (range 18-58, $M_{\text {age }}=22.60, S D=9.64 ; 70 \%$ women). Participants were randomly assigned to one of the three conditions - simulators $(N=37)$, confessors $(N=37)$, and controls $(N=37)$. The study used a $3 \times 2$ mixed model design with condition (simulators vs. confessors vs. controls) as between subjects variable, and memory testretest (T1 vs. T2) as a within subjects repeated measure variable. The dependent variable was the proportion of correctly recollected information in a free and cued recall test. Furthermore, we calculated distortion and commission errors generated during memory tests. 


\section{Materials and Procedure}

Pre-experimental phase. Participants were tested in a quiet room. The study consisted of two phases. During the pre-experimental phase, each participant was invited to complete the Structured Inventory of Malingered Symptomatology (SIMS; Smith \& Burger, 1997), and the Varieties of Inner Speech Questionnaire (VISQ; McCarthy-Jones \& Fernyhough, 2011). This last instrument was administered to explore the relation between inner speech and the memory undermining effect of simulating. In order to guarantee homogeneity in our sample before the experimental phase, the SIMS was assessed to check for possible differences among groups with regard to their feigning tendency.

Structured Inventory of Malingered Symptomatology (SIMS; Smith \& Burger, 1997). The SIMS $^{5}$ is a two option self-report measure to screen for over-reporting of mental symptoms and consists of a 75 items which are divided into five subscales (affective disorders; amnestic disorders; low intelligence; neurological impairment; psychosis). It includes items asking for atypical symptoms (e.g., "Walking is difficult for me because of my problems with balance”). Answers indicative of over-reporting are summed to obtain a total SIMS score $(\alpha=.73)$.

Varieties of Inner Speech Questionnaire (VISQ; McCarthy-Jones \& Fernyhough, 2011). The VISQ is an 18 item self-report instrument measuring the phenomenological proprieties of inner speech along four dimensions: Condensed $(\alpha=.72$; "I think to myself in words using brief phrases and single words rather than full sentences"); Dialogic ( $\alpha=.85$; "I talk back and forward to myself in my mind about things"); Other People ( $\alpha=.85$; “I experience the voices of other people asking questions in my head"); Evaluative/Motivational ( $\alpha=.76$; "I experience the voices of other people asking questions in my head"). Participants have to rate a 6-point Likert scale anchoring from "certainly does not apply to me" (1) to "certainly applies to me" (6).

Mock crime video. After the pre-experimental phase, all participants were requested to pay attention to the mock crime video and were instructed to identify themselves with the character that appeared on the scene first (i.e., offender). The crime contained a violent scene between two armed men (2.30 minutes): A man entering a restroom was attacked by another man. After a severe fight, the attacker strangled the victim with his belt leaving him lifeless on the ground. After the exposure to the mock crime video, all participants were given a 10-minutes distractor task (i.e., computer game). This task was administered to avoid the possible ceiling effect in the following memory tests (Bylin, 2002).

5 The five subscales of the SIMS (Smith \& Burger, 1997) were not included in our analyses since they were not relevant for our study. 
Memory test phase (T1). Next, participants belonging to the simulator and confessor groups received the following instruction: "Imagine being the offender. Imagine that you have been arrested because you are the prime suspect of the murder. That day, a witness saw you there and all the evidence points to you. Right now, a policeman is asking you to tell what happened". Following previous studies (e.g., Bylin \& Christianson, 2002; Mangiulli et al., 2018; Sun et al., 2009; Van Oorsouw \& Merckelbach, 2004) free and cued recall tests were employed as memory measures. Through a free recall, participants were invited to report their statements in accordance with the condition to which they were assigned. That is, simulators were instructed to report the crime as if they could not properly remember what happened. To evade punishment, simulating participants were free to omit, distort or report other information. Confessors, on the other hand, were asked to honestly report details about the crime in order to collaborate with the police. After this free recall, participants in both groups were given 14 cued recall questions concerning the mock crime video and were instructed to answer them by adhering to the instruction previously given (i.e., simulating or confessing). In line with previous research (e.g., Bylin \& Christianson, 2002; Sun et al., 2009; Van Oorsouw \& Merckelbach, 2004), and in contrast to simulators and confessors, controls were not given a memory test. Although they were asked to identify themselves with the offender, participants in the control condition did not receive any instruction after the mock crime viewing and they were directly scheduled for the second session.

Memory retest phase (T2). After one week, all participants - including controls - were specifically requested to be as specific as possible while providing all the information regarding the mock crime, as if they had decided to collaborate with the police. Contrary to the instruction received during the first memory phase, this time simulators were instructed to give up their role as feigner and recollect all they could remember about the target event. Confessors again received the instruction to comply with the police by reporting each and every detail about the mock crime video. Similarly, controls were now asked to recollect as much as they could remember about the criminal act. In the cued recall task, all participants were told to honestly answer the 14 questions. Finally, participants were thanked and debriefed.

\section{Memory Test-Retest Scoring}

Free recall. Following Mangiulli and co-workers' study (2018), a scoring system was established to assess participants' free recall. We first classified the mock crime video into 50 critical information units. Critical information was defined as a relevant piece of the video. For each correct unit of information reported (e.g., "I assaulted the victim from the back"), participants scored 1 point $($ maximum $=50$ ). Moreover, participants earned a half point for each partially 
correct unit of information given (e.g., "I assaulted the victim"). In line with previous studies (i.e., Sun et al., 2009; Van Oorsouw \& Merckelbach, 2004), the entire correct score was transformed into proportions (range $=0-1$ ) by dividing the number correct units reported by the maximum obtainable score. Additionally, we identified the number of distorted units (e.g., "I killed the victim by shooting him") and commissions (i.e., introduction of new information that was not displayed in the video: "The victim was wearing a ski mask"). The first author and two assistants, who were blind to the study conditions, scored participants' free recall. The Interclass Correlation Coefficient (ICC) average measure for the number of correct free recall scores was $.93(p<.001)$; the ICC's for distortions and commissions were .86 and .83 , respectively (both $p_{s}<.001$ ).

Cued recall. The cued recall test consisted of fourteen questions regarding both central (seven questions; i.e., weapon or blood), and peripheral details (seven questions; i.e., characters' clothing, details about the location) of the mock crime video. Participants earned 1 point for each correct answer given (e.g., Question: “Where did the murder take place?”, "In the parking lot's toilet"). Again, a half point was awarded for a partial correct answer (e.g., "In the toilet"). No penalty was given when participants did not provide any answer (e.g., "I do not remember"). The maximum obtainable score was 14. Similar to the free recall, the total cued recall score was transformed into proportions (range $=0-1$ ). Furthermore, the number of distorted details and commissions were identified (e.g., "The murder took place near a fire extinguisher in the parking lot", and "The murder took place in a bar", respectively). The ICC average measure for the number of correct cued recall information was $.96(p<.001)$; the ICC average measure of distortions and commissions for cued recall was .88 and .79 , respectively (both $p_{s}<.001$ ).

\section{Results}

\section{Manipulation Check on Feigning Tendency}

A one way ANOVA was conducted on SIMS total score to exclude possible individual differences in the feigning tendency among three groups ${ }^{6}$ before the experimental phase. The main effect of condition was found not significant, $F(2,106)=.03, p=.971$, so that participants did not differ as to their simulating predisposition.

\section{Free Recall - Correctness Scores}

A 2 × 2 repeated measures ANOVA with condition (simulators vs. confessors) as a between subjects factor and memory test-retest (T1 vs. T2) as a within subjects factor was run on the free

6 None of our participants belonging to either one of the three groups (simulators vs. confessors vs. controls) were excluded from our study based on their SIMS results. 
recall correctness score. The main effects of condition and memory test-retest were found significant, $F(1,71)=60.62, p<.001, \eta_{p}{ }^{2}=.46$, and $F(1,71)=8.86, p=.004, \eta_{p}{ }^{2}=.11$, respectively. The significant condition by test-retest interaction, $F(1,71)=24.66, p<.001, \eta_{p}{ }^{2}=$ .26 , showed that simulating participants reported more correct information at $\mathrm{T} 2$ than $\mathrm{T} 1, t(35)=$ 7.83, $p<.001, d=2.00$. This indicates that participants in the simulation condition properly followed their instruction. No difference was found for confessors in the proportion of correct information reported at the two memory phases, $t(36)=1.16, p=.25$.

In order to observe differences in the correctness score among all conditions of the design (simulators vs. confessors vs. controls), a one-way ANOVA was conducted only on the retest memory phase (T2). The main effect of condition reached significance, $F(2,107)=17.74, p<.001$, $\eta_{p}{ }^{2}=.25$. Post-hoc test with Bonferroni correction indicated that simulators reported less correct information than confessors, $p=.014,95 \% C I[-4.22-.36], d=0.61$. As expected, and in line with our hypothesis (Hp. 1), feigning amnesia undermined memory for the mock crime video. Furthermore, in line with our prediction (Hp. 2), both simulators and confessors were able to recall significantly more correct information than controls, $p=.009,95 \% C I$ [.47 .43], $d=0.83$, and $p$ $<.001,95 \% C I[2.776 .60] d=1.36$, respectively. Proportions of free recall correctness ${ }^{7}$ are shown $^{2}$ in Table 1.

\section{Free Recall - Distortion and Commission Errors}

Two 2 × 2 repeated measures ANOVAs with condition (simulators vs. confessors) as a between subjects factor and test-retest (T1 vs. T2) as a within subjects factor were separately performed on distortion and commission errors. Regarding the distortions rate, the main effect testretest, and the interaction effect condition by test-retest reached significance, $F(1,71)=6.46, p$ $=.013, \eta_{p}{ }^{2}=.08$, and $F(1,71)=12.06, p=.001, \eta_{p}{ }^{2}=.14$, respectively. By contrast, the main effect of condition was not found to be significant, $F(1,71)=1.68, p=.20$. Surprisingly, simulators provided more distorted details at $\mathrm{T} 2$ than $\mathrm{T} 1$, while confessors did not over time, $t(35)=5.50, p<$ $.001, d=1.10$, and $t(36)=-.561, p=.58$, respectively. Unexpectedly, and contrary to our

7 Additionally, we conducted similar ANOVAs on the free recall accuracy scores. Accuracy scores were calculated by dividing the correctness scores by the number of correct items plus the number of distortion and commission errors [Accuracy $=$ correctness score/(correctness score + errors)]. Overall, findings showed that simulators were less accurate than confessors during T1 $(M$ simulators $=59 \%, S D=.28$ vs. $\left.M_{\text {confessors }}=81 \%, S D=.18\right), t(69)=-4.23, p<.001, d=.95$. Moreover, at T2, confessors resulted to be more accurate than both simulators ( $M_{\text {confessors }}=86 \%$, $S D=.13$ vs. $\left.M_{\text {simulators }}=72 \%, S D=.18\right)$ and controls $\left(M_{\text {controls }}=67 \%, S D=.28\right), p=.02,95 \% C I$ [.02 .26], $d=.87$, and $p<.001,95 \% C I[.07 .31], d=.87$, respectively. No significant differences were found between simulators and controls, $p=.85,95 \%$ CI [-.06 .17]. 
hypothesis (Hp. 3), no significant differences were found between simulators and confessors at T2 on the number of distorted details provided, $t(71)=1.16, p=.25, d=.27$.

With regard to the commission errors, the main effects of condition and memory test-retest were found to be significant, $F(1,71)=16.30, p<.001, \eta_{p}{ }^{2}=.19$, and $F(1,71)=14.55, p<.001, \eta_{p}{ }^{2}$ $=.17$, respectively. Moreover, the condition by memory test-retest interaction effect was analysed, $F(1,71)=9.42, p=.003, \eta_{p}{ }^{2}=.12$. Simulators significantly provided fewer commissions at $\mathrm{T} 2$ compared to T1, while no differences were found in confessors between the two memory phases, $t(35)=3.60, p=.001, d=.81$, and $t(36)=-1.14, p=.26$, respectively. Against our assumption $(\mathrm{Hp}$ 4), simulators did not significantly differ from confessors at $\mathrm{T} 2$ on the number of commissions reported, $t(71)=1.49, p=.14, d=.34$.

Finally, two one-way ANOVAs were independently run on distortion and commission errors to investigate differences among groups (simulators vs. confessors vs. control) during T2. The main effect of condition did not reach significance with respect to both distortions and commissions, $F(2,107)=.73, p=.482$, and $F(2,107)=1.96, p=.145$, respectively. Absolute numbers for both distorted details and commission errors are displayed in Table 1.

\section{Cued Recall - Correctness Scores}

In line with the free recall analyses, an identical pattern of ANOVAs was conducted on the cued recall correctness scores. The interaction effect condition by memory test-retest, $F(1,72)=$ 27.91, $p<.001, \eta_{p}{ }^{2}=.28$, showed that simulators reported more correct information units at $\mathrm{T} 2$ than at T1, which was in line with their instruction, $t(36)=6.23, p<.001, d=1.09$. However, confessors did not differ in the amount of correct information reported from $\mathrm{T} 1$ to $\mathrm{T} 2, t(36)=-.31$, $p=.76$. Interestingly, and in contrast to our hypothesis (Hp. 1), a post-hoc test with Bonferroni correction showed no significant difference between simulators and confessors with respect to the number of correct details during $\mathrm{T} 2, p=.128,95 \% C I[-1.98 .16], d=.44$. Thus, feigning memory loss did not impair genuine memory for a mock crime when participants were requested to honestly recollect the target event through a cued recall test.

Moreover, partially supporting our prediction (Hp. 2), only confessors reported more correct details than controls since no significant differences were found between simulators and controls at $\mathrm{T} 2, p=.03,95 \% C I[.072 .22], d=.64$, and $p=1.00,95 \% C I[-.831 .31], d=.13$, respectively. See Table 1 for cued recall correctness ${ }^{8}$ proportions.

8 We furthermore calculated the cued recall accuracy scores [Accuracy = correctness score/(correctness score + errors)]. Simulators appeared to be less accurate than confessors at T1 $\left(M_{\text {simulators }}=63 \%, S D=.20\right.$ vs. $\left.M_{\text {confessors }}=75 \%, S D=.13\right), t(72)=-3.21, p=.002, d=-.75$. Yet, 


\section{Cued Recall - Distortion and Commission Errors}

By running the same set of ANOVAs, a pattern comparable to the free recall was observed on the cued recall distortion and commission errors. In contrast with our hypothesis (Hp. 3), no significant differences were found between simulators and confessors with respect to distortions at $\mathrm{T} 2 t(72)=.34, p=.73, d=.08$.

Yet, the main effect of time was found significant for the commission errors, $F(1,72)=6.20$, $p=.015, \eta_{p}{ }^{2}=.08$, showing that all participants (i.e., simulators and confessors) reduced the number of commission errors from $\mathrm{T} 1$ to $\mathrm{T} 2, t(73)=2.48, p=.01, d=.53$. No other main or interaction effects were found to be significant on commissions, $F_{s}(1,72)<1.35, p>.25, \eta_{p}{ }^{2}<.02$, meaning that simulators did not differ from confessors on commission errors at $\mathrm{T} 2$ against our expectation (Hp. 4).

With respect to differences among groups at $\mathrm{T} 2$, the main effect of condition was significant for distortion rates, $F(2,108)=5.02, p=.008, \eta_{p}^{2}=.08$. Bonferroni corrected post-hoc test revealed that controls reported more distorted details than both simulators and confessors at $\mathrm{T} 2, p=$ $.01,95 \% C I$ [.18 2.08], $d=.70$, and $p=.03,95 \% C I$ [.05 1.95], $d=.58$, respectively. Finally, no significant main or interaction effects were found on commission errors among groups at T2, $F_{s}(2,108)<1.73, p>.18$. See Table 1 for cued recall distorted information and commission errors.

during T2, both simulators and confessors were more accurate than controls $\left(M_{\text {simulators }}=75 \%, S D\right.$ $=.12$, and $M_{\text {confessors }}=75 \%, S D=.15$, vs. $\left.M_{\text {controls }}=66 \%, S D=.13\right), p=.03,95 \% C I[.01 .16], d=$ .65 , and $p=.02,95 \% C I[.01 .17], d=.62$, respectively. Finally, no significant differences were found between simulators and confessors, $p=1.00,95 \% C I[-.08 .07]$. 
Table 1. Free and cued recall proportions for each condition during the first (T1) and the second (T2) memory phase.

FREE RECALL

\begin{tabular}{lccccc}
\hline & \multicolumn{2}{c}{ Simulators } & \multicolumn{2}{c}{ Confessors } & Controls \\
Memory phase & $\mathrm{T} 1$ & $\mathrm{~T} 2$ & $\mathrm{~T} 1$ & $\mathrm{~T} 2$ & $\mathrm{~T} 2$ \\
\hline Correct & $0.04^{\mathrm{a}}(0.03)$ & $0.13^{\mathrm{a}, \mathrm{b}, \mathrm{c}}(0.06)$ & $0.19(0.09)$ & $0.17^{\mathrm{b}, \mathrm{d}}(0.08)$ & $0.07^{\mathrm{c}, \mathrm{d}}(0.04)$ \\
Distortion $^{*}$ & $0.81^{\mathrm{e}}(0.92)$ & $2.03^{\mathrm{e}}(1.30)$ & $1.81(1.24)$ & $1.62(1.67)$ & $1.78(1.31)$ \\
Commission $^{*}$ & $0.89^{\mathrm{f}}(1.19)$ & $0.14^{\mathrm{f}}(0.42)$ & $0.11(0.39)$ & $0.03(0.16)$ & $0.03(0.16)$ \\
\hline
\end{tabular}

CUED RECALL

\begin{tabular}{lccccc}
\hline & \multicolumn{2}{c}{ Simulators } & \multicolumn{2}{c}{ Confessors } & Controls \\
Memory phase & $\mathrm{T} 1$ & $\mathrm{~T} 2$ & $\mathrm{~T} 1$ & $\mathrm{~T} 2$ & $\mathrm{~T} 2$ \\
\hline Correct & $0.10^{\mathrm{a}}(0.05)$ & $0.16^{\mathrm{a}}(0.04)$ & $0.18(0.04)$ & $0.18^{\mathrm{b}}(0.04)$ & $0.15^{\mathrm{b}}(0.03)$ \\
Distortion $^{*}$ & $2.77(1.73)$ & $2.76(1.62)$ & $2.86(1.62)$ & $2.90(1.80)$ & $3.90(1.63)$ \\
Commission $^{*}$ & $0.35^{\mathrm{c}}(0.67)$ & $0.05^{\mathrm{c}, \mathrm{d}}(0.23)$ & $0.22^{\mathrm{e}}(0.58)$ & $0.10^{\mathrm{e}, \mathrm{f}}(0.31)$ & $0.22^{\mathrm{d}, \mathrm{e}, \mathrm{f}}(0.38)$ \\
\hline
\end{tabular}

Note: Standard deviations are shown between parentheses. "Distortion and commission errors are displayed in absolute numbers. Same letters within the same row display significant differences between groups at $p<.05$.

\section{Simulating Amnesia and Inner Speech}

In line with Van Oorsouw and Merckelbach (2004), we first computed the simulating amnesia effect for the feigning participants' free and cued recall performance by calculating difference scores for the memory variables $(\boldsymbol{\Delta}$ Free Recall $=$ Free Recall $\mathrm{T} 2-$ Free Recall $\mathrm{T} 1 ; \boldsymbol{\Delta}$ Cued Recall $=$ Cued Recall T2 - Cued Recall T1). Next, we correlated the simulating amnesia effect with VISQ $\left(M_{\text {Condensed }}=14.11, S D=5.24 ; M_{\text {Dialogic }}=11.38, S D=5.25 ; M_{\text {Other People }}=8.31, S D=4.46 ; M\right.$ Evaluative/Motivational $=13.02 ; S D=4.71)$. No significant correlations were found between the memoryundermining effects of feigning amnesia and these individual difference traits with respect to both free and cued recall performances, $r_{s}<.12, p>.47$, and $r_{s}<-.05, p>.11$, respectively. 


\section{Discussion}

The present study aimed to replicate and extend previous research on the feigning amnesia for a mock crime paradigm (e.g., Mangiulli et al., 2018; Van Oorsouw \& Merckelbach, 2004) to further study decrements in rehearsal as an explanation for the memory-undermining effect of simulating amnesia. With respect to our first hypothesis, feigning amnesia undermined the actual memory for the criminal event since simulators provided less correct information than confessors on the free recall. However, the memory detrimental effect following feigning of amnesia took place only during the free memory test, since previous simulators and confessors did not differ on the final cued recall test. The same pattern of results was observed on the accuracy score. Hence, feigning amnesia for a mock crime in this study did not lead to the strong memory-undermining effect as shown in previous research (e.g., Christianson \& Bylin 1999; Van Oorsouw \& Merckelbach, 2004, 2006). Moreover, it seems that the lack of the simulating amnesia effect is related to the memory test that was used, as evidenced by better performance on the cued recall test than on the free recollection test.

Next, according to our second hypothesis, simulating participants did report more correct crime-related information than those who were not interviewed in the first place (i.e., controls) on the free recall test - although no significant differences were found on the accuracy rates between both groups, in which distortion and commissions errors were taken into account. Note that this prediction is particularly important since, based on the absence of significant differences between feigners and controls on the final recall tests, "lack of rehearsal" has been pointed out as the best explanation for the memory-undermining effect of feigning amnesia (e.g., Christianson \& Bylin 1999; Van Oorsouw \& Merckelbach, 2004). On the one hand, our findings might be related to the crime stimulus that was used (i.e., mock crime video). Indeed, a considerable body of research has demonstrated that visual stimuli are typically remembered better than verbal material (Mintzer \& Snodgrass, 1999; Nelson, Reed, \& Walling, 1976; Paivio, 1976, 1986; Weldon, Roediger, \& Challis, 1989). Hence, the use of a video could have led to a more solid memory trace for the mock crime information. Relatedly, on the other hand, perhaps simulators might have processed crimerelated information more elaborately than controls - who did not receive any instructions after the mock crime viewing - in order to come up with a personal simulated version of the offense. In fact, although one could expect that feigning amnesia mainly leads to omitting information, previous studies suggested that when participants were asked to recall a mock crime in such a way they had great difficulties in remembering what happened, they were even likely to provide an alternative self-generated story (e.g., Van Oorsouw \& Giesbrecht, 2008; Van Oorsouw \& Merckelbach, 2004, 2006). Indeed, Van Oorsouw and Merckelbach (2006) found that one-third of their entire sample 
used an alternative story in an attempt to feign amnesia. Yet, this result appears to be in line with the idea that by enhancing an active elaboration of information during memory encoding (McWilliams et al., 2014), being tested in itself could promote correct recollection (Chan, 2010; Fazio, Agarwal, Marsh, \& Roediger, 2010). However, even though feigners were more accurate than controls, no significant differences were found between groups on the number of correct responses provided during the cued recall test. This may suggest that individuals who did not receive any instruction during the first memory phase might find it easier to report correct information when prompted by open-ended cued recall questions rather than through a free recollection (Craik \& McDowd, 1987; Padilla-Walker \& Poole, 2002).

Finally, regarding our third and fourth hypothesis, no significant differences were found between simulators and confessors with respect to both distortion and commission errors during free and cued recall tests. This result might indicate that feigners recovered up to the level of confessors when it concerned distorted or self-generated information. Of interest, simulators increased distortions from $\mathrm{T} 1$ to $\mathrm{T} 2$ on the free recollection test. Conceivably, when participants instructed to feign amnesia come up with a self-generated version of the crime, which is strongly related to the original event, distortions are more likely to occur (Chrobak \& Zaragoza, 2008; Otgaar \& Baker, 2017; Van Oorsouw \& Giesbrecht, 2008).

A subsidiary aim of the present study was to explore whether or not inner speech (AldersonDay \& Fernyhough, 2015) might work as a buffer against the memory-undermining effect of feigning amnesia. One could argue that the more simulators tend to think of their crime, the less simulating amnesia affects the actual memory of the offense. However, our analyses suggest that inner speech might not be involved in preserving the genuine memory for the crime.

In sum, we suggest that feigning amnesia in the first place might be seen as a way to preserve and perhaps enhance memory for the target event over time, as compared to not being initially interviewed. However, possible memory decrements for feigners might depend on simulating amnesia in itself rather than a mere lack of rehearsal (e.g., Christianson \& Bylin 1999; Van Oorsouw \& Merckelbach, 2004). That is, drawing on the Memory and Deception (MAD) framework (Otgaar \& Baker, 2017), feigning amnesia is inserted in a lying-continuum from false denial to fabrication of alternative scenarios. According to the MAD, the amount of cognitive resources required by individuals is directly proportional to the type of lie exerted, and the memory outcome for the actual target event is strictly affected by the different lie adopted. More precisely, whereas false denial implies less cognitive resources leading to omission, fabricating entire stories ex novo requires more cognitive resources leading to commission errors (Otgaar \& Baker, 2017). Therefore, located somewhere in the middle of this framework, one could expect that feigning 
amnesia might cause a more distinct memory-undermining effect on the original experience by mostly withholding information than feigning amnesia by distorting or self-generating new information might do. In this latter case, perhaps due to a cognitive re-elaboration of the event (McWilliams et al., 2014), simulating amnesia might partially affect genuine memory for the crime even though participants might potentially report distortion and/or commission errors (e.g., Chrobak \& Zaragoza, 2008; Otgaar \& Baker, 2017; Van Oorsouw \& Giesbrecht, 2008).

Also, it could be argued that the instructions given to participants to feign amnesia for a mock crime might play a role in the actual memory for those events. As rightly noticed by Otgaar and Baker (2017), when those asked to feign amnesia account for the target experience, both attempts at simulating memory loss and fabricating may be occurring. Therefore, future studies might consider to bypass the "feigning" instruction by instead instructing participants to avoid thinking of the crime as a consequence of an emotional distress. Such deliberate avoidance, which would produce forgetting in itself as some research has pointed out (e.g., Anderson \& Green, 2001; Anderson \& Hanslmayr, 2014), might better reflect memory processes in real offenders.

Several caveats of the present study need to be mentioned. Although we tested a large number of participants, our sample mainly consisted of women. Even though we asked participants to identify themselves with the main character in the video, it might be hard for women to identify themselves with a male offender. To avoid this limitation in future research, it might be better to use a mock crime video recorded in point of view (pov) in which the perpetrator's gender is indistinguishable. Moreover, we did not specifically assess participants' ability to identify with the offender, which represents a limitation. Secondly, we did not assess the emotional impact of the mock crime video on participants. Specifically, we do not know whether or not the material used had contributed to maintain the participants' memory performance over time per se regardless of the instruction given at T1. In future studies, therefore, it would be wise to assess the emotional impact of the crime material. Moreover, in future research, it might be interesting comparing two or more different types of crime materials to identify the most suitable stimulus to use in the mock crime paradigm (e.g., video vs. narrative story). It could be the case that the memory-undermining effect of simulating amnesia, that already seems to be less solid by adopting a mock crime video rather than a narrative, would perhaps be even weaker with a more ecologically valid set-up (e.g., mock crime through virtual reality). Thirdly, we did not ask participants what type of strategy they adopted to come up with a simulated version of the crime. Certainly, this information would be interesting since it is not fully clear to which degree this detrimental effect on the genuine memory for a crime is due to the feigning amnesia in itself or to the act of self-generating an alternative scenario for the same target event (Otgaar \& Baker, 2017). Finally, another limitation has to do 
with the VISQ inner speech scales and the lack of correlation between these latter and the memoryundermining effect of feigning amnesia. Arguably, for this specific measure our sample size (i.e., 37 feigners) may not have been large enough to detect the predicted correlation. Future research in this direction should involve a larger sample size to better investigate a potential relation between the simulating amnesia effect and the inner speech traits. Moreover, even though this instrument has satisfactory psychometric reliability, the VISQ in its present form does not tap traits such as cognitive functions (McCarthy-Jones \& Fernyhough, 2011). These functions - mnemonic and attentional uses of inner speech - are however assessed by other instruments which were not used in the present study (e.g., Self-Verbalization Questionnaire; Duncan \& Cheyne, 1999). In future studies it would be wise to tap participants' inner speech activities through self-report measures instead of mainly assessing their inner speech predisposition.

Although it is always difficult to generalize experimental findings to real life cases (Schacter, 1986), research using laboratory mock crime scenarios are fundamental to increase our knowledge about crime-related amnesia (e.g., McWilliams et al., 2014). As a matter of fact, knowing that genuine memory of a crime might be largely uncompromised despite having previously feigned amnesia appears to be informative to forensic practitioners who are asked to provide an opinion concerning crime-related amnesia cases. Relatedly, police investigators might find it interesting that suspects might actually preserve memory for the crime and contribute to disclose specific crime-related details. Oftentimes, indeed, crucial information of crimes remain undisclosed when a report of amnesia emerges (Van Oorsouw \& Merckelbach, 2004, 2006), regardless of the fact that some perpetrators admit their guilt (Porter et al., 2001). Thus, at least to some degree, our findings suggest that perpetrators are more likely to recall a larger amount of information when prompted by cues rather than being asked to freely recall the crime (see also Mangiulli et al., 2018, Study 2; Meissner, Redlich, Bhatt, \& Brandon, 2012), particularly when they might be persuaded to collaborate with the justice department (e.g., plea bargaining situation).

In closing, by using a mock crime video instead of a mere narrative, our findings suggest that the memory-undermining effect of simulating amnesia occurs to a lesser extent than that observed in previous research (e.g., Christianson \& Bylin 1999; Van Oorsouw \& Merckelbach, 2004, 2006). The present study, indeed, indicates that simulating amnesia partially undermines actual memory for a crime and that, apart from a tendency to distort some details, offenders might still have relatively intact memory for the target experience. 

Chapter 4

\section{Can implicit measures detect source information in crime-related amnesia?}

This chapter is based on:

Mangiulli I., Lanciano, T., Jelicic, M., van Oorsouw K., Battista, F., \& Curci A. (2018). Can implicit measures detect source information in crime-related amnesia?. Memory, 26, 1019-1029. doi: 10.1080/09658211.2018.1441421 


\begin{abstract}
Participants who are asked to simulate amnesia for a mock crime have a weaker memory for this event when they have to give up their role as a feigner, than those who are not asked to feign memory loss. According to the source monitoring framework (SMF), this memory-undermining effect of simulating amnesia for a crime would be due to misattribution of the right source of information. However, we know that the content of self-generated information (e.g., feigned version of the crime) might be preserved and recognized over time as a result of elaborative cognitive processing. In the present study, we aimed to contrast these two explanations. We showed participants a mock crime video and we instructed them to either feign amnesia (simulators) or confess the mock crime (confessors). Next, a free recall memory test was administered. After one week, participants were asked to perform a personalized source monitoring task using the autobiographical Implicit Association Test (aIAT). As predicted, we found that simulators were able to discriminate the content of their self-generated feigned story of the crime from the original version. Moreover, simulators were quicker than confessors at the aIAT task. Practical and theoretical implications of our results are discussed.
\end{abstract}

Keywords: simulating amnesia, crime-related amnesia, source monitoring, autobiographical Implicit Association Test, implicit memory 


\section{Introduction}

A nontrivial minority of criminal offenders claim amnesia for their deeds (Cima, Merckelbach, Nijman, Knauer, \& Hollnack, 2002; Pyszora, Barker, \& Kopelman, 2003). Even though genuine crime-related amnesia is not impossible, it seems that most offenders feign their memory loss (Christianson \& Merckelbach, 2004). Because of crime-related amnesia, a defendant might be found not completely responsible for a crime or may be rendered incompetent to stand trial (Smith \& Resnick, 2007). Therefore, determining the authenticity of memory loss is legally relevant (Giger, Merten, Merckelbach, \& Oswald, 2010; Merckelbach \& Christianson, 2007).

Although feigning memory loss for a crime is sometimes difficult to determine, a large body of studies supports the idea that pretending to have amnesia impairs an offender's memory for the crime (the so-called memory-undermining effect of simulating amnesia; Christianson \& Bylin 1999). That is, individuals who were instructed to simulate amnesia for a mock crime on an initial memory test (further referred to as simulators) differed from participants who were instructed to respond honestly (further referred to as confessors) when some time later they were asked to give up simulating and honestly report details about the crime (Bylin \& Christianson, 2002; Christianson \& Bylin 1999; Van Oorsouw \& Merckelbach, 2004; 2006). Thus, pretending to suffer from memory loss for an offence appears to undermine recollection of that crime.

\section{Source Monitoring Deficit as an Explanation for the Simulating Amnesia Effect}

A possible explanation for the memory-undermining effect of feigning amnesia for a mock crime has to do with the source monitoring framework (SMF; Johnson, Hashtroudi, \& Lindsay, 1993; Mitchell \& Johnson, 2009). As suggested by Christianson and Bylin (1999), simulating amnesia may cause distorted information to be incorporated into the offender's memory of the crime, thereby leading to memory distortion. In other words, when simulators are asked to feign amnesia for a mock crime they come up with a different (self-generated) story, which might be confused with the original story causing source monitoring errors. Such imagining may confuse memory for what was originally experienced, by increasing qualitative details that are typical of a real event (Johnson et al., 1993; Johnson, Raye, Foley, \& Foley, 1981). Previous research has also demonstrated that some offenders might be prompted by vivid memories of their violent acts by repeatedly thinking of the crime that they perpetrated or how it could have been prevented (Evans, 2006; Evans, Ehlers, Mezey, \& Clark, 2007). This type of prompt includes a counterfactual thinking (CFT) - reflecting on how past events might have occurred differently (Byrne, 2005, 2016; Roese \& Epstude, 2017; Roese \& Olson, 1997). For that reason, simulators might increase source confusion for their deeds by thinking how they could have avoided the crime if they would have 
acted differently. Source confusion might thus increase when imagined events resemble real events (Johnson et al., 1993).

\section{Alternative Explanation to the Source Monitoring Paradigm}

One could however argue that simulating amnesia might implicate a sort of active elaboration of the memory for the crime (McWilliams, Goodman, Lyons, Newton, \& Avila-Mora, 2014), so that individuals who feign memory loss are driven in their simulation by their ideas about how memory loss works (Bylin, 2002). As a matter of fact, previous studies have shown that participants feign amnesia by omitting all information (Iverson, 1995), exaggerating memory impairment (Baker, Hanley, Jackson, Kimmance, \& Slade, 1993), or withholding some information while reporting other or distorted information (simulation by omission vs. simulation by commission; Bylin \& Christianson, 2002; Van Oorsouw \& Merckelbach, 2004). Germane to these findings, it has also been demonstrated that the content of self-generated information (e.g., the simulated version of the crime) might remain relatively clear as a result of elaborative cognitive processing (Chrobak \& Zaragoza, 2008; Johnson, Foley, Suengas, \& Raye, 1988). Indeed, Chrobak and Zaragoza (2008) showed that individuals had preserved memory of a self-generated event and, one week later, they were unlikely to confuse the same event with another one. Consequently, although feigning amnesia may cause distorted memories for a crime, simulators might still keep in mind which information is self-generated and belongs to their own feigned story and which one belongs to the actual crime. As a result of elaborative cognitive processing, feigners might preserve fictitious crime-related information in order to stick with their personal version of the facts instead of being confused by what they formerly claimed. This effect would take place, for instance, in specific situations where the simulation is repeated, such as during police interrogations.

Hence, in the present study, we aimed to contrast the source monitoring explanation for the feigning amnesia effect (Christianson \& Bylin, 1999), to the possibility of distinguishing the content of self-generated information by simulators. Therefore, based on the line of reasoning depicted above, the main research question of the present study was: Are simulators, despite previously feigning amnesia, still able to identify the source of information during a source monitoring task? 


\section{Investigating Source Monitoring Ability via Explicit vs. Implicit Task}

So far, the SMF explanation in relation to simulated amnesia has been investigated by comparing simulators' memory errors (i.e., other or distorted information) reported in their free and cued recall at the first and second memory test to errors of participants who were asked to respond honestly (e.g., Christianson \& Bylin, 1999; Van Oorsouw \& Merckelbach, 2004). Although simulators were encouraged to come up with a self-generated version of the crime at the first memory assessment, this request did not result into a heightened percentage of errors at the second assessment - suggesting a preserved source-monitoring capacity for the crime (Christianson \& Bylin, 1999; Van Oorsouw \& Merckelbach, 2004). In line with this, Van Oorsouw and Merckelbach (2006) showed that only 5\% of the errors that simulators made while feigning amnesia was repeated in the second memory test. The poorer performance of simulators at the second session was indeed not due to self-generated errors, so that the SMF appears to be an unlikely account for the simulating amnesia effect.

However, investigating and measuring simulators' source monitoring recognition by using explicit self-reported task (e.g., free and cued recall) may be problematic for at least two reasons. First, even if simulators reported information belonging to their own feigned version in a recall task, they could do so by anchoring their statements to some beliefs concerning how simulation works. Indeed, rather than using actual information regarding a specific event, people use their knowledge or beliefs when they provide responses on specific self-reported tasks (Thompson, Skowronski, Larsen, \& Betz, 2013). Second, in a recall task, simulators might arbitrarily report a number of errors without discriminating among self-generated information, parts of the crime stimulus, or reelaborations of both sources. Arguably, even though different pieces of information coexist in memory and are accessible under some circumstance (Wilson, Lindsey, \& Schooler, 2000), participants may confuse memory for details with memory for sources when interviewed through explicit measures (Bayen, Murnane, \& Erdfelder, 1996).

Memory theorists have made a distinction between explicit and implicit memory tasks. While explicit measures reflect conscious recollections of previous experiences, implicit measures entail automatic, nonconscious changes in task performance that can be attributed to previous experiences (Greenwald \& Banaji, 1995; Roediger, 1990; Schacter, 1992). Implicit tasks reduce the role of selfreflective processes and decrease the mental control necessary to provide an explicit response (Nosek, Greenwald, \& Banaji, 2007). Furthermore, such measures have been found to provide an index of specific individual properties (e.g., attitude, cognition), even though participants do not have control over the measurement outcome (De Houwer, 2006; Fazio \& Olson, 2003). Through implicit measures, information can be identified when memory tasks require item-source 
associations that are stored together in a single trace (Diana, Yonelinas, \& Ranganath, 2007; Mollison \& Curran, 2012).

\section{The Present Study}

In the present study, we used an implicit measure in a source monitoring task in order to assess automatic mental associations that are difficult to tap with explicit measures (Hofmann, Gawronski, Gschwendner, Le, \& Schmitt, 2005). Among implicit measures, the autobiographical Implicit Association Test (aIAT; Sartori, Agosta, Zogmaister, Ferrara, \& Castiello, 2008) has been designed to detect the strength of automatic associations between mental representations of concepts in people's memory (Curci, Lanciano, Maddalena, Mastandrea, \& Sartori, 2015). Preserving the original idea behind the Implicit Association Test (IAT; Greenwald, McGhee, \& Schwartz, 1998; Greenwald, Nosek, \& Banaji, 2003; Nosek, Greenwald, \& Banaji, 2007), the underlying assumption of the aIAT is that associated concepts are paired together in memory leading to an easier and faster responding when they are processed at the same time. The aIAT combines stimuli belonging to four categories: two of those categories are formed by logical true ("I am writing a paper") or false ("I am swimming in the sea") statements; the other two categories are represented by real ("I was in Italy during Christmas") or fabricated ("I was in Serbia during Christmas") autobiographical events that individuals report. In aIAT terms, faster responses should be facilitated when a true logical statement is associated with a real autobiographical event congruent block - rather than when a true logical statement is associated with a fabricated autobiographical event - incongruent block. The aIAT has been used in different domains such as mock crimes (Sartori et al., 2008), detection of past intentions (Zangrossi, Agosta, Cervesato, \& Sartori, 2015) flashbulb memories (Curci et al., 2015; Lanciano, Curci, Mastandrea, \& Sartori, 2013), eyewitness identification (Helm, Ceci, \& Burd, 2016), and performed vs. not-performed and imagined vs. not-imagined actions discriminations (Takarangi, Strange, \& Houghton, 2015; Takarangi, Strange, Shortland, \& James, 2013).

To our knowledge, the only studies using the aIAT as a memory discrimination task were conducted by Takarangi and colleagues $(2013,2015)$. These authors pointed out that imagination decreases the ability to discriminate between true and false events on the aIAT, as a result of source confusion between performed vs. not-performed actions. Participants were presented objects (e.g., toothpick) and associated action statements (e.g., break the toothpick), differing whether those statements were seen, imagined or performed. After two weeks, the authors rated participants' belief and memory for performing a list of actions and requested participants to complete an aIAT task to distinguish performed (real) vs. not-performed (not-real) actions. Findings showed that the more participants remembered or believed having performed a not-performed action, the less the 
aIAT discriminated between performed and not-performed actions. Thus, the aIAT seems to be susceptible to the effects of imagining a not-real event (Takarangi et al., 2015; 2013). However, unlike Takarangi and colleagues, we aimed to investigate whether individuals would be able to recognize the correct source of information by adopting the aIAT as source monitoring task, rather than using the aIAT to detect real or not-real events. Hence, this brings us to extend our research question: Can the aIAT function as a possible source monitoring detector when simulators are requested to identify their own self-generated information - associated with true statements - from the original event?

Overview and hypotheses. We aimed to determine whether individuals who previously simulated amnesia were capable to accurately recognize the source of information by adopting the aIAT as a source monitoring task. We showed participants a mock crime video and requested them to either feign amnesia (simulator group) or confess the crime (confessor group) during the memory test phase through a free recall test. Next, we asked participants to figure out how they could have avoided the crime if they would have acted in a different way (i.e., CTF). As part of the procedure during the memory test phase, we introduced the CFT task to force participants to make a personal source of confusion. CFT is constrained by reality and it is essentially focused on plausible alternatives to one's own actions (Roese \& Epstude, 2017), thereby increasing the degree of confusion. We used this type of thinking to resemble, as much as possible, the naturalist situation of perpetrators thinking back to their offence. One week later, each participant was invited to come to the laboratory and requested to recognize the source of information represented by statements belonging either to their free recall or not (present vs. absent discrimination). It is important to note that our task requires discrimination between information present vs. absent in the recollection taking place at the first test session, and not between real vs. not-real (performed vs. not-performed) as in the study by Takarangi and colleagues (2013). We thus administered participants a personalized source monitoring task through the aIAT. Participants who confidently preserved the memory of the correct source would faster categorize true logical statements associated with details that were present in their free recall at the first test session, as compared with true logical statements associated with details that were absent in their free recall. We predicted, thus, that both simulators and confessors exhibit high positive average values of the aIAT effect (Hypothesis 1). Moreover, we expected a significant difference between groups in the aIAT effect. That is, because of having developed a self-generated story as a result of elaborative cognitive processing of the mock crime, simulators would find the aIAT's discrimination task less difficult than confessors. Hence, we anticipated simulators would be quicker than confessors in the aIAT categorization when information present in their free recall was associated with true logical statements (congruent 
block), rather than information present in their free recall was associated with false logical statements (incongruent block). In other words, we predicted simulators would be faster than confessors in identifying source information (Hypothesis 2). Finally, we tested whether the aIAT index is a measure able to discriminate between simulators and confessors (Hypothesis 3).

\section{Method}

\section{Participants and Design}

A group of 119 students participated in the present study for course credit hours. We excluded 11 participants with unusual data patterns, leaving 108 participants $\left(67 \%\right.$ women; $M_{\text {age }}=$ 24.03; $S D=2.75$ ). Specifically, eleven participants did not comply with the instructions received during session 1 by reporting an insufficient number of statements either in the free recall or in the CFT task. The lack of details in these reports did not allow us to construct a personalized aIAT for those participants. The study used a 2 x 2 mixed model design with condition (simulators vs. confessors) as a between subjects factor and the aIAT block (congruent vs. incongruent) as a within-subjects factor. Participants were randomly assigned to one of the conditions. The dependent variable was the implicit measure of the aIAT effect calculated as $D$ index.

\section{Measures and Procedure}

Session 1. Participants involved in the study completed two sessions in the laboratory. Each participant was randomly assigned to one of two conditions. During the screening phase, participants were preliminary assessed with the Positive and Negative Affect Schedule-Trait and State (PANAS-T and -S; Terraciano, McCrae, \& Costa Jr, 2003; Watson, Clark, \& Tellegen, 1988) and the Structured Inventory of Malingered Symptomatology (SIMS; La Marca, Rigoni, Sartori, \& Lo Priore, 2011; Windows, \& Smith, 2009). The PANAS-T and S were used to assess the participants' emotional trait and state and to exclude individual differences in terms of the affective state. The PANAS-S was administered a second time to evaluate the emotional impact of the stimulus material. The SIMS was used to assess individual malingering tendency.

The Positive and Negative Affect Schedule-Trait and State (PANAS-T and-S; Terraciano et al., 2003; Watson et al., 1988). The scales require participants to rate on twenty 5-point items how they experience different emotional states along two dimensions, matching to Positive Affect (PA) and Negative Affect (NA). For both PANAS-T and $-\mathrm{S}$ item score were summed up. The PA-T scale $(\alpha=.75)$ indicates the individual positive level of emotions generally felt by people, while in contrast the NA-T scale $(\alpha=.90)$ indicates the individual general dimension of aversive 
affect and distress. The PA-S $(\alpha=.87)$ and the NA-S $(\alpha=.92)$ scales reflect how individuals experience in that precise moment.

The Structured Inventory of Malingered Symptomatology (SIMS; La Marca, et al., 2011; Windows \& Smith, 2009). The $\mathrm{SIMS}^{9}$ is a 75 self-report screening questionnaire for malingering of mental disorders. The items are divided into five subscales (affective disorders; amnestic disorders; low intelligence; neurological impairment; psychosis). Answers indicative of malingering are summed to obtain a total SIMS score $(\alpha=.87)$.

Mock crime video. After participants had completed the screening phase, a mock crime video was shown to them. The mock crime video (3 minutes) was recorded in point of view (pov) perspective in order to avoid the potential confounding effect caused by the offenders' gender $^{10}$ and was accompanied by background music. Participants were instructed to pay attention to the mock crime and were asked to identify themselves with the character that performed actions in the scene (the offender). The video describes the offender's day in which s/he woke up and went to the office and after having dinner s/he went to different pubs for drinking. Once in the restroom of the last pub, the offender had an intense fight with a young person. The scene ended with the strangling of the victim.

The mock crime video was divided into one hundred critical information units. A critical information unit was defined as a significant portion of the crime (maximum $=100$ ). Participants' free recalls were scored by the first author and two research assistants. Participants earned 1 point for every correct unit reported (e.g., "I strongly pushed the victim by the wall") while half point was assigned for a partial correct answer (e.g., "I pushed the victim"). The Interclass Correlation Coefficient (ICC) average measure for the number of correct free recall information was .966 with a $95 \%$ confidence interval from .95 to $.97, F(107,11)=29.61, p<.001$. Furthermore, the number of errors was identified (i.e., introduction of other or distorted information; for example, "I hit my head against the wall" or "I strangled the victim with my belt"). The ICC average measure for the errors was .80 with a $95 \%$ confidence interval from .71 to $.86, F(107,11)=5.09, p<.001$. After the video presentation, a 10 min filler interval followed during which all participants played a computer game.

9 With the purpose of checking differences in participants' malingering tendency, we analysed only the SIMS total scores (Windows \& Smith, 2009). Therefore, we did not include the others subscale in our analysis.

10 As the majority of the studies in this field (e.g., Bylin \& Christianson, 2002; Van Oorsouw \& Merckelbach, 2006) ask female students to identify themselves with a male offender, we created a mock crime video in pov to avoid this problematic aspect of the procedure. 
Memory test phase. After the filler task, participants were asked to figure themselves in a simulated police interrogation in which they had been arrested on suspicion of homicide. In line with previous research (e.g., Christianson \& Bylin, 1999; Van Oorsouw \& Merckelbach, 2004), we requested participants to report their statements through a free recall memory test. The simulator group was instructed to feign amnesia to evade punishment by claiming not being able to remember the strangulation. Thus, simulators were free to omit, distort and report other information, pretending they had great difficulties to remember committing the violent crime. In contrast with simulators, confessors were instructed to collaborate with the police by reporting as many details as possible about the crime. Immediately after the free recall, a manipulation check was run by administering the PANAS-S a second time in order to check the affective impact of the mock crime event. Participants then completed another 10-min filler task.

Finally, we invited each participant of both conditions to write down how they could have prevented the murder if they would have behaved differently (i.e., CFT; Roese \& Epstude, 2017; Roese \& Olson, 1997). By requesting participants to generate an individual source of confusion, we included these statements (i.e., CFT) into the subsequent aIAT statements. The Interclass Correlation Coefficient (ICC) average measure for the number of CFT statements was .90 with a $95 \%$ confidence interval from .86 to $.94, F(107,11)=10.66, p<.001$. Once participants completed this last phase, they were scheduled for a second session one week later.

Session 2. In session 2, participants' task on the aIAT was to discriminate information among four categories as accurately and as quickly as possible. A tailored aIAT was created for each participant (see Table 1) following the a/IAT methods (Greenwald et al., 2003; Sartori et al., 2008). Simulator and confessor groups followed the same instruction, meaning that simulators were asked to give up their role of a feigner while engaged in the aIAT source monitoring task. Namely, each participant categorized statements as being "true" (five statements; e.g., "I am in front of a computer") or "false" (five statements; e.g., "I am in the car"), and statements as being "present" or "absent" in their free recall that they had generated during the session 1. The "true" and "false" statements were selected and readjusted from Sartori and colleagues (2008). True and false sentences were the same for all participants. "Present" statements (five) were obtained from the free recall test by participants during the session 1: For "present" statements we used only statements from the participants' free recall that were not displayed in the mock crime video. Thus, "present" simulators' statements concerned their feigned story (e.g., "I hit my head against the wall in the toilet"), whereas "present" confessors' statements concerned their distorted errors regarding the mock crime video (e.g., "I strangled the victim with my belt"). On the other hand, the "absent" 
statements (five) were obtained from both mock crime video and $\mathrm{CFT}^{11}$ procedure during the session 1 (see Table 1). Moreover, mock crime video details were those pieces of information that either participants deliberately did not report (i.e., simulators) or did forget to report (i.e., confessors). Each statement that appeared on the screen belonged either to one or to the other category (e.g., "present" vs. "absent”).

11 We counterbalanced the order and the number of both mock crime video and CFT details in the "absent" category within subject for each personalized aIAT (see Table 1). Both mock crime video and CFT statements were randomly chosen. 
Table 1. Example of statements' list used during the aIAT task.

Simulators

\section{Categories}

\section{Statements}

True $^{*} \quad$ 1. I am in front of a computer

2. I am in Bari

3. It is 2017

4. I am doing a psychological test

5. I am sitting on a chair

False

1. I am in a car

2. I am in Milan

3. It is 1851

4. I am doing a card playing game

5. I am in mountain

Present $^{\dagger} \quad$ 1. I was sober $\quad$ 1. I was in a cab

2. I just saw the victim for an instant $\quad$ 2. I met a friend of mine

$\begin{array}{ll}\text { 3. I was pushed by the victim } & \text { 3. I drank Cosmopolitan }\end{array}$

4. I hit my head against the wall $\quad$ 4. I was punched by the victim

$\begin{array}{ll}\text { 5. I passed out } & \text { 5. I strangled the victim with my belt }\end{array}$

Absent $^{\ddagger}$ 1. I strangled the victim ${ }^{(\cdot)} \quad$ 1. I could have stopped myself before ${ }^{(\ldots)}$

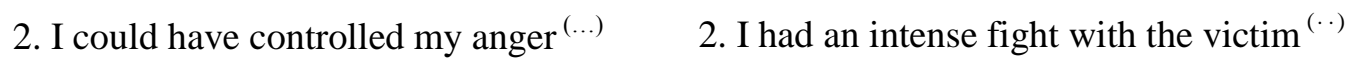

3. I vomited in the toilet $\operatorname{sink}^{(\cdot)} \quad$ 3. I should have calmed myself down ${ }^{(\ldots)}$

4. I should have stayed at home ${ }^{(\ldots)} \quad$ 4. I importuned a young $\operatorname{girl}{ }^{(\cdot)}$

5. I smoked some cigarettes ${ }^{(\cdot)} \quad$ 5. I just should have said sorry ${ }^{(\ldots)}$

* True and False statements were the same for both groups.

† Present statements were obtained from each participant's free recall.

${ }^{\ddagger}$ Absent statements were obtained from both mock crime video ${ }^{(\cdot)}$ and counterfactual thinking ${ }^{(\ldots)}$ and counterbalanced by order and number.

The aIAT task consisted of five separate blocks of categorization trials. In each trial, the statement was presented in the centre of a computer screen. In block 1 ("true" vs "false" 
discrimination; 20 trials), participants categorized statements as belonging to "true" (key E) or "false" (key I). In block 2 ("present" vs. "absent" discrimination; 20 trials), participants had to classify statements as "present" (key E) or "absent" (key I) in their free recall of Session 1. In block 3 (initial double categorization; 60 trials), participants had to indicate whether statements were either belonging to "true" or "present" (key E) or whether they were either belonging to "false" or "absent" (key I). In block 4 (reversed logical discrimination; 40 trials), participants had to categorize statements as "false" (key E) or "true" (key I). In block 5 (reversed double categorization; 60 trials), participants had to classify whether statements were either "false" or "present" (key E) or whether statements were either "true" or "absent" (key I). The presentation order and repetitions number of each trial were randomised for each participant within a number of blocks. An error feedback (red "X" letter) appeared when participants made an incorrect response; they were required to correct the responses pressing the other key. The $D$ index was calculated according to Greenwald and colleagues' procedure (2003). This index expresses the IAT effect in terms of the standard deviation of the latency measures and it includes a penalty for incorrect responses. Specifically, the $D$ index corresponds to the weighted difference of the mean response latencies of critical blocks (i.e., congruent vs. incongruent associations) divided by the standard deviation of all critical trials (Greenwald et al., 2003; Nosek et al., 2007). Finally, participants were thanked for their participation and debriefed.

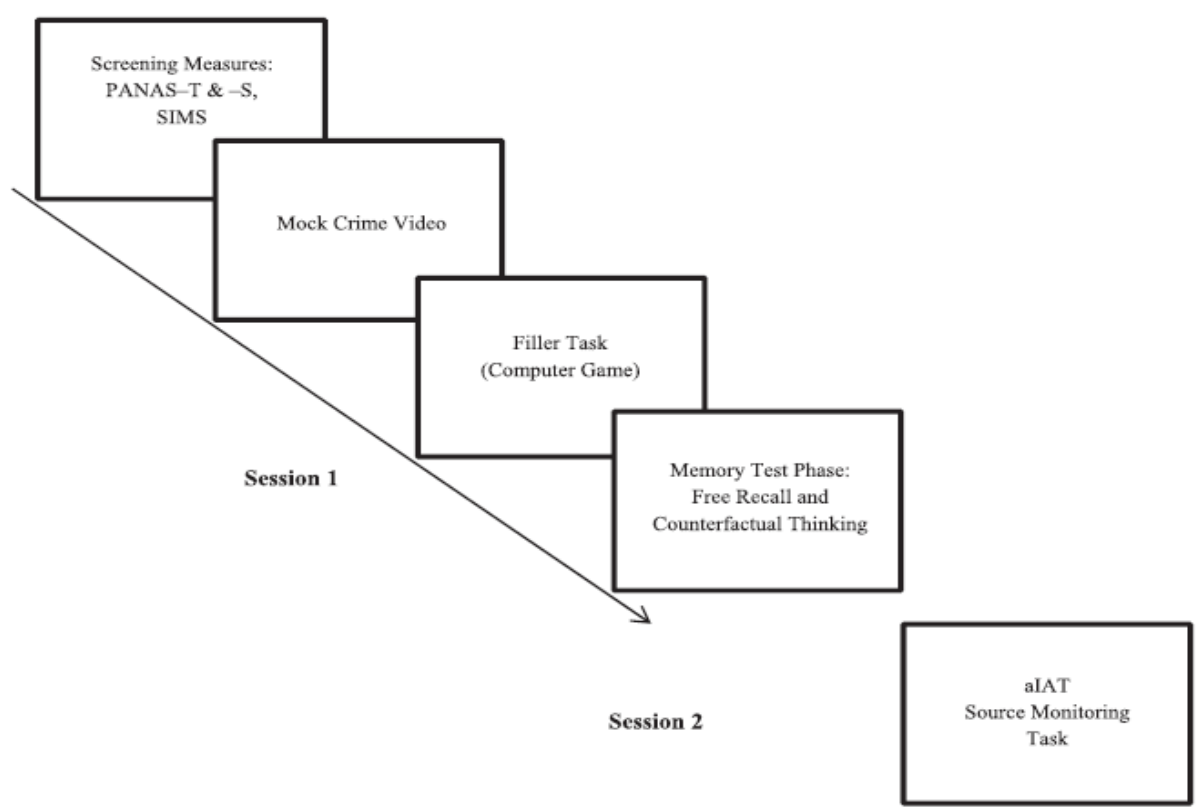

Figure 1. Procedure adopted in the current study is displayed. Screening measures, mock crime video, filler task and memory test phase, compose Session1. During Session 2, participants performed a tailored aIAT source monitoring task. 


\section{Results}

\section{Screening Analysis}

In order to prevent individual differences in the participants' affective state, we analysed positive and negative PANAS-T scores through an independent t-test. Participants did not differ neither in the PA-T $\left[M_{\mathrm{PA} \text { simulators }}=27.61 ; S D=4.60 ; M_{\mathrm{PA} \text { confessors }}=27.44 ; S D=4.64 ; t(106)=.19\right.$, $p=.85, d .=.03]$ nor in the NA-T level before the experimental session $\left[M_{\text {NA simulators }}=11.07 ; S D=\right.$ $\left.6.97 ; M_{\mathrm{NA} \text { confessors }}=10.76 ; S D=8.44 ; t(106)=.21, p=.83, d=.04\right]$. Further, in order to exclude the individual malingering tendency an independent sample t-test was run on SIMS total score. No significant difference was found between groups $\left[M_{\text {simulators }}=8.44 ; S D=4.38 ; M_{\text {confessors }}=8.60\right.$; $S D=4.30 ; t(106)=-.18, p=.86, d .=.04]$. To sum up, these findings suggest that participants did not differ in their affective state nor in their malingering tendencies before being exposed to the mock crime event.

\section{Affective Impact of the Mock Crime Event}

A $2 \times 2$ repeated measures ANOVA with condition (simulators vs. confessors) as between subjects factor and pre-post mock crime viewing (pre-mock crime vs. post-mock crime) as a within subjects factor was conducted in order to check the affective impact of the mock crime on participants. Only the main effect of the pre-post mock crime viewing was found to be significant on both PA-S and NA-S scores, $F(1,105)=10.17, p=.002, \eta_{p}{ }^{2}=.09$, and $F(1,105)=23.58, p$ $<.001, \eta_{p}{ }^{2}=.18$, respectively. The initial participants' positive state decreased after the video was shown to both simulators $(M$ PA pre-mock crime $=26.43 ; S D=6.80$ vs. $M$ PA post-mock crime $=25.57 ; S D=$ $6.27)$ and confessors groups $\left(M_{\text {PA pre-mock crime }}=26.96 ; S D=6.29\right.$ vs. $M_{\text {PA post-mock crime }}=24.68 ; S D=$ 8.01). At the same time, the initial participants' negative state increased for both simulators $\left(M_{\mathrm{NA}}\right.$ pre-mock crime $=5.80 ; S D=6.96$ vs. $\left.M_{\text {NA post-mock crime }}=7.96 ; S D=8.68\right)$ and confessors $\left(M_{\text {NA pre-mock }}\right.$ crime $=5.20 ; S D=6.64$ vs. $\left.M_{\mathrm{NA} \text { post-mock crime }}=10.19 ; S D=10.64\right)$. No other main or interaction effects were found, $F s(1,105)<2.21, p>.15, \eta_{p}{ }^{2}<.02$. These findings suggest that our mock crime video had an affective impact on participants.

\section{Present Category: Analysis of the Free Recall}

We analysed whether participants complied with their instruction, meaning that simulators would report less correct information and more errors than confessors. With respect to this, an independent sample t-test was run on both correct and error rate scores. Simulators reported fewer correct details and more errors than confessors, $t(106)=-12.05, p<.001, d .=2.32$, and $t(106)=$ $5.19, p<.001, d .=.99$, respectively (see Table 2 ). Findings show both simulators and confessors 
reported information in their free recall in accordance with the instruction received at the memory test phase.

\section{Absent Category: Analysis of the Counterfactual Thinking (CFT)}

To test whether participants differed on the number of CFT generated- later used as statements in the absent category $^{12}$ - an independent sample t-test was run on the CFT rate score. No significant difference was found between simulators and confessors, meaning that both groups reported a similar amount of CFT statements, $t(106)=.87, p=.384, d .=.17$ (see Table 2).

Table 2. Means of correct information, errors, and counterfactual thinking (CFT) statements reported by simulators vs. confessors during the free recall are displayed. Standard deviations are shown between parentheses.

\begin{tabular}{lcc}
\hline & Simulators & Confessors \\
Correct & $6.39^{\mathrm{a}}(4.20)$ & $22.58^{\mathrm{a}}(8.93)$ \\
Error & $11.26^{\mathrm{a}}(5.98)$ & $6.67^{\mathrm{a}}(2.54)$ \\
CFT & $3.57(1.51)$ & $3.33(1.34)$ \\
\hline
\end{tabular}

${ }^{\mathrm{a}} p<.001$ between groups at the memory test phase.

\section{aIAT Measure}

Before any additional analysis, we calculated the $D$ index for the IAT design with the built-in error procedure. We follow these steps: (1) use data from congruent and incongruent blocks (blocks 3 and 5); (2) eliminate trials with latencies $>10,000 \mathrm{~ms}$ and participants who obtained in more than $10 \%$ of trials a latency $<300 \mathrm{~ms}$; (3) compute the standard deviation for all practice trials in the both crucial blocks ( 3 and 5 blocks) and the standard deviation for all test trials in both crucial blocks ( 3 and 5); (4) compute separated means for practice congruent trials, practice incongruent trials, test congruent trials and test incongruent trials; (5) compute two difference scores (one difference between practice congruent trials and practice incongruent trials, and the other between test congruent trials and test incongruent trials); (6) divide each difference score by its associated standard deviation from Step (3); and (7) average the two quotients from Step (6).

12 In the absent category, we also analysed information that was not reported by each group (simulators vs confessors). Specularly to the correct rate investigated in the free recall, simulators omitted more information than confessors, $t(106)=11.74, p<.001, d=2.30$. 
In the current study, the $D$ index (Greenwald et al., 2003; Nosek et al., 2007) was employed as main measure of the aIAT effect ${ }^{13}$. In accordance with our hypothesis (1), positive average $D$ values were observed for both simulators $\left(M_{\text {simulators }}=.90 ; S D=.25\right)$ and confessors $\left(M_{\text {confessors }}\right.$ $=.76 ; S D=.42$ ) groups, confirming a high aIAT effect for the task. Thus, both groups were fast in identifying the right source of information when statements belonging to their free recall were presented in association with true statements. An independent sample t-test was run in order to compare groups' average $D$ values of the IAT effect. As predicted, the $D$ value was found to be higher for simulators than for confessors, $t(106)=2.14, p=.03, d=.40$. Consistent with our hypothesis (2), simulators were quicker than confessors in discriminating source information.

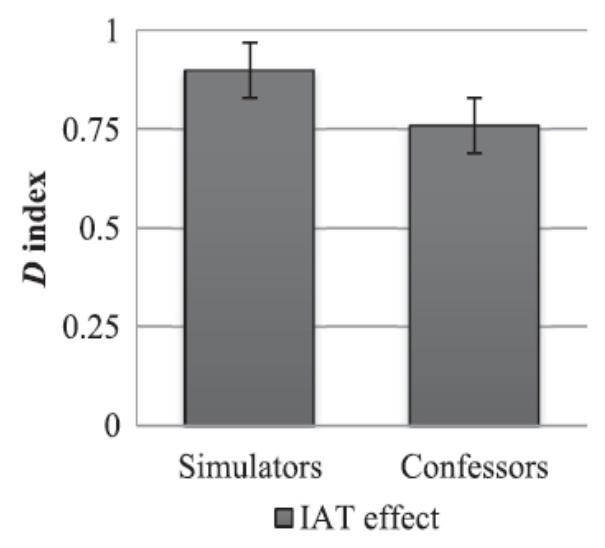

Figure 2. Participants' mean D index by simulators and confessors group. Errors bars show standard errors of means.

\section{Receiver-Operating-Characteristic (ROC) Analysis}

A receiver-operating-characteristic (ROC) analysis was run to test whether and how well the aIAT would discriminate between simulators and confessors at the implicit level (Hypothesis 3). The $D$ index was used as a test variable and condition (simulators vs. confessors) as a state variable. The value of the state variable indicates which category should be considered as positive (in our case simulators). The ROC analysis presents an Area Under the Curve (AUC) which provides a measure of discrimination from 1 (perfect discrimination) to 0 (null discrimination). In our study,

13 Additionally, we also calculated error rates for congruent and incongruent block (Blocks 3 and 5) by each group. Simulators and confessors did not differ in error rates neither on congruent $\left(M_{\text {simulators }}=3.94 ; S D=3.01\right.$, and $\left.M_{\text {confessors }}=4.78 ; S D=4.10 ; t(106)=-1.20, p=.231, d=.23\right)$ nor on incongruent blocks $\left(M_{\text {simulators }}=10.50 ; S D=6.10\right.$, and $M_{\text {confessors }}=10.67 ; S D=6.57 ; t(106)$ $=-1.37, p=.892, d=.03$ ). Findings suggest that errors made by participants during the aIAT did not affect their ability at identifying the correct source of information regardless of the group they belonged to, in accordance with our hypothesis (Hp 1). 
the ROC analysis exhibited an AUC of .60 when "simulator" was considered as the positive value of the state variable. At the implicit level, the IAT differentiated simulators from confessors, thereby confirming our hypothesis 3 .

\section{Discussion}

When individuals feign amnesia for a mock crime and are later requested to give up their role as a feigner, mental confusion caused by an inability to recognize source information may result in impaired and distorted memory of the crime. Some authors suggested that source monitoring errors might cause the memory-undermining effect of simulating amnesia (e.g., Christianson \& Bylin 1999). However, several studies have also shown that the content of self-generated information remains relatively clear in people's memory (e.g., Chrobak \& Zaragoza, 2008; Johnson et al., 1988; Johnson et al., 1981). Even though simulating amnesia for a crime can impair memory for the event, it is possible that individuals might distinctly keep in mind which information is selfgenerated or not. Consequently, in designing the present study, we wondered whether individuals would identify the correct source of information despite they previously simulated amnesia. To this purpose, we applied the aIAT (Sartori et al., 2008) as a possible source monitoring task since we also aimed to investigate whether or not an implicit measure would automatically detect individuals' source recognition capacity.

The results were in line with our expectations. To begin with, participants of both conditions (simulators vs. confessors) were faster in categorizing their self-generated information - belonging to their free recall - associated with true statements and non-self-generate information - belonging either to mock crime video or to the CFT task - associated with false statements (congruent block), than when categorizing self-generated information associated with false statements and non-selfgenerate information associated with true statements (incongruent block). It seems that participants were capable to automatically recognize which displayed information belonged to themselves or came from different sources. For both groups, the positive and high $D$ value indicated that a strong association was obtained when true logical dimension was combined with participants' statements.

Second, in accordance with our prediction, we found simulators faster than confessors. Precisely, when true logical statements were associated with statements concerning the fake crimerelated version (congruent block), simulators were able to recognize the right source of information. Thus, even though simulators were previously asked to feign amnesia, they clearly were able to identify their own self-generated variant of the crime from the original version. On the other hand, confessors also showed a positive $D$ value of the aIAT effect even though their $D$ index was lower than that obtained by the simulator group. This means that confessors seemed to be slower than 
simulators in the aIAT source monitoring task. Given that confessors' assignment was to report as many details as possible about the crime, confessors" free recall statements ("present" statements in the aIAT task) might easily be confused with statements reporting a mere recollection of the original mock crime details ("absent" statements in the aIAT task). Moreover, although assembled into two categories (i.e., "present" vs "absent"), it appears that simulators had to discriminate the displayed statements among three sources - their feigned version of the crime vs. memory for the crime vs. the CFT task - whereas confessors have been pulled by only two - memory for the crime vs. CFT task - rendering their confession and the memory for the mock crime video essentially one source (i.e., memory for the crime). Indeed, drawing on the SMF, source monitoring accuracy decreases when qualitative details are shared between sources (Johnson et al., 1993; Lindsay, 2008). Thus, confessors' performance was exposed to a higher possibility of source monitoring errors as compared with simulators: Identifying the correct source of information based on similar statements - belonging either to the free recall or to the original mock crime - was more difficult for confessors than for simulators. It follows that the specificity of the statements in participants' free recall may represent the keystone for understanding the difference between groups in discriminating source information. That is, each simulator generated a personal feigned version of the crime, which was easily differentiated from the original version. As some authors suggested (e.g., Chrobak \& Zaragoza, 2008), self-generated information is likely to be remembered because composed by sequences of acts precisely identifiable from the beginning to the end. Moreover, as predicted by the SMF, the more memories require elaborate cognitive processing, the simpler individuals should find to remember the source (Chrobak \& Zaragoza, 2008; Johnson, Raye, Foley, \& Foley, 1981). It is a common experience that individuals who simulate memory loss after a crime tend to be consistent with their supposed amnesia state during police investigations, being thus able to identify the correct sequence of events to be coherently reported. In the constancy of their retelling there might be the reason why individuals who feigned a loss of memory were better at accurately distinguishing between sources of information and at the aIAT source monitoring task.

By applying the aIAT as a source monitoring task we extended our research question: Can the aIAT be a possible source monitoring detector? Previous studies (e.g., Van Oorsouw \& Merckelbach, 2004) have shown that simulators did not exhibit a heightened percentage of errors in their self-reported free and cued recall at the second memory test, leading the source-monitoring explanation to fail as an adequate interpretation for the memory-undermining effect of simulating amnesia. An important consequence of the present findings is that simulators appear to be able to automatically recognize the correct source of information by using an implicit measure as source monitoring task. Arguably, the poorer performance of simulators in recalling the crime after time, 
as reported in the literature (e.g., Christianson \& Bylin 1999; Van Oorsouw \& Merckelbach, 2004), might be independent on their source monitoring errors. Moreover, asking simulators to recognize source information through aIAT task may have caused an association between item and source, perhaps based on a feeling of familiarity. As a matter of fact, some studies pointed to the importance of the feeling of familiarity in source monitoring recognition (e.g., Diana, Yonelinas, \& Ranganath, 2008; Hicks, Marsh, \& Ritschel, 2002; Mollison \& Curran, 2012; Yonelinas, Kroll, Dobbins, \& Soltani, 1999). Familiarity-based recognition implies the contribution of some subprocesses such as those supporting implicit memory (Jacoby, 1991; Yonelinas, 2002). Furthermore, sometimes and to some extent, the IAT effects measure the attributes that they are expected to measure (e.g., De Houwer, Teige-Mocigemba, Spruyt, \& Moors, 2009). Hence, in our study, the aIAT was successful in detection of correct information required by the used type of the task. The ROC analysis, indeed, showed that the aIAT was successful at discriminating simulators from confessors (hypothesis 3), implying that the test can differentiate individuals who previously feigned amnesia for a crime from those who honestly reported information about the same event by requesting them to distinguish the right source of information. In accordance with this, we argue that the aIAT might be useful as a task to retrieve crime-related information. By recognizing the right source, which might be stored together with the related information in a single trace, offenders might be facilitated in recollecting details of the crime when they are motivated to collaborate with the justice department (e.g., plea bargaining case). Indeed, specific crime-related information is directly related to feelings and mood evoked at the time of the event and, thus, more accessible through implicit association than through traditional methods of assessment (Schacter, 1987; Tobias, Kihlstrom, \& Schacter, 1992).

However, the generalizability of our results is related to the aIAT's ability to detect source information since, for instance, external factors have been shown to affect implicit measures (Greenwald \& Nosek, 2001). Moreover, some evidence has shown how it is strategically possible to influence outcomes of implicit measures (De Houwer, 2006). Therefore, in order to better delineate the aIAT's efficacy as a possible source monitoring detector, the test should be administered in association with an explicit source monitoring task (e.g., multiple discrimination task). That is, future research might focus on comparing the aIAT to an explicit source monitoring measure. Perhaps, individuals who pretend such memory loss might be more successful on an explicit task than confessors at distinguishing among different source of information. Previous studies have shown that comparing explicit vs implicit measures would indeed enable researchers to draw more specific conclusions on the purpose of the aIAT (e.g., Curci et al., 2015). In a related vein, and opposite to our study in which we asked participants to recognize the correct source of 
information, it would perhaps be wise to investigate in further research how, and to which extent, simulators might perform on the tests (aIAT vs. explicit measure) by requesting them to keep feigning during a source monitoring task.

Finally, some limitations of the present study need to be mentioned. To begin with, we instructed students to either feign amnesia or to confess a violent crime. Given that our sample differs in many ways from individuals who commit a severe crime (Schacter, 1986), our findings may have a limited ecological validity. Second, in our study we were more interested in investigating simulators' source monitoring ability than in simulators' memory performance over time. In other words, the present study was not focused on observing the well-known memoryundermining effect of simulating amnesia (e.g., Christianson \& Bylin 1999) since we aimed to investigate whether individuals who feigned a memory loss would accurately discriminate the source of information by using an implicit measure as source monitoring task. For this reason, we did not assess a second delayed free recall memory test as usually it has been done in previous studies in this field (Bylin \& Christianson, 2002; Christianson \& Bylin 1999; Van Oorsouw \& Merckelbach, 2004; 2006). Futures studies should extend our findings by including a memory retest phase assessing the association between simulators' source monitoring ability and their memory for the crime. Third, one could argue that the CFT statements might have played a significant role on the aIAT participants' performance since, in the "absent" category, we brought together CFT statements with crime-related details which participants did not mention in their free recall. Without doubt these two types of statements are very different. Whereas the CFT illustrates acts that participants knew did not happen, information belonging to the mock crime video may be details that, especially within the confessors group, participants knew happened but they did not mention. Although the CFT task correctly applies to the "absent" category, because what perpetrators think of the crime in terms of plausible alternatives to their offence, it is not what they claim when they are interviewed, further research is necessary. Future studies should consider including CFT (Roese \& Epstude, 2017; Roese \& Olson, 1997) as a condition of the experimental design - thus subjected to corresponding analyses - rather than as part of the procedure, to assess to which extent this way of thinking may affect participants' source monitoring capacity.

To conclude, our study sheds new light on the debate regarding the memory-undermining effect of simulating amnesia. We aimed to unravel the mechanism behind the simulating amnesia phenomenon by applying the aIAT as possible source monitoring task. Our main findings suggest that simulators may preserve the memory of a crime despite feigning amnesia and seem to be capable to automatically recognize their own self-generated version of the crime from the original one. Although the aIAT still prompts a controversy within the legal context (e.g., Takarangi et al., 
2013), this study suggests that an implicit measure might be helpful in retrieving the source of some crime-related information. We believe that the present study would be a step forward for the understanding of both memory-undermining effect of simulating amnesia and aIAT's forensic relevance. 

Chapter 5

\section{Retrieval-Induced Forgetting in Feigning Amnesia for a Crime Paradigm}

This chapter is based on:

Mangiulli, I., Van Oorsouw, K., Curci, A., \& Jelicic, M. (2018). Retrieval-Induced Forgetting in Feigning Amnesia for a Crime Paradigm. Manuscript under review. 


\begin{abstract}
Previous studies demonstrated that, when asked to honestly provide information about a mock crime, former feigners performed worse than those who were requested to confess to this event. We examined whether retrieval-induced forgetting (RIF) underlies the memory-undermining effect of feigning amnesia for a crime. After watching a mock crime, participants had to feign amnesia or confess to have committed that crime. Feigners were given retrieval practice instructions (i.e., retrieval-practice group) or no further instructions (i.e., control group). Immediately and one day later all participants had to genuinely report the crime. Although simulators in the retrieval-practice group reported the largest amount of total information as a positive consequence of retrieval, the ratio for crucial crime-related details was lower than that exhibited by both simulators that were given no instructions and confessors. These findings suggest that a RIF effect might play a role in forgetting critical information in crime-related amnesia. Theoretical and practical implications of our results will be discussed.
\end{abstract}

Keywords: retrieval-induced forgetting; inhibition; feigning amnesia; malingering; memory errors 


\section{Introduction}

Many offenders feign amnesia for serious crimes (Christianson \& Merckelbach, 2004; Jelicic \& Merckelbach, 2015; Pyszora, Fahy, \& Kopelman, 2014). Although crime-related amnesia in itself does not lead to incompetency to stand trial judgment, defendants may feign memory loss for their acts in the hope to be held diminished responsible for their offence (Cima, Merckelbach, Nijman, Knauer, \& Hollnack, 2002; Tysee, 2005; Tysse \& Hafemeister, 2006). There is reason to believe that simulating amnesia for a crime may lead to forgetting of information pertaining to the offence (e.g., Christianson \& Bylin 1999). The memory-undermining effect of feigned amnesia has been observed in several studies (e.g., Bylin \& Christianson, 2002; Mangiulli, Lanciano, Van Oorsouw, Jelicic, \& Curci, 2018; Mangiulli, Van Oorsouw, Curci, Merckelbach, \& Jelicic, 2018; Van Oorsouw \& Merckelbach, 2004, 2006). Compared to those who were instructed to confess a mock crime, participants who were previously asked to feign amnesia for this event exhibit poorer memory performance when they are subsequently requested to give up their role as feigner. Because feigning participants tend to comply with their instructions by omitting, distorting and introducing new information on the initial memory test (Bylin, 2002; Van Oorsouw \& Merckelbach, 2006), simulating amnesia can lead to both omission and commission errors on the final recall test (Ackil \& Zaragoza, 2011; Chroback \& Zaragoza, 2008, 2012; Mangiulli et al., 2018b; Van Oorsouw \& Giesbrecht, 2008).

Christianson and Bylin (1999) suggested that - during the process of feigning amnesia - some details of the mock crime would be strengthened in memory, while other details are weakened, leading to poorer recall of some elements of the mock crime over time. In other words, they argued that the simulating amnesia effect might be the result of retrieval-induced forgetting (RIF, Anderson, 2003; Anderson, Bjork, \& Bjork, 1994; Levy \& Anderson, 2002). RIF is a memory phenomenon that occurs when selective retrieval of specific memories leads to forgetting of other related memories. It has been demonstrated by research using the retrieval-practice procedure (Anderson et al., 1994). Firstly, participants are given a set of category-item pairs (e.g., fruitbanana, drink-gin). During the retrieval-practice phase, participants are requested to retrieve half of the studied items from half of the categories, triggered by cues to facilitate the recollection (e.g. fruit-ba___ ( After a distractor task, participants are tested on their ability to recall all of the previously encoded items. Usually, participants are better able to recall retrieved items from practiced category (e.g., fruit-banana; $\mathrm{Rp}+$ items) than both un-retrieved items from practiced category (e.g., fruit-apple; Rp - items) and un-practiced items from un-practiced category (e.g., drink-gin; Nrp items). This pattern is known as a positive consequence of retrieval, namely called as facilitation effect (Roediger \& Butler, 2011; Roediger \& Karpicke, 2006). However, a second 
pattern is also observed: $\mathrm{Rp}$ - items are recalled worse than Nrp items, indicating reduced recalling of un-practiced items from the practiced category, also referred to as retrieval-induced forgetting (Anderson, 2003; Anderson et al., 1994). By and large, according to the inhibition-based forgetting theory, the RIF effect is due to an inhibitory mechanism which supports selective retrieval by suppressing the conflict from related memories (e.g., Anderson, 2003; Levy \& Anderson, 2002). From this perspective, the inhibition of un-practiced items from practiced category $(\mathrm{Rp}-)$ produces the RIF effect during the retrieval-practice phase.

Note that the RIF effect has been extensively investigated and demonstrated within the area of eyewitness memory (e.g., Camp, Wesstein, \& De Bruin, 2012; Garcia-Bajos, Migueles, \& Anderson, 2009; MacLeod, 2002; Migueles \& Garcia-Bajos, 2007; Pica, Pierro, \& Giannini, 2015; Shaw, Bjork, \& Handal, 1995). Specifically, the impact of repeated questioning of a witness has been explored. In the initial crime-view phase, participants are shown a series of slides depicting a number of items belonging to two different categories - typically a set of category-item pairs of stolen objects and suspects' characteristics - and asked to memorize all the items. During the interrogation phase, participants are questioned about half of the items of one category. When later asked to recall items from both categories, a RIF effect takes place, indicating forgetting of offender's characteristics or crime scene (e.g., MacLeod, 2002; Migueles \& Garcia-Bajos, 2007; Pica et al., 2015; Saunders \& MacLeod, 2006; Shaw et al., 1995).

One could argue that, when offenders try to be consistent with a simulated version of the crime during police investigations, they might be inclined to selectively retrieve some pieces of the crime and omit other relevant details. This could lead to RIF (Anderson, 2003; Anderson et al., 1994), whereby crucial information of the crime will be forgotten due to selective retrieval of other elements of the offence during repeated police interviews. Following this line, RIF could play a part in the memory-undermining effect of feigning amnesia.

To our knowledge, the present study is the first to investigate RIF in participants involved in a mock crime. Specifically, we sought to determine whether RIF might explain the simulating amnesia effect by applying the retrieval-practice procedure to the feigning amnesia paradigm. We exposed participants to a violent mock crime video. Next, we requested participants to either feign amnesia by retrieving specific information (simulators retrieval-practice group), feign amnesia without giving any specific information (simulators control group), or to give an honest account of the mock crime (confessors group). Immediately after the simulation phase, all participants were asked to genuinely recall the target event as well as confessors. After a 24-hour delay, we requested all participants to recall as much information as possible about the mock crime. We predicted that simulators in the retrieval-practice group would perform better for practiced information (i.e., Rp 
+ ), and worse for un-practiced information (i.e., Rp -), compared to those in the simulators control group both immediately and after a 24-hour delay (RIF effect; hypothesis 1). Also, we expected that feigning amnesia would undermine memory for the mock crime, meaning that both simulator groups would recall a lower total amount of correct information $(\mathrm{Rp}+$ and $\mathrm{Rp}-$ ) than confessors on the final recall tests (hypothesis 2). Moreover, we anticipated both simulator groups to report more errors than confessors during both immediate and delayed tests (hypothesis 3 ).

\section{Method}

\section{Participants and Design}

G*Power with a power of 0.95 and a predicted medium effect size indicated that a sample of 102 participants was needed. A total of 120 students were recruited for this study (74\% women; $M$ age $=21.21, S D=2.83)$. They were randomly assigned to the three groups - simulators retrievalpractice (simulators RP; $N=40)$, simulators control $(N=40)$, and confessors $(N=40)$. After participating, each person was rewarded with course credit or a 10 euro voucher. The study adopted a 3 x 2 mixed model design with group (simulators RP vs. simulators control vs. confessors) as between-subjects variable, and memory test (immediate vs. after one day) as a within-subjects repeated measure variable. The dependent variable was the proportion of correct crime-related information reported in the free recall tests (i.e., information type: $\mathrm{Rp}+$ and $\mathrm{Rp}-$ ). Furthermore, we also calculated errors generated during each memory test.

\section{Measures and Procedure}

Pre-experimental phase. The present study consisted of two phases, both conducted in a quiet test room. During the pre-experimental phase, participants were asked to fill in the Positive and Negative Affect Schedule-Trait and State (PANAS-T and -S; Watson, Clark, \& Tellegen, 1988) and the Structured Inventory of Malingered Symptomatology (SIMS; Smith \& Burger, 1997; Windows \& Smith, 2009). While the PANAS-T and $-\mathrm{S}$ were used as a baseline measure for the participants' emotional state, PANAS-S was also administered a second time, immediately after the mock crime video, to examine the affective impact of the stimulus material. The SIMS was administered to exclude individual differences in participants' malingering tendency, thereby guaranteeing homogeneity of this tendency in our sample before the experimental phase.

The Positive and Negative Affect Schedule-Trait and State (PANAS-T and-S; Watson et al., 1988). The scales require participants to rate on twenty 5-point items how they experience different emotional states along two dimensions, matching to Positive Affect (PA) and Negative 
Affect (NA). For both PANAS-T ${ }^{14}$ and $-\mathrm{S}$ item scores were summed up. The PA-T scale $(\alpha=$ .72) indicates the individual positive level of emotions generally felt by people, while in contrast the NA-T scale $(\alpha=.88)$ indicates the individual general dimension of aversive affect and distress. The PA-S $(\alpha=.85)$ and the NA-S $(\alpha=.91)$ scales reflect how individuals experience at that precise moment.

\section{The Structured Inventory of Malingered Symptomatology (SIMS; Windows \& Smith,} 2009). The SIMS ${ }^{15}$ is a self-report screening questionnaire for malingering of mental disorders and it contains 75 true-false items that pertain to atypical or bizarre symptoms (e.g. "Sometimes my muscles go limp for no apparent reason so that my arms and legs feel as though they weigh a ton"). The items are divided into five subscales (affective disorders; amnestic disorders; low intelligence; neurological impairment; psychosis). Answers indicative of malingering are summed to obtain a total SIMS score $(\alpha=.70)$.

Mock crime event. A mock crime video (about 3 minutes) was shown to participants after they had completed the pre-experimental phase. Mainly accompanied by background music, the mock crime video was recorded in point of view $(p o v)^{16}$. Participants were invited to pay attention to the crime stimulus and were requested to identify themselves with the character that performed actions in the video (the offender). The video showed a seemingly normal day in which a person comes home after a hard day's work. After having dinner at his/her flat, the person decides to go to the inner city for some drinks. In the restroom of the last club, the offender has a violent fight with another person. The scene ends with the strangling of the victim. Finally, a $10 \mathrm{~min}$ filler interval followed the video presentation during which all participants played a computer game.

Session 1. Next, participants were asked to imagine that they had been arrested on suspicion of murder and that, in a few days' time, they would have to stand trial. Similar to previous studies (e.g., Christianson \& Bylin, 1999; Mangiulli et al., 2018a, 2018b; Van Oorsouw \& Merckelbach, 2004), we asked participants to report their statements through a free recall memory test in accordance with one of the following conditions. During the simulation phase, in order to evade responsibility for the offence, feigners in the retrieval-practice group (simulators RP) were

14 No significant differences were observed among participants on both their positive and negative states before the experimental phase, $F(2,117)=.29, p=.75$, and $F(2,117)=.43, p=.65$.

15 We did not include the others subscale in our data set since we analysed only the SIMS total scores (Windows \& Smith, 2009) to check differences in participants' malingering tendency. Participants did not differ on their feigning tendency before the experimental phase, $F(2,117)=$ $2.25, p=.11$.

16 Given that it might be problematic asking to female students to identify themselves with a male offender, we used a mock crime video in pov to exclude the potential confounding effect caused by the offenders' gender. 
instructed to feign amnesia by learning, practising, and retrieving some specific information of the mock crime. Based on previous research (e.g., Garcia-Bajos et al., 2009; Migueles \& Garcia-Bajos, 2007; Pica et al., 2015), we amended the RIF procedure in such a way that it could be used in the feigning amnesia paradigm. A separate group of pilot participants $(N=13)$ was requested to select $\mathrm{Rp}+$ and $\mathrm{Rp}$ - information (see Appendix A). In the present study, after watching the mock crime video, we asked simulators in the retrieval practice group to study 20 pieces of information $(\mathrm{Rp}+)$ which covered the sequence of the event from the beginning to the end, omitting crucial details pertaining to the mock crime $(\operatorname{Rp}-)$. First, they were given a cued recall task that tested their memory for the 20 pieces of information they had studied (see Appendix B). After a 5 minutes distractor task (i.e., computer game), they were asked to feign memory loss on a free recall test by reporting all the information they previously studied and practiced $(\mathrm{Rp}+)$, thereby leaving out of the report all the other details. Finally, after a distractor task of 5 minutes the participants were given a free recall test, wherein simulators were requested to cooperate with the police by giving up their role as feigner and genuinely report all they could remember about the mock crime (i.e., immediate recall).

In contrast with the simulators in the retrieval-practice group, after being exposed to the mock crime video, participants in the simulators control group were simply asked to simulate memory loss with the purpose of evading responsibility for the criminal act. Thus, during the simulation phase, they did not receive any specific instruction regarding how to feign amnesia for the mock murder. After a 10 minutes distractor task (i.e., computer game), participants in this group were asked to cooperate with the police and honestly report about the mock crime act by recollecting as many details as possible (i.e., immediate recall).

Finally, in contrast with both simulators groups, after viewing the mock crime and the same 10 minutes distractor task, participants in the confessors group were directly given a recall test. They were instructed to collaborate with the police and admit their guilt by genuinely reporting as many details as possible of the mock crime. Once all participants (simulators RP vs. simulators control vs. confessors) completed this last phase, they were scheduled for a second session the following day.

Session 2. After a 24-hour delay, all participants (simulators RP vs. simulators control vs. confessors) were given a free recall test and, again, were asked to provide as much information about the mock crime as possible (i.e., after one day recall). Next, participants rated their ability to 
identify themselves with the offender ${ }^{17}$ on a 5-point scale anchoring from 0 ("Not at all") to 4 ("At all'). Finally, participants were individually thanked and debriefed.

\section{Memory Recall Scoring.}

The following scoring system was employed to assess participants' reports. For each correct unit of information provided (i.e., Rp +: "I got in my green car", and Rp -: "I strangled the victim”) participants scored 1 point (maximum = 40). Following previous studies (e.g., MacLeod, 2002; Miguels \& Garcia-Bajos, 2007), both $\mathrm{Rp}+$ and $\mathrm{Rp}$ - scores were transformed into proportions (range $=0-1$ ) by dividing the number correct information provided by the maximum obtainable score. Additionally, the number of distortions (e.g., "The victim pushed me against the wall") and commissions (i.e., the introduction of new information that was not displayed in the video: "The victim had a knife") were calculated and collapsed into one score (i.e., errors). The first author and a research assistant, who was blind to the hypotheses and design of the study, scored participants' free recall reports. The Interclass Correlation Coefficient (ICC) average measure for both $\mathrm{Rp}+$ and $\mathrm{Rp}$ - information was .97 and .81( $\left.p_{s}<.001\right)$. The ICC for errors was .83 $(p<.001)$.

\section{Results}

\section{Affective Impact of the Mock Crime Event}

To evaluate the affective impact of the mock crime on participants, a 3 x 2 repeated measures ANOVA with group (simulators RP vs. simulators control vs. confessors) as a between-subjects factor and pre-post mock crime viewing (pre-mock crime vs. post-mock crime) as a within-subjects factor was conducted. There was a significant main effect of the pre-post mock crime viewing for both PA-S and NA-S scores, $F(1,117)=67.24, p<.001, \eta_{p}{ }^{2}=.36$, and $F(1,117)=116.61, p<.001$, $\eta_{p}{ }^{2}=.49$, while no other main or interaction effects were found, $F s(2,117)<1.37, p>.26$, and $F s(2,117)<.79, p>.77$. After watching the mock crime video, the initial participants' positive mood state decreased $\left(M_{\text {PA pre-mock crime }}=22.76, S D=6.54\right.$ vs. $\left.M_{\text {PA post-mock crime }}=18.43, S D=6.50\right)$, $t(117)=5.39, p<.001, d=.52$. Simultaneously, the initial participants' negative mood state increased $\left(M_{\text {NA pre-mock crime }}=5.69, S D=6.52\right.$ vs. $\left.M_{\text {NA post-mock crime }}=15.24, S D=10.37\right), t(119)=-$ $8.69, p<.001, d=-.82$. These findings suggest that the mock crime event had an affective impact on participants by increasing their negative and reducing their positive mood state.

17 No significant differences were observed among participants belonging to the three groups (simulators RP vs. simulators control vs. confessors) with respect to their ability to identify themselves with the offender, $F(2,116)=1.90, p=.15$. 


\section{Facilitation Effect}

Following previous research (e.g., Migueles \& Garcia-Bajos, 2007), practiced information $(\mathrm{Rp}+)$ from the simulators retrieval-practice group and un-practice information $(\mathrm{Rp}-)$ from the simulators control group were compared in order to ascertain the facilitation effect due to retrievalpractice. A 2 × 2 repeated measures ANOVA with group (simulators RP vs. simulators control) as a between-subjects factor, and memory test (immediate vs. after one day) as a within-subjects factor was conducted. The main effect of group was found to be significant, while the main effect of memory test was not, $F(1,78)=47.40, p<.001, \eta_{p}{ }^{2}=.38$, and $F(1,78)=1.65, p=.20$. There was a significant group by memory test interaction effect, $F(1,78)=4.67, p=.03, \eta_{p}{ }^{2}=.06$. In accordance with our prediction ${ }^{18}$ (Hp. 1), the retrieval-practice produced the facilitation effect. Simulators in the retrieval-practice group significantly disclosed more Rp + information than unpracticed information reported by simulator control group at both immediate and after one day memory tests, $t(78)=5.18, p<.001, d=2.63$, and $t(78)=7.58, p<.001, d=2.80$ (see Table 1 ). Moreover, the facilitation effect slightly increased from the immediate to the 24-hours delayed memory test, $t(39)=2.90, p<.001, d=.47($ see Table 1$)$.

\section{Retrieval-induced forgetting effect}

Un-practiced information from both simulator groups were analysed to verify whether retrieval-practice caused a retrieval-induced forgetting effect (e.g., Migueles \& Garcia-Bajos, 2007). A 2 x 2 repeated measures ANOVA was performed with group (simulators RP vs. simulator controls) as a between-subjects factor and memory test (immediate vs. after one day) as a withinsubjects factor. The main effect of group was significant, $F(1,78)=14.18, p<.001, \eta_{p}{ }^{2}=.15$. No other main or interaction effects were found to be significant, $F_{s}(1,78)<.38, p>.59$. In line with our expectation ${ }^{19}$ (Hp. 1), the retrieval-practice produced the RIF. Overall simulators in the retrieval-practice group $(M=6.86, S D=2.48)$ reported less un-practiced information than simulator control group $(M=9.10, S D=2.82), t(78)=-3.76, p<.001, d=.84$.

18 We also conducted an identical mixed ANOVA with the purpose of ascertaining the facilitation effect by comparing simulators RP to confessors group. Overall, simulators in the retrieval-practice group $(M=13.14, S D=2.41)$ significantly disclosed more $\mathrm{RP}+$ information than un-practiced information in the confessors group $(M=11.10, S D=3.03), t(78)=3.32, p=.001, d=$ .74.

19 The RIF effect was even found in the comparison between simulators RP and confessors, by running the same mixed ANOVA. Overall, simulators in the retrieval-practice group $(M=6.86$, $S D=2.48)$ significantly reported less RP - information than confessors $(M=11.10, S D=3.03)$, $t(78)=-6.84, p=.001, d=1.53$. 
Table 1. Mean proportions of practiced and un-practiced information (i.e., $\mathrm{Rp}+$ and $\mathrm{Rp}-$ ) by simulators groups, and retrieval-practice effects at both immediate and delayed memory tests.

\begin{tabular}{|c|c|c|c|c|c|}
\hline & $\begin{array}{r}\text { Simulatc } \\
\text { prc }\end{array}$ & $\begin{array}{l}\text { retrieval } \\
\text { ice }\end{array}$ & & Facilitation & RIF \\
\hline & $\mathrm{Rp}+$ & $\mathrm{Rp}-$ & Control & $\begin{array}{l}(\mathrm{Rp}+)- \\
\text { Control }\end{array}$ & $\begin{array}{l}(\mathrm{Rp}-)- \\
\text { Control }\end{array}$ \\
\hline Immediate & $.63(.14)$ & $.34(.13)$ & $.46(.16)$ & $.17(.22)$ & $-.12(.23)$ \\
\hline $\begin{array}{l}\text { After one } \\
\text { day }\end{array}$ & $.68(.12)$ & $.34(.14)$ & $.45(.15)$ & $.23(.17)$ & $-.11(.22)$ \\
\hline
\end{tabular}

Note: $\mathrm{Rp}+$ and $\mathrm{Rp}$ - information from the simulators retrieval-practice group are shown. Control displays un-practiced information from simulators control group. Standard deviations are presented between parentheses.

\section{Free Recall - Correctness Scores}

Correct free recall scores (i.e., information type: $\mathrm{Rp}+$ and $\mathrm{Rp}-$ ) were summed and entered in a $2 \times 3$ repeated measures ANOVA with group (simulators RP vs. simulators control) as a betweensubjects factor and memory test (simulation vs. immediate vs. after one day) as a within-subjects factor, in order to assess whether both simulator groups properly complied with their instructions. The main effects of group and memory test were found to be significant, $F(1,77)=117.26, p$ $<.001, \eta_{p}{ }^{2}=.60$, and $F(1,77)=187.66, p<.001, \eta_{p}{ }^{2}=.71$. Moreover, there was a significant group by memory test interaction, $F(1,77)=22.75, p<.001, \eta_{p}{ }^{2}=.23$. During the simulation phase, participants in the simulator retrieval-practice group reported more correct information than those in the simulator control group, $t(77)=20, p=.001, d=1.15$ (see Table 2). However, this effect was due to the retrieval-practice instruction since the retrieval rate for $\mathrm{Rp}+$ information in the simulator retrieval-practice group was $99 \%(S D=.03)$, meaning that our manipulation was successful. Moreover, the amount of correct information recollected over time increased in the retrieval-practice group, $t(38)=5.69, p<.001, d=.93$, and $t(38)=7.30, p<.001, d=1.21$ (see Table 2). Finally, as a result of the instruction given, participants in the simulator control group reported more correct information at both immediate and delayed memory test than during the simulation phase, $t(39)=11.13, p<.001, d=1.99$, and $t(39)=11.73, p<.001, d=1.75($ see Table 2).

Next, in order to ascertain differences between groups on the total amount of correct crimerelated information provided (i.e., information type: $\mathrm{Rp}+$ and $\mathrm{Rp}-$ ), a 3 × 2 repeated measures ANOVA was performed with group (simulators RP vs. simulators control vs. confessors) as a between-subjects factor and memory test (immediate vs. after one day) as a within-subjects factor. 
The main effect of group was significant, $F(2,177)=19.88, p<.001, \eta_{p}{ }^{2}=.25$. No other main or interaction effects reached significance, $F_{s}(2,177)<1.26, p>.29$. A post-hoc test with Bonferroni correction indicated that overall participants in the simulators control group $(M=13.80, S D=5.05)$ disclosed less correct information than confessors $(M=18.53, S D=5.07), p<.001,95 \% C I[-7.22$ 2.22], $d=.61$. However, no significant difference was observed between simulators in the retrieval practice group $(M=20.01, S D=3.70)$ and confessors, $p=.46,95 \% C I[-1.023 .97], d=.33$, thereby partially supporting our hypothesis (Hp. 2). Moreover, participants in the simulator retrieval-practice group outperformed those in the simulator control group, $p<.001,95 \%$ CI [3.70 8.69], $d=1.40$.

Given the unexpected pattern of findings depicted above, we conducted further analyses on the ratio rates for un-practiced information (i.e., crucial information pertaining to the crime) enclosed in participants' total correct free recall scores. We calculated the ratio for un-practiced information by dividing the number of $\mathrm{Rp}$ - information by the total amount of information $[\mathrm{Rp}-/$ $(\mathrm{Rp}+)+(\mathrm{Rp}-)]$. The ratio for $\mathrm{Rp}$ - information was entered in a 3 x 2 repeated measures ANOVA with group (simulators RP vs. simulators control vs. confessors) as as a between-subjects factor and memory test (immediate vs. after one day) as a within-subjects factor. The main effect of condition was found to be significant, $F(1,177)=133.18, p<.001, \eta_{p}{ }^{2}=.70$. No other main or interaction effects were found, $F_{s}(2,177)<.545, p>.58$. Overall, a post-hoc test with Bonferroni correction showed that both confessors $(61 \%, S D=.11)$ and participants in the simulators control group (69\%, $S D=.13)$ provided significantly more un-practiced information than simulators in the retrievalpractice group $(34 \%, S D=.09), p<.001,95 \% C I[-.22 .33], d=2.68$, and $p<.001,95 \% C I$ [.29 .40], $d=3.13$. Interestingly, participants in the simulator control group slightly recollected more crucial details of crime than confessors, $p=.005,95 \% C I[.02 .13], d=.66$. These findings suggest that, although simulators in the retrieval-practice group recollected a remarkable number of details pertaining to the crime, the prevalence of crucial crime-related information in the free recall of those participants was significantly lower than that in the other two groups. 
Table 2. Total correct proportions [i.e., $(\mathrm{Rp}+)+(\mathrm{Rp}-)$ ] and corresponding information type ratios [i.e., $\mathrm{Rp}+/(\mathrm{Rp}+)+(\mathrm{Rp}-)$, and $\mathrm{Rp}-/(\mathrm{Rp}+)+(\mathrm{Rp}-)$ ] reported by each group during the three memory tests (simulation vs. immediate vs. after one day).

\begin{tabular}{|c|c|c|c|c|c|c|}
\hline & \multicolumn{2}{|c|}{$\begin{array}{c}\text { Simulators retrieval } \\
\text { practice }\end{array}$} & \multicolumn{2}{|c|}{ Simulators control } & \multicolumn{2}{|c|}{ Confessors } \\
\hline & $\mathrm{Rp}+$ & $\mathrm{Rp}-$ & $\mathrm{Rp}+$ & $\mathrm{Rp}-$ & $\mathrm{Rp}+$ & $\mathrm{Rp}-$ \\
\hline \multirow[t]{2}{*}{ Simulation } & \multicolumn{2}{|c|}{$.41(.06)$} & \multicolumn{2}{|c|}{$.11(.06)$} & & \\
\hline & $99 \%(.03)$ & $01 \%(.02)$ & $68 \%(.21)$ & $32 \%(.22)$ & & \\
\hline \multirow[t]{2}{*}{ Immediate } & \multicolumn{2}{|c|}{$.49(.09)$} & \multicolumn{2}{|c|}{$.35(.14)$} & \multicolumn{2}{|c|}{$.46(.14)$} \\
\hline & $65 \%(.10)$ & $35 \%(.11)$ & $31 \%(.13)$ & $69 \%(.13)$ & $39 \%(.10)$ & $61 \%(.10)$ \\
\hline \multirow[t]{2}{*}{$\begin{array}{l}\text { After one } \\
\text { day }\end{array}$} & \multicolumn{2}{|c|}{$.51(.09)$} & \multicolumn{2}{|c|}{$.39(.13)$} & \multicolumn{2}{|c|}{$.46(.15)$} \\
\hline & $67 \%(.10)$ & $33 \%(.10)$ & $32 \%(.13)$ & $68 \%(.14)$ & $38 \%(.12)$ & $62 \%(.12)$ \\
\hline
\end{tabular}

Note: Total correct scores are displayed in bold text. Standard deviations are shown between parentheses.

\section{Free Recall - Error Scores}

A 2 × 3 repeated measures ANOVA with group (simulators RP vs. simulators control) as a between-subjects factor and memory test (simulation vs. immediate vs. after one day) as a withinsubjects factor, was run on the error scores (i.e., distortions and commissions). There was a significant main effect of group and a significant group by memory test interaction, $F(1,73)=$ $34.62, p<.001, \eta_{p}{ }^{2}=.32$, and $F(2,146)=25.62, p<.001, \eta_{p}{ }^{2}=.26$. The main effect of time was not found to be significant, $F(2,146)=1.61, p=.20$. Participants in the simulators in the retrievalpractice group made more errors during both immediate and delayed memory tests compared to the simulation phase, $t(36)=6.26, p<.001, d=1.01$, and $t(36)=4.92, p<.001, d=.85$ (see Table 3 ). Instead, participants in the simulator control group made less errors at both immediate and after one day memory tests compared to the simulation phase, $t(37)=3.97, p<.001, d=.52$, and $t(39)=$ $3.40, p=.002, d=.43$ (see Table 3). Moreover, during the simulation phase, this latter group made more errors than simulators in the retrieval-practice condition, $t(75)=7.30, p<.001, d=1.69$ (see Table 3). 
Finally, to compare differences between groups on the error scores, a 3 x 2 repeated measures ANOVA was conducted with group (simulators RP vs. simulators control vs. confessors) as a between-subjects factor and memory test (immediate vs. after one day) as within subjects factor. Only the main effect of condition was found to be significant, while neither other main or interaction effects were not, $F(2,113)=6.16, p=.003, \eta_{p}{ }^{2}=.10$, and $F_{s}(1,113)<1.09, p>.30$. Partially supporting our prediction (Hp. 3), a post-hoc test with Bonferroni correction highlighted that overall only participants in the simulators control group $(M=3.78, S D=2.96)$ slightly made more errors than confessors $(M=2.52, S D=2.37)$, while no significant differences were found between this latter group and participants in the simulator retrieval-practice condition $(M=2.06, S D$ = 2), $p=.04,95 \% C I[.02$ 2.49], $d=.47$, and $p=1,95 \% C I[-.761 .68], d=.20$. Furthermore, simulators in the retrieval-practice group made fewer errors than participants in the simulator control group during, $p=.03,95 \% C I[.492 .96], d=.68$.

Table 3. Total error scores provided by each group during the three memory tests (simulation vs. immediate vs. after one day).

\begin{tabular}{lcccc}
\hline & \multicolumn{1}{c}{ Simulators retrieval practice } & & Simulators Control & Confessors \\
\cline { 2 - 2 } Simulation & $.32(.70)$ & & $6.17(4.82)$ & \\
Immediate & $1.82(1.44)$ & $3.68(2.55)$ & $2.54(2.42)$ \\
After one day & $2.30(2.54)$ & $3.87(3.34)$ & $2.65(2.47)$ \\
\hline
\end{tabular}

Note: Errors are displayed in absolute numbers. Standard deviations are shown between parentheses. 


\section{Discussion}

The present study yielded a number of findings concerning the impact of RIF on memory for a mock crime. To begin with, retrieval-practice produced the expected facilitation and RIF effects. This pattern of results is consistent with the retrieval specificity principle (see for a review: Murayama, Miyatsu, Buchli, \& Storm, 2014). That is, the diminished recollection of un-practiced information is assumed to be caused by inhibition, which is likely to occur during the retrievalpractice. Anderson and colleagues (2000), for instance, observed that although expected RIF was exhibited when participants were asked to recall the practiced items (e.g. fruit-or___, their memory performance was unimpaired when they were requested to recall the category name (e.g., fr___orange). Without having actual retrieval, indeed, there is no need for un-practiced information to be inhibited, thereby observing genuine forgetting. One could argue that the very act of retrieving their feigned version of the crime - by firstly being involved in the cued task and secondly actively rehearsing the same $\mathrm{Rp}+$ information via free recall - led participants in the retrieval-practice group to inhibit crucial crime-related memories. Moreover, the instructions to recall only $\mathrm{Rp}+$ information were likely to strengthen and consolidate simulators retrieval-practice performance for those practiced items (e.g., Payne, 1987, Shaw, et al., 1995), slightly increasing the positive effects of the retrieval-practice over time.

Relatedly, the overall memory performance of participants in the simulator retrieval-practice group might have yielded a deceptive hypermnesia at the final test. That is, in the first place those findings might have led to assume that prior retrieving of some crime information might have helped simulators in the retrieval-practice group to better remember the entire event and enhance their memory over time. However, the percentage of crucial crime-related information ( $\mathrm{Rp}-$ ) remembered by those feigners was significantly lower than that exhibited by participants in the simulator control and confessor groups. In light of this, if we consider impairments of crucial information about the crime being the core of the feigning amnesia effect, our findings reflect the idea that RIF might play a part into feigners' memory detriments in crime-related amnesia. Thus, extending recent research on the nature of retrieval-induced forgetting (e.g., MacLeod, 2002; MacLeod \& Macrae, 2001; Storm, Bjork, Bjork, \& Nestojko, 2006), possible memory impairments for feigners might be due to inhibition of un-practiced information, wherein inhibition is clearly elicited by the strengthened recollection of practiced-target items. Moreover, although the difference between total amount of information given by participants in the simulator control group and those in the confessor group resembled the standard memory-undermining effect of feigning amnesia (e.g., Van Oorsouw \& Merckelbach, 2004), it is noteworthy that they slightly remembered even more Rp - information than confessors. Perhaps, when feigners are not given any specific 
instructions regarding how to pretend memory loss following a crime, feigning amnesia might be seen as a buffer against forgetting and, at least to some degree, could increase recollection for such crucial crime-related information (e.g., Mangiulli et al., 2018b).

Furthermore, while no differences were found between participants in both the simulator retrieval-practice group and the confessor groups, those in the simulator control group made more errors than confessors. On the one hand, these results might imply that repeatedly retrieving a specific version of the crime prevents distortion and commission errors during a later recall test when one honestly tries to remember the experience. On the other hand, when individuals come up with an alternative version of the crime (e.g., Van Oorsouw \& Merckelbach, 2006) without being specifically instructed regarding how to malingering memory loss, they are likely to increase the number of distortions and/or commission errors over time (Chrobak \& Zaragoza, 2008; Otgaar \& Baker, 2017; Van Oorsouw \& Giesbrecht, 2008).

Several limitations of the present study need to be addressed. Firstly, our sample was mainly composed by students, who differ in a myriad of ways from people who perpetrate serious crimes (Schacter, 1986). Although research using laboratory mock crime paradigms are fundamental to increase our knowledge about crime-related amnesia, our findings may have a limited ecological validity. Secondly, RP + and Rp - information was not counterbalanced across the simulator in the retrieval-practice group. One could argue, indeed, that the lack of counterbalancing across this group does not indicate whether RP + and Rp - information differed on participants' baseline memorability. However, it is unlikely that simulator in the retrieval-practice group could have shown differences between $\mathrm{RP}+$ and $\mathrm{Rp}$ - information even regardless of the retrieval-practice instruction because RP + and Rp - information pattern observed in this latter group was as opposed to that exhibited by both simulator control and confessor groups. Thirdly, in this study, it remains unclear what information, among all un-practiced items, is most affected by the RIF effect. Arguably, adopting a more controlled memory measure (i.e., cued recall) might enable researchers to draw more specific conclusions on the RIF effect on offenders' memory impairments. For those reasons, therefore, replications of this work are needed. Finally, although our findings suggest that the RIF effect could potentially occur in crime-related amnesia cases, the long-term consequences of the RIF effect remain to be determined (e.g., Anderson, 2003; Garcia-Bajos et al., 2009; Storm, Bjork, \& Bjork, 2012). Besides studying the long term effects of RIF, future research may focus on the effect of repeatedly feigning of crime-related amnesia. Relatedly, retrieval-practice trials, in our study, might be seen as a form of strategy to feign amnesia. In contrast to simulators RP, it is unknown which approach was adopted by simulator controls to come up with their feigned version 
of the crime. This would lead us to further investigate possible strategies adopted by simulators in future studies.

In closing, the present research might have practical relevance. Many offenders are interviewed by the police about their crimes. Because some of them retrieve their version of the crime in a way to minimize legal and perhaps emotional consequences of their deeds (e.g., Christianson \& Merckelbach, 2004), the act of feigning amnesia might lead to strengthening of trivial crime-related details in memory and forgetting of more important facts due to inhibitionbased mechanism. Thus, extending RIF to the feigning amnesia paradigm represents a step forward to understanding impaired memory for a crime after feigning amnesia. In addition, even when perpetrators are motivated to plead guilty after having previously feigned amnesia, police investigators should take into account that these offenders have genuine memory loss for details of their crimes. Thus, dubious memory enhancing techniques as hypnosis or imagination exercises should not be used to help perpetrators remember their crimes. Such techniques might lead to distorted recollections of their offences (e.g., Loftus, 1997; Scoboria, Mazzoni, Kirsch, \& Milling, 2002). Of course, in view of differences between experimental setting and real-life cases, we carefully generalize our findings to actual crime-related amnesia. What remains worthwhile, however, is that our study contributes to the understanding of feigners' memory impairment after simulating amnesia and its relevance in the legal context. 


\section{Appendix A}

List of practiced and un-practiced information adopted for the retrieval-practice manipulation in the present study.

Practiced Information ( $R p+)$

1. I left my apartment

2. I got in my green car

3. I entered my office

4. My boss got in the office

5. My boss left me some work-folders

6. My boss scolded me

7. I left the office immediately after

8. I got back home

9. I briefly cocked the dinner

10. I left my apartment

11. I bought a beer

12. I set on a chair

13. I smoked a cigarette

14. I entered the restroom

15. I tried to open a toilet

16. It was locked up

17. I left the restroom

18. I crashed into a tall man

19. I got back in my green car

20. I drove toward home

\section{Un-practiced Information ( $\mathbf{R p}-)$}

1. I drank vodka at my place

2. I went clubbing

3. I drank a cocktail

4. I drank a shot

5. I bumped into a guy while I was walking

6. We started arguing

7. I tried to molest a girl

8. I got drunk

9. I vomited in the restroom sink

10. The victim came out of the toilet

11. The victim approached me

12. I pushed the victim against the wall

13. I strongly shook the victim

14. We had a physical fight

15. I knocked the victim down

16. I put my hands around her neck

17. I strangled the victim

18. I moved away from the body

19. I came back to the toilet

20. I tried to revive the victim 


\section{Appendix B}

Cued recall task employed for simulators in the retrieval-practice group to retrieve their simulated version of the crime based on Rp + information. Between parentheses are shown missing words of Rp + information that feigners had to fill in.

Well, I do not have a great memory of that day. I remember that I left my (apartment) and I got in my (green car). I entered my (office) and then my (boss) got in. He left me some (folders). Well, I am not really sure but I think he (scolded) me. Next, I left the (office) immediately and I got back (home). There, I briefly cocked (the dinner) and I left my (apartment). Even since then, my memories are not very clear. All seems very confusing and obscure, but still, I remember that I bought a (beer) and I set down on a (chair) somewhere. I also smoked a (cigarette). Then, I entered in the (restroom). I tried to open a (toilet) but it was (locked up). I left the (restroom), and I crashed into a (tall man). But I am sorry, I do not remember well. Everything is absolutely vague. I think that later I got back in my (green car) and I drove toward (home). That is all I remember about that day. 


Chapter 6

General Discussion 


\section{Introduction}

Judicial decision-makers and mental health practitioners are sometimes confronted with claims of memory loss from perpetrators of serious crimes. In the absence of any structural or momentary brain damage, however, crime-related amnesia should be handled with skepticism. There is a possibility that defendants intentionally fabricate memory loss to obtain personal goals. Some accused, for instance, report to have no memory for their crimes in order to appear incompetent to stand trial. Others take advantage of such claims in order to avoid being reminded of emotional and painful consequences of their deeds. However, it seems that some defendants are truly unable to remember their offence. For instance, Peters, van Oorsouw, Jelicic and Merckelbach (2013) reported about a case in which a man who claimed not being able to remember having stabbed his employer's son (i.e., “A man from Kurdistan”). Even though the man pled guilty for his offence, during several police interrogations he consistently claimed that he was unable to remember how he stabbed the victim with a knife. According to the authors, the defendant had genuine crime-related amnesia because the stabbing was conducted in a reflex-like manner. Although many defendants who report an inability to remember their crime are feigning their amnesic episode, research in cognitive psychology suggests that malingered memory loss can actually negatively impact a later recall of the offence (i.e., the memory-undermining effect of feigning amnesia; Christianson \& Bylin, 1999; van Oorsouw \& Merckelbach, 2004). Thus, a fabricated claim of crime-related amnesia not only obstructs the police investigation and impedes legal proceedings, it may also jeopardize a valuable source of information by genuinely impairing memory for the crime.

\section{Cognitive Memory-Undermining Mechanisms}

The memory-undermining effect of feigning amnesia has been demonstrated in a number of experimental studies (see also Table 1 in Chapter 1). That is, when one week after feigning amnesia for a mock crime or a narrative story of an offence, participants were asked to honestly account for the target experience, they had weaker memory than confessors who truthfully recalled the crime on both occasions. Feigners' memory performance differed that from confessors in terms of impaired total amount of correct information, and increased number of errors reported over time. Three explanations have been put forward to explain why feigned amnesia might evolve into real memory detriments: (1) lack of rehearsal, (2) source monitoring confusion, and (3) retrievalinduced forgetting. 


\section{Lack of Rehearsal}

Lack of rehearsal has been pointed out as the most likely explanation for the feigning amnesia effect, because simulating amnesia would be linked to a reduction of thinking about the crime. However, it is possible that, even without intentional rehearsing, some defendants experience unwanted intrusions or flashbacks of the crime, prompting them into thinking about the criminal experience. Thereby, as a consequence, they would not entirely forget the criminal act. Following this line of reasoning, in Chapter 2 we examined whether simulators who are prompted to think of the crime no longer exhibit the memory-undermining effect of feigning amnesia following a crime. We tried to induce rehearsal of the crime stimulus through visual and verbal cues (i.e., study 1 vs. study 2). Only the verbal rehearsal induction was successful in keeping relevant information active in ex-feigners memory. In contrast, at the base-line condition, when both simulators and confessors who did not receive any cues were compared, the memory-undermining effect of feigning did take place (study 2). However, the memory enhancing effect of cues was not observed when using a visual rehearsal induction (study 1). These two studies suggest that the memory-undermining effect of feigning amnesia appears to be less robust than the effect found in previous studies (e.g., Christianson \& Bylin, 1999; Van Oorsouw \& Merckelbach, 2004).

Of importance, and in contrast to previous research (e.g., Sun et al., 2009), we argued that lack of rehearsal in the feigning amnesia effect cannot fully explain the present findings. That is, in both studies (Chapter 2), simulating participants outperformed the delayed testing-only control group regardless of rehearsal induction. These findings suggest that the very act of feigning amnesia cannot be merely restricted to a lack of practice. For that reason, we further investigated lack of rehearsal as a possible account for the memory-undermining effect of feigned amnesia for a crime. In Chapter 3 we argued that feigning amnesia should be considered as a way to preserve and perhaps enhance memory for the target event over time, as compared to not being initially interviewed. Malingering memory loss for a mock crime in itself could promote correct recollection by inducing an active elaboration of information during memory encoding (McWilliams et al., 2014). Specifically, even though feigning participants may withhold details for the offence, they are also likely to distort and fabricate information in their feigned version of the crime (e.g., Van Oorsouw \& Merckelbach, 2004, 2006; Van Oorsouw \& Giesbrecht). By doing so, simulators would actively elaborate the crime stimulus, thereby retaining some traces of the crime more efficiently than controls. Hence, both possible memory outcomes of feigning amnesia are likely to occur (i.e., forgetting vs. remembering). This idea finds its roots in the Memory and Deception (MAD) framework (Otgaar \& Baker, 2017). According to this model, different types of lying demand different levels of cognitive resources. While minimal cognitive resources are used 
when falsely denying an event, more cognitive resources are spent when one lies by fabricating/confabulating information. Because the level of cognitive resources affect the quality and quantity of information stored in memory, different forms of lying have different effects on memory. That is, denying leads to forgetting (e.g., Otgaar, Howe, Smeets, \& Wang, 2016), while fabricating/confabulating information leads to memory errors (e.g., Van Oorsouw \& Giesbrecht, 2008), but does not seem to undermine the gist of correct recollection (e.g., Chrobak \& Zaragoza, 2008). Feigning amnesia appears to be located in the middle of this lying-continuum from false denial to fabrication/confabulation of information. One could argue, therefore, that feigning amnesia by mostly withholding information might affect genuine memory for the crime to a larger extent than feigning amnesia by distorting or fabricating new information. In the latter circumstance, malingered memory loss might partially impair memory for the crime, although it might lead to distortion and/or commission errors over time. Indeed, findings in Chapter 3 suggest that besides the likelihood of distorting some information, former feigners still have relatively intact memory for the target experience.

\section{Source Monitoring Confusion}

According to the source monitoring framework (SMF), the memory-undermining effect of feigning amnesia for a crime would be due to misattribution of the right source of information. However, it might be the case that both the content of self-generated information (e.g., feigned version of the crime) and information pertaining to the actual crime are preserved and distinguishable over time as a result of elaborative cognitive processing. In Chapter 4, we sought to contrast these two explanations. By applying the aIAT as a source monitoring task, we showed that simulators who were previously asked to feign amnesia are able to differentiate their own selfgenerated script of the crime from the original version of the crime. Thus, decrements in performance of feigning participants in delayed recall, as reported in the literature (e.g., Christianson \& Bylin, 1999; Van Oorsouw \& Merckelbach, 2004), seem to be independent of their source monitoring errors.

To our knowledge, no previous study has tried to investigate ex-simulators' ability to distinguish source monitoring information in crime-related amnesia. By using an implicit measure, we found that feigners are capable of automatically identifying the correct source of information. Arguably, such automatic identification via an aIAT task may be due to an association between item and source, perhaps based on a feeling of familiarity. Models of familiarity-based identification have been shown to be able to support implicit source recognition (e.g., Elfman, Parks \& Yonelinas, 2008; Mollison \& Curran, 2012). Germane to this, several authors suggested that, to some extent, memories for negative events are more accessible through implicit association because they are 
directly linked to feelings and mood evoked at the time of the event (e.g., Graf \& Schacter, 1985; Schacter, 1987; Tobias, Kihlstrom, \& Schacter, 1992). This would promote retrieval of crimerelated details. Although the aIAT still raises a controversy within the legal context (e.g., Takarangi et al., 2013), findings in Chapter 4 suggest that the source regarding a criminal event, and therefore its corresponding crime-related information, might be retrieved by using an implicit source monitoring task.

\section{Retrieval-induced Forgetting}

The third and final explanation for the memory-undermining effect of feigning memory loss concerns retrieval-induced forgetting. Chapter 5 represents the first attempt at investigating RIF in participants who simulated memory loss for a mock crime. Specifically, when involved in the process of feigning amnesia, simulators might be inclined to selectively retrieve some details of the crime and simultaneously omit other relevant information. This mechanism might lead to retrievalinduced forgetting effects (RIF), wherein crucial crime-related information might be forgotten due to selective retrieval of other elements of the offence. Findings showed the expected facilitation and RIF effects in simulating participants who were instructed to retrieve only some specific details of the crime event. This is in line with the retrieval specificity principle (e.g., Murayama et al., 2014). Namely, the reduced recollection of un-practiced information is assumed to be caused by inhibition, which is likely to take place during the retrieval-practice. Research has shown (Anderson et al., 2000) that while asking participants to recall the category name (e.g., fr___orange) does not lead to memory impairments, requesting to recall the practiced items (e.g. fruitor ) will result in memory decrements. Thus, RIF is considered to be retrieval specific. In addition, RIF should only take place if retrieval practice trials actually involve active attempts at retrieving information (e.g., Murayama et al., 2014). Without retrieval, indeed, there is no need for un-practiced information to be inhibited, thereby observing genuine forgetting (Anderson et al., 2000). Therefore, if we consider detriments of crucial details of crime (i.e., un-practiced information) being the core of the memory-undermining effect of feigned amnesia, our results reflect the idea that RIF might contribute to feigners' memory impairments in crime-related amnesia.

Of importance, by using the retrieval-induced forgetting procedure in Chapter 5, we obtained two distinct memory outcomes within the simulator groups. That is, when feigners keep claiming (and retrieving) that only some events pertaining to the crime took place, few memory errors but some forgetting is likely to occur. Conceivably, when during police interrogations perpetrators intentionally put emphasis on some parts of the experience, other crucial crime-related information is likely to become less accessible because of a RIF effect. Instead, when individuals do not follow 
this specific pattern of behavior and they feign amnesia by adopting other deceptive strategies (e.g., distorting and fabricating information), some memory errors but hardly any forgetting would occur. Possibly, when during police interrogations defendants falsely introduce self-generated details in their version of the crime, they are more likely to remember both these latter details and the actual crime experience (e.g., Chrobak \& Zaragoza, 2008; Otgaar \& Baker, 2017). From this perspective, feigning amnesia in itself might be seen as a buffer against forgetting, although distortions and/or commission errors might emerge over time. All in all, findings in Chapter 5 shed some new light on the understanding of feigners' mnestic consequences due to malingered amnesia.

\section{Theoretical and Practical Implications}

Overall, the most important findings of the current dissertation applied to claims of memory loss raised by perpetrators are: (1) perhaps due to cognitive re-elaboration of the criminal experience during the act of simulating, defendants who simulate memory loss remember crimerelated information better than individuals who are not interviewed in the first place but only after a delay; (2) although to some extent retrieval-induced forgetting might explain simulators' impaired recollection, genuine memory for a crime in general remains uncompromised despite a previously simulated amnesia claim; (3) "memory-enhancing" cues might stimulate individuals who formerly feigned crime-related amnesia to retrieve the actual event.

Even though previous research found that feigning amnesia undermines genuine memory for a crime as a delayed-only interview does (e.g., Christianson \& Bylin, 1999; Van Oorsouw \& Merckelbach, 2004, 2006), the findings of the studies described in this thesis suggest that malingered amnesia might enhance memory for the same target event. In real-life situations, individuals who have committed a crime often cannot ignore recollections of their deeds. For instance, some of them might be dealing with the emotional consequences of a traumatic event (i.e., by having unwanted memories or flashbacks). Others might be thinking of how they came to their criminal behavior and how they could have prevented the crime if they would have acted differently (i.e., counterfactual thinking, Roese \& Epstude, 2017). Such thinking, therefore, would produce rehearsal in itself, protecting crucial crime-related information against a faster decay. Even when feigners come up with a personal, self-generated version of the crime - by introducing distorted or new information in their memory - the act of feigning amnesia might strengthen and differentiate the original experience from the alternative scenario: The more fabricated details are reported, the clearer both the alternative version and the original experience for the crime are.

Because of the risk of undisclosed information in high-stake cases, perpetrators' memory for the crime is crucial for examinations - especially when the perpetrator and victim are the sole 
witnesses to a crime. Take for instance the notorious serial killer Ted Bundy. He was charged and convicted for a range of kidnappings, rapes, and murders in the United States during the 1970s. Prior to being put to death, Bundy provided the Washington State Attorney General's chief investigator with information of about fifty women that he had murdered. However, many police officers directly involved with the Bundy case believed he murdered at least hundred women (Carlisle, 2014). This case clearly shows how vital details regarding a crime are for the legal system. Based on the outcome of the current dissertation, police investigators might find it helpful knowing that defendants can actually store memory for the crime and contribute to disclosure of specific crime-related information. Although defendants can potentially incorporate distortion and/or commission errors in a final statement, the core of the criminal event may remain intact (e.g., Ackil \& Zaragoza, 2011; Chrobak \& Zaragoza, 2008). Moreover, it might be interesting to forensic practitioners - who are asked to act as experts in court concerning crime-related amnesia cases that actual memory for the event might be largely uncompromised despite individuals pretending to have memory loss for (parts of) the act. Therefore, at least in some circumstances, the fact that those ex-feigners seem to have some trouble remembering the crime does not necessarily mean that memory for the crime is completely inaccessible.

Alternatively, some other defendants might be engaged in selectively retrieving, or omitting, specific actual information of the crime in an attempt at being consistent with their claims of memory loss through various police interrogations. This narrowed strategy as compared to a more broad way of malingering amnesia (i.e., both distorting and fabricating original or new information of the event), might lead offenders to forget crucial information surrounding the crime. In this regard, some of our findings (Chapter 5) suggest that retrieval-induced forgetting effects are likely to explain possible perpetrators' memory decrements due to claims of memory loss. Because our study represents the very first attempt at investigating RIF effects within the domain of crimerelated amnesia, our conclusion should be considered with some caution. By and large, out of the three possible cognitive explanations for the memory-undermining effect of feigning amnesia, RIF seems the most plausible account for this phenomenon.

Apart from the fact that a memory-undermining effect can take place when offenders tend to feign memory loss, it should be noted here that they are likely to be facilitated in remembering details pertaining to the criminal experience. This might occur in circumstances in which defendants are motivated to collaborate with the justice department, such as in plea bargaining cases. Plea bargaining has been defined as any agreement between the prosecutor and defendant in a criminal case, wherein, for instance, the defendant agrees to plead guilty to a less serious charge or to one of the several charges, in return for some concession from the prosecutor (e.g., Bryan, 
2000). Some findings from the current dissertation suggest that the use of mnemonic elicitation techniques such as cognitive cues (Meissner, Redlich, Bhatt, \& Brandon, 2012), might perhaps help defendants to retrieve their criminal actions during information-gathering investigations (Memon, Meissner, \& Faser, 2010). For instance, when prompted with verbal cues, feigning participants no longer showed a memory gap for the mock crime when they had to give up their role as a feigner (see study 2, Chapter 2). Relatedly, it seems that the lack of memory-undermining effects of simulating amnesia is linked to the memory test used, as evidenced by better performance on a cued recall test than on a free recall test (see Chapter 3). Yet, because some details are strictly related to feelings and mood experienced during an event, implicit associations between the source and the crime-related information may be elicited by cues, thereby promoting an increase in accessibility in memory for a crime (see Chapter 4). Note that positive effect of retrieval cues are also reported in the literature on witness memory. Take for instance techniques that involve context reinstatement, in which the interviewee is encouraged to mentally reconstruct the context experienced at the time of the event [e.g., the Cognitive Interview (CI), Fisher \& Geiselman, 1992; Fisher \& Perez, 2007; Memon, et al., 2010]. Research typically shows that adults benefit from cues provided by the context reinstatement instruction of the $\mathrm{CI}$ in terms of memory accuracy for an event. However, in order to address whether defendants who are initially unable to retrieve the offence can later on provide legal professionals with relevant crime-related information, future research is needed.

\section{Directions for Future Studies}

Research using laboratory mock crime paradigms is necessary to increment our knowledge pertaining to crime-related amnesia (e.g., McWilliams et al., 2014), even though it is always problematic to generalize experimental findings to real life cases (Schacter, 1986). Note that the studies described in the current dissertation have several limitations. Future research on the effects of feigning amnesia on actual memory should take these shortcomings into consideration to get a better insight in this phenomenon. One limitation of our studies is related to the composition of the samples. Although our sample sizes were sufficient, they mainly consisted of female students. Because students, especially female students, differ in many ways from individuals who commit crimes (Schacter, 1986), our findings may have a limited ecological validity. Also, participants' general cognitive functioning level should be taken into the account. Offenders are often poorly educated and raised in low socio-economic environments (Palermo, 2004). Therefore, offenders may process crime-related amnesia differently from other populations such as students, because of previous experience with criminality, expectations and/or experience with memory loss, and 
memory skills. Ideally, future studies on the effects of malingering amnesia for a crime should include people with a social and educational background comparable to that of offenders

Additionally, an ecological valid mock crime stimulus should be used in future research. One of the possibilities why the feigning amnesia effects found in this dissertation differ from those reported in previous studies (e.g., Christianson \& Bylin, 1999; Bylin \& Christianson, 2002; Van Oorsouw \& Merckelbach, 2004, 2006; Sun et al., 2009) might be related to the crime stimulus adopted. That is, we conducted our studies by using a mock crime video. This might have led to results that differ from findings from previous research in which more traditional stimuli were used (i.e., scripts or narrative story). Conceivably, the memory-undermining effect of simulating amnesia could be even weaker than that found in the present studies when a more ecologically valid set-up is used (e.g., mock crime through virtual reality). In real-crime situations, memories for crimes often have a strong emotional component which makes them difficult to be forgotten (McGaugh, 2006; McNally, 2005). However, the opposite could also be true: the role of "motivated forgetting" cannot be ruled out (e.g., Anderson \& Hanslmayr, 2014). The term "motivated forgetting" refers to a mechanism recruited to prevent unwanted and unpleasant memories from entering awareness (e.g., Anderson \& Hanslmayr, 2014; Anderson \& Green, 2001; Levy \& Anderson, 2002). Several authors pointed out that people may voluntarily suppress memories for negative events (e.g., Anderson \& Green, 2001; Bergstrom, Anderson, Buda, Simons, \& Richardson-Klavehn, 2013; Hu, Bergstrom, Bodenhausen, \& Rosenfeld, 2015). Although we argued that unwanted intrusions or flashbacks might prompt offenders to think of the crime thereby feeding the actual memory for the criminal experience -we cannot exclude that some perpetrators are distressed by cues that remind them of their violent behavior (Evans, 2006). Retrieval of the crime-related events might, consequently, be hampered by avoiding or suppressing those reminders. As also mentioned in Chapter 3, therefore, such deliberate suppression of unwanted memories, which would produce forgetting, might also reflect memory processes in some offenders. Hence, future research might focus on the effect of instructing participants to intentionally avoid thinking of the crime as a possible consequence of emotional distress.

Simulating amnesia might be accomplished in at least two manners (i.e., by withholding or omitting information vs. by distorting and introducing new information). Therefore, it might be interesting to examine how different strategies in feigning amnesia affect genuine memory for a crime. During police interrogations, defendants might omit certain information of the crime while simultaneously fabricating other aspects. Applying this line of reasoning to the MAD framework (Otgaar \& Baker, 2017), one could speculate that omitting crime-related information might lead to impaired memory for elements of the offence, while fabricating new elements could result in 
relatively uncompromised recollections of the crime. This research avenue resembles what Christianson and Bylin (2002) have already tried to investigate. Participants were instructed to either confess to a traffic crime or feign amnesia by withholding or distorting information surrounding the same event. Findings from this study showed that participants instructed to feign amnesia by omitting information recollected less correct information than those who were instructed to genuinely account for the crime. Yet, no significant differences were found between the two simulator groups or between feigners instructed to distort information and the genuine group. However, Christianson and Bylin used a small number of participants which might have obscured differences between conditions.

Finally, another relevant research avenue might pertain to retrieval of crucial crime-related information following simulating amnesia. If we assume that memory for a crime is solidly stored as a result of its emotional impact (e.g., McGaugh, 2006; McNally, 2005) and that feigning amnesia has a detrimental effect on the actual memory for the crime (e.g., Van Oorsouw \& Merckelbach, 2004, 2006), memory impairments in offenders might be due to a retrieval deficit rather than poor encoding of information. A range of potential memory improvement techniques have been explored over the past decades, especially within the domain of eyewitness memory. Hypnosis, imagination exercises, and pharmaceuticals all failed to enhance individuals' memory performance without a risk of creating false memories (Kebbell \& Wagstaff 1998; Vedder \& Klaming, 2010). Therefore, it would be interesting to adopt new methods such as neurotechnologies, to explore the potential to improve memory in individuals who claim crime-related amnesia. Take for instance transcranial magnetic stimulation (TMS) and transcranial direct current stimulation (tDCS). They are two of the most commonly used techniques in noninvasive brain stimulation research. Depending on the stimulation parameters applied and the brain-regions involved (e.g., dorsolateral prefrontal cortex), these neurobiological approaches might affect retrieval processing, thereby enhancing cognitive performance (e.g., Gray, Brookshire, Casasanto, \& Gallo, 2015). Although this perspective might be seen as currently unrealistic, by adopting tools from modern neuroscience in the future, we might potentially enhance correct recollection for crucial crime-related information in individuals who previously feigning amnesia. 


\section{Final Remarks}

The main goal of the current dissertation was to experimentally verify possible cognitive mechanisms behind the memory-undermining effect of feigning amnesia for a crime. By and large, based on findings described in this thesis, we suggest that feigners' memory decrements are most likely due to the retrieval-induced forgetting effect (e.g., Anderson, 2003; Anderson, Bjork, \& Bjork, 1994). The current dissertation also shows that feigning crime-related amnesia does not lead to serious problems in the ability to recollect details of crime-related events. On the contrary, the memory-undermining effect of simulating amnesia might paradoxically be interpreted as a way of keeping the actual memory for the crime intact. That is, if defendants decide to malinger memory loss following their deeds, they must remember exactly what has happened in order to choose what they will misreport. Perhaps, while being involved in this cognitive re-elaboration of the event, offenders might re-think and generally rehearse the memory for the criminal experience. However, it should be noted here that simulating amnesia may have adverse effects on memory: While the overall genuine memory of the crime might still be intact, distortions and/or commissions errors are likely to occur over time.

In closing, the present dissertation supports the idea that, in the absence of any permanent or temporary brain injury, crime-related amnesia should be treated with skepticism. Traces of the crime are located in offenders' memory. Because some of these traces may lie somewhat dormant in memory, it would be interesting to study the effects of memory-enhancing such as neurotechnologies in individuals reporting crime-related amnesia. 



\section{References}

Ackil, J. K., \& Zaragoza, M. S. (2011). Forced fabrication versus interviewer suggestions: Differences in false memory depend on how memory is assessed. Applied Cognitive Psychology, 25, 933-942. doi:10.1002/acp.1785

Alderson-Day, B., \& Fernyhough, C. (2015). Inner speech: development, cognitive functions, phenomenology, and neurobiology. Psychological Bulletin, 141, 931-965. doi:10.1037/bul0000021

Alderson-Day, B., McCarthy-Jones, S., Bedford, S., Collins, H., Dunne, H., Rooke, C., \& Fernyhough, C. (2014). Shot through with voices: dissociation mediates the relationship between varieties of inner speech and auditory hallucination proneness. Consciousness and Cognition, 27, 288-296. doi:10.1016/j.concog.2014.05.010

Anderson, M. C. (2003). Rethinking interference theory: executive control and the mechanisms of forgetting. Journal of Memory and Language, 49, 415-445. doi:10.1016/j.jml.2003.08.006

Anderson, M. C., Bjork, E. L., \& Bjork, R. A. (2000). Retrieval-induced forgetting: Evidence for a recall-specific mechanism. Psychonomic Bulletin \& Review, 7, 522-530. doi:10.3758/bf03214366

Anderson, M. C., Bjork, R. A., \& Bjork, E. L. (1994). Remembering can cause forgetting: retrieval dynamics in long-term memory. Journal of Experimental Psychology: Learning, Memory, and Cognition, 20, 1063-1087. doi:10.1037/0278-7393.20.5.1063

Anderson, M. C., \& Green, C. (2001). Suppressing unwanted memories by executive control. Nature, 410, 366-369. doi: 10.1038/35066572

Anderson, M. C., \& Hanslmayr, S. (2014). Neural mechanisms of motivated forgetting. Trends in Cognitive Sciences, 18, 279-292. doi: 10.1016/j.tics.2014.03.002

Baker, G. A., Hanley, J. R., Jackson, H. F., Kimmance, S., \& Slade, P. (1993). Detecting the faking of amnesia: Performance differences between simulators and patients with memory impairment. Journal of Clinical and Experimental Neuropsychology, 15, 668-684. doi: 10.1080/01688639308402588 
Bayen, U. J., Murnane, K., \& Erdfelder, E. (1996). Source discrimination, item detection, and multinomial models of source monitoring. Journal of Experimental Psychology: Learning, Memory, and Cognition, 22, 197-215. doi: 10.1037//0278-7393.22.1.197

Bergman, E. T., \& Roediger, H. L. (1999). Can Bartlett's repeated reproduction experiments be replicated? Memory \& Cognition, 27, 937-947.

Bergström, Z. M., Anderson, M. C., Buda, M., Simons, J. S., \& Richardson-Klavehn, A. (2013). Intentional retrieval suppression can conceal guilty knowledge in ERP memory detection tests. Biological Psychology, 94, 1-11. doi:10.1016/j.biopsycho.2013.04.012

Bernstein, E. M., \& Putnam, F. W. (1986). Development, reliability, and validity of a dissociation scale. The Journal of Nervous and Mental Disease, 174, 727-735. doi: 10.1097/00005053198612000-00004

Bornstein, B. H., Liebel, L. M., \& Scarberry, N. C. (1998). Repeated testing in eyewitness memory: A means to improve recall of a negative emotional event. Applied Cognitive Psychology, 12, 119-131. doi: 10.1002/(sici)1099-0720(199804)12:2<119::aid-acp500>3.0.co;2-4

Bourget, D., \& Whitehurst, L. (2007). Amnesia and crime. Journal of the American Academy of Psychiatry and the Law, 35, 469-80.

Bower, G. H. (1981). Mood and memory. American Psychologist, 36, 129-148. doi:10.1037/0003066x.36.2.129

Bryan, G., A., (2000). Black's law dictionary (7th ed.). St. Paul, Minn.: West Group.

Bylin, S. (2002). How does repeated simulation of memory impairment affect genuine memory performance? Psychology, Crime and Law, 8, 265-288. doi: 10.1080/10683160208401819

Bylin, S., \& Christianson, S. Å. (2002). Characteristics of malingered amnesia: Consequences of withholding vs. distorting information on later memory of a crime event. Legal and Criminological Psychology, 7, 45-61. doi:10.1348/135532502168379

Byrne, R. M. J. (2005). The rational imagination: How people create alternatives to reality. Cambridge, MA: MIT Press.

Byrne, R. M. J. (2016). Counterfactual thought. Annual Review of Psychology, 67, 135-157. doi: 10.1146/annurev-psych-122414-033249 
Camp, G., Wesstein, H., De Bruin, A. B. H. (2012) Can questioning induce forgetting? Retrievalinduced forgetting of eyewitness information. Applied Cognitive Psychology, 26, 431-435. doi:10.1002/acp.2815

Carlisle, A. (2014). I'm not guilty: The case of Ted Bundy. Encino, CA: Genius Book.

Centor, A. (1982). Criminals and amnesia: Comment on Bower. American Psychologist, 37, 240.

Chan, J. C. K. (2010). Long-term effects of testing on the recall of nontested materials. Memory, 18, 49-57. doi: 10.1080/09658210903405737

Christianson, S. A., \& Bylin, S. (1999). Does simulating amnesia mediate genuine forgetting for a crime event? Applied Cognitive Psychology, 13, 495-511. doi:10.1002/(sici)10990720(199912)13:6<495::aid-acp615>3.0.co;2-0

Christianson, S. A., \& Merckelbach, H. (2004). Crime-related amnesia as a form of deception. In: P.A. Granhag \& L.A, Strömwall (Eds.), The Detection of Deception in Forensic Contexts (pp. 195-225). New York: Cambridge University Press. doi: 10.1017/CBO9780511490071.009

Chroback, Q. M., \& Zaragoza, M. S. (2012). The misinformation effect. In A. M. Ridley, F. Gabbert, \& D. J. La Rooy (Eds.), Suggestibility in legal contexts: Psychological research and forensic implications (pp. 21-44). London: Wiley Blackwell.

Chrobak, Q. M., \& Zaragoza, M. S. (2008). Inventing stories: Forcing witnesses to fabricate entire fictitious events leads to freely reported false memories. Psychonomic Bulletin and Review, 15, 1190-1195. doi: 10.3758/pbr.15.6.1190

Cima, M., Merckelbach, H. L. G. J., Nijman, H., Knauer, E., \& Hollnack, S. (2002). I can't remember your honor: Offenders who claim amnesia. German Journal of Psychiatry, 5, 2434.

Cima, M., Nijman, H., Merckelbach, H., Kremer, K., \& Hollnack, S. (2004). Claims of crime related amnesia in forensic patients. International Journal of Law and Psychiatry, 27, 215221. doi: 10.1016/j.ijlp.2004.03.007

Craik, F. I., \& McDowd, J. M. (1987). Age differences in recall and recognition. Journal of Experimental Psychology: Learning, Memory, and Cognition, 13, 474-479. doi: 10.1037//0278-7393.13.3.474 
Curci, A., Lanciano, T., Maddalena, C., Mastandrea, S., \& Sartori, G. (2015). Flashbulb memories of the Pope's resignation: Explicit and implicit measures across differing religious groups. Memory, 23, 529-544. doi: 10.1080/09658211.2014.908923

De Houwer, J. (2006). What are implicit measures and why are we using them. The handbook of implicit cognition and addiction, 11-28. doi: 10.4135/9781412976237.n2

De Houwer, J., Teige-Mocigemba, S., Spruyt, A., \& Moors, A. (2009). Implicit measures: A normative analysis and review. Psychological Bulletin, 135, 347-368. doi:10.1037/a0014211

Diana, R. A., Yonelinas, A. P., \& Ranganath, C. (2008). The effects of unitization on familiaritybased source memory: testing a behavioral prediction derived from neuroimaging data. Journal of Experimental Psychology: Learning, Memory, and Cognition, 34, 730-740. doi: $10.1037 / 0278-7393.34 .4 .730$

Diana, R. A., Yonelinas, A. P., \& Ranganath, C. (2007). Imaging recollection and familiarity in the medial temporal lobe: a three-component model. Trends in Cognitive Sciences, 11, 379-386. doi: 10.1016/j.tics.2007.08.001

Duncan, R. M., \& Cheyne, J. A. (1999). Incidence and functions of self-reported private speech in young adults: A self-verbalization questionnaire. Canadian Journal of Behavioural Science / Revue Canadienne Des Sciences Du Comportement, 31, 133-136.

Elfman, K., W., Parks, C., M., Yonelinas, A., P. (2008). Testing a neuro-computational model of recollection, familiarity, and source recognition. Journal of Experimental Psychology. Learning, Memory, and Cognition, 34,752-768. doi: 10.1037/0278-7393.34.4.752

Engelkamp, J., Zimmer, H. D., Mohr, G., \& Sellen, O. (1994). Memory of self-performed tasks: Self-performing during recognition. Memory \& Cognition, 22, 34-39. doi:10.3758/bf03202759

Evans, C. (2006). What violent offenders remember of their crime: Empirical explorations. Australian and New Zealand Journal of Psychiatry, 40, 508-518. doi: 10.1080/j.14401614.2006.01833.x

Evans, C., Ehlers, A., Mezey, G., \& Clark, D. M. (2007). Intrusive memories and ruminations related to violent crime among young offenders: Phenomenological characteristics. Journal of Traumatic Stress, 20, 183-196. doi: 10.1002/jts.20204 
Evans, C., Ehlers, A., Mezey, G., \& Clark, D. M. (2007b). Intrusive memories in perpetrators of violent crime: Emotions and cognitions. Journal of Consulting and Clinical Psychology, 75, 134-144. doi: 10.1037/0022-006X.75.1.134

Fazio, L. K., Agarwal, P. K., Marsh, E. J., \& Roediger, H. L. (2010). Memorial consequences of multiple-choice testing on immediate and delayed tests. Memory \& Cognition, 38, 407-418. doi:10.3758/mc.38.4.407

Fazio, R. H., \& Olson, M. A. (2003). Implicit measures in social cognition research: Their meaning and use. Annual Review of Psychology, 54, 297-327. doi: 10.1146/annurev.psych.54.101601.145225

Fisher, R. P., \& Geiselman, R. E. (1992). Memory-enhancing techniques for investigative interviewing: The cognitive interview. Springfield, IL: Charles C. Thomas

Fisher, R. P., \& Perez, V. (2007). Memory-Enhancing Techniques for Interviewing Crime Suspects. In S. A. Christianson (Ed.), Offenders' memories of violent crimes (pp. 329-354). Chichester, England: Wiley. doi: 10.1002/9780470713082.ch14

Garcia-Bajos, E., Migueles, M., Anderson, M. C. (2009) Script knowledge modulates retrievalinduced forgetting for eyewitness events. Memory, 17, 92-103. doi:10.1080/09658210802572454

Geraerts, E., Schooler, J. W., Merckelbach, H., Jelicic, M., J.A. Hauer, B., \& Ambadar, Z. (2007). The Reality of Recovered Memories. Psychological Science, 18, 564-568. doi:10.1111/j.1467-9280.2007.01940.x

Giger, P., Merten, T., Merckelbach, H., \& Oswald, M. (2010). Detection of feigned crime-related amnesia: A multi-method approach. Journal of Forensic Psychology Practice, 10, 440-463. doi: 10.1080/15228932.2010.489875

Goodman, L.A. (1961). "Snowball sampling". Annals of Mathematical Statistics, 32, 148-170. doi:10.1214/aoms/1177705148

Graf, P., \& Schacter, D. L. (1985). Implicit and explicit memory for new associations in normal and amnesic subjects. Journal of Experimental Psychology: Learning, Memory, and Cognition, 11, 501-518. doi:10.1037/0278-7393.11.3.501 
Gray, S. J., Brookshire, G., Casasanto, D., \& Gallo, D. A. (2015). Electrically stimulating prefrontal cortex at retrieval improves recollection accuracy. Cortex, 73, 188-194. doi:10.1016/j.cortex.2015.09.003

Greenwald, A. G., \& Banaji, M. R. (1995). Implicit social cognition: attitudes, self-esteem, and stereotypes. Psychological Review, 102, 4-27. doi: 10.1037//0033-295x.102.1.4

Greenwald, A. G., McGhee, D. E., \& Schwartz, J. L. (1998). Measuring individual differences in implicit cognition: the implicit association test. Journal of Personality and Social Psychology, 74, 1464-1480. doi: 10.1037//0022-3514.74.6.1464

Greenwald, A. G., Nosek, B. A., \& Banaji, M. R. (2003). Understanding and using the implicit association test: I. An improved scoring algorithm. Journal of Personality and Social Psychology, 85, 197-216. doi: 10.1037/0022-3514.85.2.197

Helm, R. K., Ceci, S. J., \& Burd, K. A. (2016). Can Implicit Associations Distinguish True and False Eyewitness Memory? Development and Preliminary Testing of the IATe. Behavioral Sciences \& the Law, 34, 803-819. doi: 10.1002/bs1.2272

Hermann, D. H. (1986). Criminal defenses and pleas in mitigation based on amnesia. Behavioral Sciences \& the Law, 4, 5-26. doi: 10.1002/bs1.2370040102

Hicks, J. L., Marsh, R. L., \& Ritschel, L. (2002). The role of recollection and partial information in source monitoring. Journal of Experimental Psychology: Learning, Memory, and Cognition, 28, 503-508. doi: 10.1037//0278-7393.28.3.503

Hofmann, W., Gawronski, B., Gschwendner, T., Le, H., \& Schmitt, M. (2005). A meta-analysis on the correlation between the Implicit Association Test and explicit self-report measures. Personality and Social Psychology Bulletin, 31, 1369-1385. doi:10.1177/0146167205275613

Hu, X., Bergström, Z. M., Bodenhausen, G. V., \& Rosenfeld, J. P. (2015). Suppressing Unwanted Autobiographical Memories Reduces Their Automatic Influences. Psychological Science, 26, 1098-1106. doi:10.1177/0956797615575734

Iverson, G. L. (1995). Qualitative aspects of malingered memory deficits. Brain Injury, 9, 35-40. doi: 10.3109/02699059509004569 
Jacoby, L. L. (1991). A process dissociation framework: Separating automatic from intentional uses of memory. Journal of Memory and Language, 30, 513-541. doi: 10.1016/0749596x(91)90025-f

Jelicic, M., \& Merckelbach, H. (2015). Amnesic Defense. In R. Cautin, \& S. Lilienfeld (Eds.), The Encyclopedia of Clinical Psychology (pp. 128-131). Hoboken: John Wiley \& Sons. doi:10.1002/9781118625392.wbecp064

Jelicic, M., \& Merckelbach, H. (2007). Evaluating the authenticity of crime-related amnesia. In: S. Å. Christianson (Ed.), Offenders' Memories of Violent Crimes (pp 215-233). Chichester: Wiley. doi: 10.1002/9780470713082.ch9

Jelicic, M., Merckelbach, H., \& Bošković, I. (2017). Seven Myths About Feigning. In H. Otgaar, \& M. L. Howe (Eds.), Finding the Truth in the Courtroom. Dealing with Deception, Lies, and

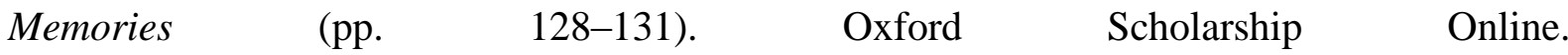
doi:10.1093/oso/9780190612016.003.0011

Jelicic, M., Merckelbach, H., \& van Bergen, S. (2004). Symptom validity testing of feigned amnesia for a mock crime. Archives of Clinical Neuropsychology, 19, 525-531. doi: 10.1016/j.acn.2003.07.004

Johnson, M. K. (2006). Memory and reality. American Psychologist, 61, 760-771. doi: 10.1037/0003-066x.61.8.760

Johnson, M. K., Foley, M. A., Suengas, A. G., \& Raye, C. L. (1988). Phenomenal characteristics of memories for perceived and imagined autobiographical events. Journal of Experimental Psychology: General, 117, 371-376. doi: 10.1037/0096-3445.117.4.371

Johnson, M. K., Hashtroudi, S., \& Lindsay, D. S. (1993). Source monitoring. Psychological Bulletin, 114, 3-28. doi: 10.1037/0033-2909.114.1.3

Johnson, M. K., Raye, C.L., Foley, H. J., \& Foley, M. A. (1981). Cognitive operations and decision bias in reality monitoring. American Journal of Psychology, 94, 37-64. doi: 10.2307/1422342

Kebbell, M. R., \& Wagstaff, G. F. (1998). Hypnotic interviewing: The best way to interview eyewitnesses?. Behavioral Sciences \& the Law, 16, 115-129. doi: 10.1002/(sici)10990798(199824)16:1<115::aid-bsl296>3.0.co;2-i

Kopelman, M. D. (2002). Disorders of memory. Brain, 125, 2152-2190. doi: 10.1093/brain/awf229 
Kopelman, M. D. (2000). Focal retrograde amnesia and the attribution of causality: An exceptionally critical view. Cognitive Neuropsychology, 17, 585-621. doi: $10.1080 / 026432900750002172$

Kopelman, M. D. (1995). The assessment of psychogenic amnesia. In A. D. Baddeley, B. A.Wilson, \& F. N. Watts (Eds.), Handbook of memory disorders (pp. 427-448). New York: John Wiley.Koson, D., \& Robey, A. (1973). Amnesia and competency to stand trial. American Journal of Psychiatry, 130, 588-592.

Lanciano, T., Curci, A., Mastandrea, S., \& Sartori, G. (2013). Do automatic mental associations detect a flashbulb memory? Memory, 21, 482-493. doi: 10.1080/09658211.2014.894221

Leitch, A. (1948). Notes on amnesia in crime for the general practitioner. The Medical Press, 26, 459-463.

Levy, B. J., \& Anderson, M. C. (2008). Individual differences in the suppression of unwanted memories: the executive deficit hypothesis. Acta Psychologica, 127, 623-635. doi: 10.1016/j.actpsy.2007.12.004

Levy, B. J. \& Anderson, M. C. (2002). Repression can (and should) be studied empirically. Trends in Cognitive Sciences, 6, 502-503. doi: 10.1016/S1364-6613(02)02025-9

Liepmann, H. (2002/1910). Contribution to the understanding of the amnesic symptom complex. Cortex, 38, 635-639.

Lindsay, D. S. (2008). Source monitoring. In H. L. Roediger, III (Ed.), Cognitive psychology of memory. Vol. 2 of Learning and memory: A comprehensive reference (pp. 325-348). Oxford: Elsevier.

Loftus, E. F. (2005). Planting misinformation in the human mind: A 30-year investigation of the malleability of memory. Learning \& Memory, 12, 361-366. doi: 10.1101/lm.94705

Loftus, E. F. (1997). Creating False Memories. Scientific American, 277, 70-75. doi:10.1038/scientificamerican0997-70

MacDonald, M., \& Gould, A. (1987). The Violent Years of Maggie MacDonald: an Autobiography. Scarborough, Ont.: Prentice-Hall Canada. 
MacLeod, M. D. (2002). Retrieval-induced forgetting in eyewitness memory: Forgetting as a consequence of remembering. Applied Cognitive Psychology, 16, 135-149. doi: 10.1002/acp.782

MacLeod, M. D., \& Macrae, C. N. (2001). Gone but not forgotten: The transient nature of retrievalinduced forgetting. Psychological Science, 12, 148-152. doi:10.1111/1467-9280.00325

Mangiulli, I., Lanciano, T., Van Oorsouw, K., Jelicic, M., \& Curci, A. (2018). Do visual and verbal reminders of the crime reverse the memory-undermining effect of simulating amnesia?. Manuscript under review.

Mangiulli, I., Van Oorsouw, K., Curci, A., Merckelbach, H., \& Jelicic, M. (2018). Feigning amnesia moderately impairs memory for a mock crime video. Frontiers in Psychology, 6:625. doi: 10.3389/fpsyg.2018.00625

Marsh, E. J., Tversky, B., \& Hutson, M. (2005). How eyewitnesses talk about events: Implications for memory. Applied Cognitive Psychology, 19, 531-544. doi: 10.1002/acp.1095

Marshall, W. L., Serran, G., Marshall, L. E., \& Fernandez, Y. M. (2005). Recovering memories of the offense in" amnesic" sexual offenders. Sexual Abuse: A Journal of Research and Treatment, 17, 31-38. doi: 10.1177/107906320501700104

McCarthy-Jones, S., \& Fernyhough, C. (2011). The varieties of inner speech: links between quality of inner speech and psychopathological variables in a sample of young adults. Consciousness and Cognition, 20, 1586-1593. doi: 10.1016/j.concog.2011.08.005

McGaugh, J.L. (2006). Memory and Emotions: Making Lasting Memories. New York, NY: Columbia University Press.

McNally, R. J. (2005). Remembering trauma. Cambridge, MA: Harvard University Press.

McSherry, B. (1998). Getting away with murder?: Dissociative states and criminal responsibility. International Journal of Law and Psychiatry, 21, 163-176. doi: 10.1016/S01602527(98)00006-5

McWilliams, K., Goodman, G. S., Lyons, K. E., Newton, J., \& Avila-Mora, E. (2014). Memory for child sexual abuse information: Simulated memory error and individual differences. Memory \& Cognition, 42, 151-163. doi: 10.3758/s13421-013-0345-2 
Meissner, C., Redlich, A., Bhatt, S., \& Brandon, S. (2012). Interview and interrogation methods and their effects on investigative outcomes. Campbell Systematic Reviews, 8, 1-49.

Memon, A., Meissner, C. A., \& Fraser, J. (2010). The Cognitive Interview: A meta-analytic review and study space analysis of the past 25 years. Psychology, Public Policy, and Law, 16, 340372. doi: 10.1037/a0020518

Merckelbach, H., \& Christianson, S. A. (2007). Amnesia for homicide as a form of malingering. In S. A. Christianson (Ed.), Offenders' memories of violent crimes (pp. 165-190). Chichester, England: Wiley. doi: 10.1002/9780470713082.ch7

Migueles, M., Garcia-Bajos, E. (2007) Selective retrieval and induced forgetting in eyewitness memory. Applied Cognitive Psychology, 21, 1157-1172. doi:10.1002/acp.1323

Milner, B., Corkin, S., \& Teuber, H. L. (1968). Further analysis of the hippocampal amnesic syndrome: 14-year follow-up study of HM. Neuropsychologia, 6, 215-234. doi: 10.1016/0028-3932(68)90021-3

Mintzer, M. Z., \& Snodgrass, J. G. (1999). The picture superiority effect: Support for the distinctiveness model. American Journal of Psychology, 112, 113-146. doi: 10.2307/1423627

Mitchell, K. J., \& Johnson, M. K. (2009). Source monitoring 15 years later: what have we learned from fMRI about the neural mechanisms of source memory? Psychological Bulletin, 135, 638-677. doi: 10.1037/a0015849

Moldea, D. E. (1995). The killing of Robert F. Kennedy: an investigation of motive, means, and opportunity. New York, NY: Norton.

Mollison, M. V., \& Curran, T. (2012). Familiarity in source memory. Neuropsychologia, 50, 25462565. doi: 10.1016/j.neuropsychologia.2012.06.027

Murayama, K., Miyatsu, T., Buchli, D., \& Storm, B. C. (2014). Forgetting as a consequence of retrieval: a meta-analytic review of retrieval-induced forgetting. Psychological Bulletin, 140, 1383-1409. doi: 10.1037/a0037505

Nahari, G., \& Ben-Shakhar, G. (2011). Psychophysiological and behavioral measures for detecting concealed information: The role of memory for crime details. Psychophysiology, 48, 733-744. doi: 10.1111/j.1469-8986.2010.01148.x 
Nelson, D. L., Reed, V. S., \& Walling, J. R. (1976). Pictorial superiority effect. Journal of Experimental Psychology: Human Learning and Memory, 25, 523-528. doi: 10.1037//02787393.2 .5 .523

Nosek, B. A., Greenwald, A. G., \& Banaji, M. R. (2007). The Implicit Association Test at age 7: A methodological and conceptual review. In J. A. Bargh (Ed.), Automatic processes in social thinking and behavior (pp. 265-292). New York, NY: Psychology Press.

O'Connell, B.A. (1960). Amnesia and homicide. British Journal of Delinquency, 10, 262-276.

Ornish, S. A. (2001). A blizzard of lies: Bogus psychiatric defenses. American Journal of Forensic Psychiatry, 22, 19-30.

Otgaar, H., \& Baker, A. (2017). When lying changes memory for the truth. Memory, 22, 1-13. doi: 10.1080/09658211.2017.1340286

Otgaar, H., Howe, M. L., Smeets, T., \& Wang, J. (2016). Denial-Induced Forgetting: False Denials Undermine Memory, But External Denials Undermine Belief. Journal of Applied Research in Memory and Cognition, 5, 168-175. doi:10.1016/j.jarmac.2016.04.002

Padilla-Walker, L. M., \& Poole, D. A. (2002). Memory for previous recall: A comparison of free and cued recall. Applied Cognitive Psychology, 16, 515-524. doi: 10.1002/acp.809

Palermo, G.B. (2004). The faces of violence (2nd ed.). Springfield, IL: Charles C. Thomas Publisher, Ltd.

Paivio, A. (1986). Mental representation: A dual coding approach. Hillsdale, NJ: Erlbaum.

Paivio, A. (1976). Imagery in recall and recognition. In J. Brown (Ed.), Recall and recognition. New York, NY: Wiley.

Papanastassiou, M., Waldron, G., Boyle, J., \& Chesterman, L. P. (2004). Post-traumatic stress disorder in mentally ill perpetrators of homicide. Journal of Forensic Psychiatry \& Psychology, 15, 66-75. doi: 10.1080/14789940310001630419

Paulhus, D. L., \& Vazire, S. (2007). The self-report method. Handbook of research methods in personality psychology, 1, 224-239. 
Payne, D. G. (1987). Hypermnesia and reminiscence in recall: A historical and empirical review. Psychological Bulletin, 101, 5-27. doi:10.1037/0033-2909.101.1.5

Peters, M. J., van Oorsouw, K. I., Jelicic, M., \& Merckelbach, H. (2013). Let's use those tests! Evaluations of crime-related amnesia claims. Memory, 21, 599-607. doi: $10.1080 / 09658211.2013 .771672$

Pica, G., Pierro, A., \& Giannini, A. (2015). The relationship between thought suppression and retrieval-induced forgetting: an analysis of witness memories. Cognitive Processing, 16, 3544. doi: 10.1007/s10339-014-0626-0

Picknett, L., Prince, C. \& Prioir, S. (2001) Double standards: The Rudolf Hess Cover-Up. London: Little, Brown \& Company.

Ponds, W. H. M., Van Boxtel, M.P.J., \& Jolles, J., R. (2000). Age-related changes in subjective cognitive functioning. Educational Gerontology, 26, 67-81. doi: 10.1080/036012700267402

Porter, S., Birt, A. R., Yuille, J. C., \& Hervé, H. F. (2001). Memory for murder: A psychological perspective on dissociative amnesia in legal contexts. International Journal of Law and Psychiatry, 24, 23-42. doi: 10.1016/S0160-2527(00)00066-2

Pyszora, N. M., Barker, A. F., \& Kopelman, M. D. (2003). Amnesia for criminal offences: a study of life sentence prisoners. The Journal of Forensic Psychiatry, 14, 475-490. doi: 10.1080/14789940310001599785

Pyszora, N. M., Fahy, T., \& Kopelman, M. D. (2014). Amnesia for violent offenses: factors underlying memory loss and recovery. Journal of the American Academy of Psychiatry and the Law Online, 42, 202-213.

Roediger, H. L., III, \& Butler, A. C. (2011). The critical role of retrieval practice in long-term retention. Trends in Cognitive Sciences, 15, 20-27. doi: 10.1016/j.tics.2010.09.003

Roediger, H. L., III, \& Karpicke, J. D. (2006). The power of testing memory basic research and implications for educational practice. Perspectives on Psychological Science, 1, 181-210. doi: 10.1111/j.1745-6916.2006.00012.x

Roesch, R., \& Golding, S. L. (1986). Amnesia and competency to stand trial: A review of legal and clinical issues. Behavioral Sciences \& the Law, 4, 87-97. doi: 10.1002/bs1.2370040107 
Roese, N. J., \& Epstude, K. (2017). The Functional Theory of Counterfactual Thinking: New Evidence, New Challenges, New Insights. Advances in Experimental Social Psychology, 56, 1-79. doi: 10.1016/bs.aesp.2017.02.001

Roese, N. J., \& Olson, J. M. (1997). Counterfactual thinking: The intersection of affect and function. Advances in Experimental Social Psychology, 29, 1-59. doi: 10.1016/s00652601(08)60015-5

Ross, S. M. (2000). Profound Retrograde Amnesia Following Mild Head Injury: Organic or Functional? Cortex, 36, 521-537. doi:10.1016/s0010-9452(08)70536-7

Sadoff, R.L. (1974). Evaluation of amnesia in criminal-legal situations. Journal of Forensic Sciences, 19, 98-101. doi: 10.1520/jfs 10075j

Sartori, G., Agosta, S., Zogmaister, C., Ferrara, S. D., \& Castiello, U. (2008). How to accurately detect autobiographical events. Psychological Science, 19, 772-780. doi: 10.1111/j.14679280.2008.02156.x

Saunders, J., \& MacLeod, M. D. (2006). Can inhibition resolve retrieval competition through the control of spreading activation? Memory \& Cognition, 34, 307-322. doi: 10.3758/bf03193409

Scoboria, A., Mazzoni, G., Kirsch, I., \& Milling, L. S. (2002). Immediate and persisting effects of misleading questions and hypnosis on memory reports. Journal of Experimental Psychology: Applied, 8, 26-32. doi:10.1037/1076-898x.8.1.26

Schacter, D. L. (1992). Understanding implicit memory: A cognitive neuroscience approach. American Psychologist, 47, 559-569. doi: 10.1037//0003-066x.47.4.559

Schacter, D. L. (1987). Implicit memory: History and current status. Journal of Experimental Psychology: Learning, Memory, and Cognition, 13, 1-5. doi: 10.1037//0278-7393.13.3.501

Schacter, D. L. (1986). Amnesia and crime: How much do we really know? American Psychologist, 41, 286-295. doi: 10.1037/0003-066X.41.3.286

Shaffer, W., \& Shiffrin, R. M. (1972). Rehearsal and storage of visual information. Journal of Experimental Psychology, 92, 292-296. doi: 10.1037/h0032076

Shaw, J. S., Bjork, E. L., Handal, A. (1995) Retrieval-induced forgetting in an eyewitness paradigm. Psychonomic Bulletin \& Review, 2, 249-253. doi:10. 3758/BF03210965 
Slobogin, C. (1982). Estelle v. Smith: The constitutional contours of the forensic evaluation. Emory LJ, 31, 71 .

Smith, G. P., \& Burger, G. K. (1997). Detection of malingering: validation of the Structured Inventory of Malingered Symptomatology (SIMS). Journal of the American Academy of Psychiatry and the Law Online, 25, 183-189. doi: 10.1037/t04573-000

Smith, D., \& Resnick, Ph. (2007). Amnesia and competence to stand trial. Journal of the American Academy of Psychiatry and the Law, 35, 541-543.

Storm, B. C., Bjork, E., \& Bjork, R. (2012). On the durability of retrieval-induced forgetting. Journal of Cognitive Psychology, 24, 617-629. doi: 10.1080/20445911.2012.674030

Storm, B. C., Bjork, E. L., Bjork, R. A., \& Nestojko, J. F. (2006). Is retrieval success a necessary condition for retrieval-induced forgetting? Psychonomic Bulletin \& Review, 13, 1023-1027. doi:10.3758/bf03213919

Sun, X., Punjabi, P. V., Greenberg, L. T., \& Seamon, J. G. (2009). Does feigning amnesia impair subsequent recall? Memory \& Cognition, 37, 81-89. doi: 10.3758/MC.37.1.81

Swihart, G., Yuille, J., \& Porter, S. (1999). The role of state-dependent memory in "red-outs". International Journal of Law and Psychiatry, 22, 199-212. doi: 10.1016/s01602527(99)00005-9

Symons, C. S., \& Johnson, B. T. (1997). The self-reference effect in memory: A meta-analysis. Psychological Bulletin, 121, 371-394. doi:10.1037/0033-2909.121.3.371

Takarangi, M. K., Strange, D., \& Houghton, E. (2015). Event familiarity influences memory detection using the aIAT. Memory, 23, 453-461. doi: 10.1080/09658211.2014.902467

Takarangi, M. K., Strange, D., Shortland, A. E., \& James, H. E. (2013). Source confusion influences the effectiveness of the autobiographical IAT. Psychonomic Bulletin \& Review, 20, 1232-1238. doi: 10.3758/s13423-013-0430-3

Taylor, P. J., \& Kopelman, M. D. (1984). Amnesia for criminal offences. Psychological Medicine, 14, 581-588. doi: 10.1017/S003329170001518X 
Terraciano, A., McCrae, R. R., \& Costa Jr, P. T. (2003). Factorial and construct validity of the Italian Positive and Negative Affect Schedule (PANAS). European Journal of Psychological Assessment, 19, 131-141. doi: 10.1027//1015-5759.19.2.131

Thompson, C. P., Skowronski, J. J., Larsen, S. F., \& Betz, A. L. (2013). Autobiographical memory: Remembering what and remembering when. London, UK: Psychology Press.

Tobias, B. A., Kihlstrom, J. F., \& Schacter, D. L. (1992). Emotion and implicit memory. The Handbook of Emotion and Memory: Research and Theory, 67-92. doi: $10.4324 / 9781315807454$

Tysse, J. E. (2005). Note: The Right to an Imperfect Trial-Amnesia, Malingering, and Competency to Stand Trial. Wm. Mitchell L. Rev., 32, 353.

Tysse, J. E., \& Hafemeister, T. L. (2006). Amnesia and the determination of competency to stand trial. Developments in Mental Health Law, 25, 65-80.

Van Oorsouw, K., \& Giesbrecht, T. (2008). Minimizing culpability increases commission errors in a mock crime paradigm. Legal and Criminological Psychology, 13, 335-344. doi.: $10.1348 / 135532507 \times 228539$

Van Oorsouw, K., \& Merckelbach, H. (2012). The effects of alcohol on crime-related memories: A field study. Applied Cognitive Psychology, 26, 82-90. doi: 10.1002/acp.1799

Van Oorsouw, K., \& Merckelbach, H. (2010). Detecting malingered memory problems in the civil and criminal arena. Legal and Criminological Psychology, 15, 97-114. doi: $10.1348 / 135532509 \times 451304$

Van Oorsouw, K., \& Merckelbach, H. (2006). Simulating amnesia and memories of a mock crime. Psychology, Crime \& Law, 12, 261-271. doi: 10.1080/10683160500224477

Van Oorsouw, K., \& Merckelbach, H. (2004). Feigning amnesia undermines memory for a mock crime. Applied Cognitive Psychology, 18, 505-518. doi: 10.1002/acp.999

Van Oorsouw, K., \& Merckelbach, H. (2004b). Amnesie als paradoxaal effect van herinneren. [Amnesia as a paradoxical effect of remembering]. De Psycholoog, 39, 544-549. 
Van Oorsouw, K. I. M., Merckelbach, H., Ravelli, D., Nijman, H., \& Mekking-Pompen, I. (2004). Alcoholic blackout for criminally relevant behavior. Journal of the American Academy of Psychiatry and the Law Online, 32, 364-370.

Vedder, A., \& Klaming, L. (2010). Human Enhancement for the Common Good-Using Neurotechnologies to Improve Eyewitness Memory. AJOB Neuroscience, 1, 22-33. doi:10.1080/21507740.2010.483996

Watkins, M. J., Peynircioĝlu, Z. F., \& Brems, D. J. (1984). Pictorial rehearsal. Memory \& Cognition, 12, 553-557. doi: 10.3758/bf03213343

Watson, D., Clark, L. A., \& Tellegen, A. (1988). Development and validation of brief measures of positive and negative affect: the PANAS scales. Journal of Personality and Social Psychology, 54, 1063-1070. doi: 10.1037/0022-3514.54.6.1063

Weldon, M. S., Roediger, H. L., \& Challis, B. H. (1989). The properties of retrieval cues constrain the picture superiority effect. Memory \& Cognition, 17, 95-105. doi: 10.3758/bf03199561

Wiggins, E. C., \& Brandt, J. (1988). The detection of simulated amnesia. Law and Human Behavior, 12, 57-78. doi:10.1007/bf01064274

Wilson, T. D., Lindsey, S., \& Schooler, T. Y. (2000). A model of dual attitudes. Psychological Review, 107, 101-126. doi: 10.1037//0033-295x.107.1.101

Windows M. R., \& Smith, G. P (2009). SIMS - Structured Inventory of Malingered Symptomatology. Adattamento italiano a cura di La Marca S., Rigoni D., Sartori G., \& Lo Priore C. Firenze, IT: Giunti OS.

Wright, D. B., Loftus, E. F., \& Hall, M. (2001). Now you see it; now you don't: Inhibiting recall and recognition of scenes. Applied Cognitive Psychology, 15, 471-482. doi.org/10.1002/acp.719.abs

Yonelinas, D. (2002). The nature of recollection and familiarity: A review of 30 years of research. Journal of Memory and Language, 46, 441-517. doi: 10.1006/jmla.2002.2864

Yonelinas, A. P., Kroll, N. E. A., Dobbins, I. G., \& Soltani, M. (1999). Recognition memory for faces: When familiarity supports associative recognition judgments. Psychonomic Bulletin \& Review, 6, 654-661. doi: 10.3758/bf03212975 
Zangrossi, A., Agosta, S., Cervesato, G., Tessarotto, F., \& Sartori, G. (2015). "I didn't want to do it!" The detection of past intentions. Frontiers in Human Neuroscience, 9:608. doi: 10.3389/fnhum.2015.00608

Zaragoza, M. S., Payment, K. E., Ackil, J. K., Drivdahl, S. B., \& Beck, M. (2001). Interviewing Witnesses: Forced Confabulation and Confirmatory Feedback Increase False Memories. Psychological Science, 12, 473-477. doi:10.1111/1467-9280.00388 



\section{Summary}

Oftentimes individuals charged with severe crimes, such as homicide and sexual assault, claim amnesia for their deeds. Crime-related amnesia represents a way for defendants to (1) try to obstruct police investigations, (2) keep silent about a shameful offence, or (3) be rendered incompetent to stand trial. Because genuine amnesia following a crime is quite rare, the likelihood of pretending to suffer from memory loss (i.e., malingering) should be taken into consideration. Moreover, when perpetrators choose to simulate memory loss for their criminal acts, relevant crime-related information might be forgotten. That is, research has shown that feigning amnesia has a detrimental effect on the actual memory for a crime (also known as the memory-undermining effect of feigning amnesia).

The main purpose of the current dissertation was to experimentally investigate the mechanism behind the simulating amnesia effect. Chapter 1 provides an introduction to the phenomenon of claims of crime-related amnesia. This chapter describes different types of amnesia, highlighting that claims of memory loss for severe crimes should (in most cases) be considered as a form of malingering. The relevance of crime-related amnesia for the legal system is also discussed. Finally, several hypotheses are given explaining why feigning leads to impairments in actual memory for a crime: (1) lack of rehearsal, (2) source monitoring confusion, (3) retrieval-induced forgetting.

Chapter 2 describes two studies that aimed to rule out the lack of rehearsal as the most likely explanation for the feigning amnesia effect. During the first memory phase, after being exposed to a violent mock crime video, participants were asked to either simulate amnesia (i.e., simulator group) or confess the crime (i.e., confessor group). A delayed testing-only control group was also involved (i.e., control group). After seven days, all participants were requested to genuinely recollect the crime event. Additionally, during the week between the first and second memory phase, some participants were provided with reminders of the crime in two different ways. In study 1, participants received visual cues related to the video via WhatsApp. Findings showed that visual reminders did not improve feigners' memory, meaning that confessors recollected the target experience better than simulators. In study 2, verbal cues were adopted, and this led to improved memory for the offence in simulators as well as confessors. Interestingly, simulators outperformed control participants in both studies. This supports the idea that memory decrements for feigners might not be due to lack of rehearsal.

In Chapter 3 a study is described in which a mock crime video was used to study the effect of simulating amnesia on actual memory. Moreover, in this chapter, we tried to extend previous findings by investigating whether the memory-undermining effect of feigning amnesia is modulated 
by inner speech activity. While inner speech traits were not found to be related to the simulators' memory decrements, this study showed that the effect of feigning amnesia on actual memory was smaller than that observed in previous research. That is, apart from a tendency to distort some crime-related information, perpetrators still had relatively intact memory for the crime.

Chapter 4 describes a study initiated to determine to which degree the simulating amnesia effect for a crime could be attributed to misattribution of the right source of information. Participants watched a mock crime video and they were instructed to either feign amnesia or confess the event. After one week, participants performed a personalized source monitoring task using the autobiographical Implicit Association Test (aIAT). Findings showed that simulators were able to discriminate the content of their self-generated feigned story of the crime from the original version. Moreover, they were faster than confessors at the aIAT task. These findings suggest that an implicit measure might be helpful in retrieving the source of some crime-related information and that simulators may preserve their memory for a crime despite previously feigning amnesia.

In Chapter 5 a study is described that examined whether retrieval-induced forgetting (RIF) underlies the memory-undermining effect of feigning amnesia for a crime. After watching a mock crime, participants had to feign amnesia or confess to having committed that crime. Feigners were given retrieval practice instructions (i.e., retrieval-practice group) or no further instructions (i.e., simulator control group). Immediately and one day later all participants had to genuinely report the crime. Although simulators in the retrieval-practice group reported the largest amount of total information as a positive consequence of retrieval, the ratio for crucial crime-related details was lower than that exhibited by both simulator control and confessors. This study suggests that RIF might play a role in forgetting critical information in crime-related amnesia.

Finally, in Chapter 6 the most important findings of the present dissertation are summarized. Theoretical and practical implications are provided, and avenues for future studies are described and discussed. Because the work reported in the current dissertation suggest that the feigning amnesia effect appears to be less solid than previously reported, further research on this phenomenon is needed. It is argued that the use of a non-invasive neuropsychological technique such as Transcranial Magnetic Stimulation (i.e., TSM) might perhaps enhance ex-feigners' memory for the criminal experience. 




\section{Sommario}

Individui spesso accusati di crimini violenti, come omicidi e violenze sessuali, dichiarano amnesia per i loro reati. Fingere di non ricordare a seguito di un crimine rappresenta per gli imputati un modo per ostruire le indagini poliziesche, nondimeno un tentativo per interferire con i procedimenti giudiziari. Poiché l'amnesia genuina a seguito di un crimine è abbastanza rara, la possibilità che tale condizione sia fabbricata (i.e., simulazione) deve essere presa in considerazione. Inoltre, quando gli autori di reato scelgono di dichiarare perdita di memoria per i loro atti criminali, rilevanti informazioni possono essere dimenticate. Ovvero, ricerche hanno dimostrato che la simulazione di amnesia ha un effetto di deterioramento sulla memoria genuina dello stesso crimine (i.e., the memory-undermining effect of feigning amnesia).

L'obiettivo principale della presente tesi è di investigare sperimentalmente i possibili meccanismi cognitivi sottostanti l'effetto negativo della simulazione di amnesia. Il Capitolo 1 è una introduzione al fenomeno della "amnesia simulata" pertinente gli autori di reato. Questo capitolo descrive i differenti tipi di amnesia, mettendo in luce come tali affermazioni di perdita di memoria possano essere considerate come una forma di simulazione a seguito di crimini violenti. La rilevanza pratica in ambito legale di tali dichiarazioni di amnesia sono oltremodo discusse. Infine, sono fornite diverse possibili ipotesi esplicative in merito al perché, col passare del tempo, la memoria degli autori di reato in merito al crime commesso è compromessa: (1) assenza di reiterazione, (2) confusione nel monitoraggio della fonte, (3) dimenticanza-indotta dal recupero.

Il Capitolo 2 descrive due studi che hanno cercato di confutare l'assenza di reiterazione come spiegazione più parsimoniosa in merito all'effetto negativo della simulazione di amnesia sul ricordo di un crimine. Durante la prima sessione, dopo essere stati esposti a un filmato di un finto crimine violento, ai partecipanti è stato chiesto di fingere amnesia (i.e., gruppo di simulatori) o di confessare il crimine (i.e., gruppo di confessori). Anche un gruppo testato solo durante la seconda sessione è stato coinvolto (i.e., gruppo di controllo). Dopo sette giorni, a tutti i partecipanti è stato chiesto di rievocare l'evento in modo genuino. Inoltre, durante la settimana tra la prima e la seconda sessione, alcuni partecipanti hanno ricevuto reminder del crimine in due diverse modalità. Nello studio $1, \mathrm{i}$ partecipanti hanno ricevuto cue visivi relativi al video. I risultati hanno dimostrato che tali reminder visivi non hanno incrementato la memoria dei simulatori. In altre parole, i confessori hanno ricordato meglio l'esperienza target rispetto ai simulatori. Nello studio 2, cue verbali sono stati adoperati e questo ha portato ad incrementare la performance mnestica dei simulatori per il crimine tanto quanto quella dei confessori. D'interesse, i simulatori hanno ricordato meglio rispetto al gruppo di controllo in entrambi gli studi. Questo risultato supporta l'idea che deficit mnestici per 
i simulatori possono essere dovuti all'atto della simulazione in se piuttosto che all'assenza di reiterazione.

Il Capitolo 3 replica la procedura standard per lo studio degli effetti della simulazione di amnesia utilizzando lo stesso stimolo criminoso utilizzato nei precedenti studi (i.e., video di un crimine) anziché una storia narrativa. Inoltre, questo capitolo cerca di estendere i risultati precedenti investigando se gli effetti negativi della simulazione di amnesia sulla memoria siano modulati da attività di inner speech. Mentre i tratti individuali di inner speech non sono stati trovati essere in relazione con gli effetti negativi sulla memoria della simulazione di amnesia, questo studio ha mostrato che l'effetto della simulazione si verifica in una misura minore rispetto allo stesso osservato in passate ricerche. Ossia, nonostante una tendenza nel distorcere alcune informazioni pertinenti il crimine commesso, gli autori di reato possono ancora avere memoria intatta del crimine nonostante aver simulato precedentemente amnesia.

Il Capitolo 4 indaga la misura in cui l'effetto della simulazione di amnesia per un crimine possa essere dovuta ad una attribuzione errata della corretta fonte di informazione. Dopo aver guardato un videoclip di un finto crimine, ai partecipanti è stato richiesto di simulare una perdita di memoria oppure di confessare l'evento. Dopo una settimana, ogni partecipante ha svolto un compito di monitoraggio della fonte usando l'autobiographical Implicit Association Test (aIAT). I risultati hanno mostrato come i simulatori sono stati abili nel discriminare il contenuto della loro personale versione simulata del crimine dall'evento originale. Inoltre, essi sono stati più rapidi dei confessori nel compito aIAT. Questo studio suggerisce come una misura implicita potrebbe essere d'aiuto nel recuperare la fonte di alcune informazione pertinenti il crimine e come i simulatori potrebbero preservare la memoria dello stesso nonostante aver precedentemente finto di non ricordare l'accaduto.

Il Capitolo 5 esamina se la dimenticanza-indotta dal recupero (RIF) possa essere alla base dell'effetto negativo della simulazione di amnesia sul ricordo di un crimine. Dopo aver guardato il mock crime video, ai partecipanti è stato chiesto di simulare amnesia oppure di confessare. Alcuni simulatori hanno ricevuto istruzione su come ripetere determinate informazioni dell'evento, oppure nessuna specifica indicazione. Immediatamente e dopo ventiquattro ore, tutti i partecipanti sono stati invitati a richiamare onestamente l'evento criminoso. Sebbene i simulatori che hanno ricevuto istruzioni in merito a come ripetere specifiche informazioni del crimine, abbiano riportato un maggior numero totale di dettagli - presumibilmente come effetto positivo della pratica di ripetizione - la percentuale d'informazioni cruciali in merito al crimine riportata da questo gruppo di simulatori è stata inferiore rispetto a quella del gruppo di controllo ed ai confessori. Questo 
studio argomenta come il RIF effect possa giocare un ruolo nella dimenticanza d'informazioni cruciali del crimine in casi di amnesia a seguito di reati.

Infine, nel Capitolo 6 i risultati più importanti degli studi sopra esposti sono riassunti. Implicazioni teoriche e pratiche, e indicazioni per futuri studi sono fornite e discusse. Nel complesso, poiché nella presente tesi l'effetto dell'amnesia simulata sembra essere meno solido rispetto a quello dimostrato in precedenti ricerche, nuove indagini concernenti la misura in cui questo fenomeno mina effettivamente la memoria per un crimine sono necessarie. Forse, l'uso di "cue", in grado di aumentare le probabilità di un recupero mnestico in combinazione con nuove neuropsicologiche tecniche non invasive - come ad esempio la Stimolazione Magnetica Transcranica (TSM) - potrebbe contribuire a migliorare la memoria per il crimine commesso in autori di reato che in precedenza hanno simulato amnesia per lo stesso evento criminoso. 



\section{Valorisation Addendum}

In the following pages, four issues will be addressed with regard to the current dissertation. Firstly, the relevance of the research described in the thesis will be discussed. Secondly, the target population to whom this dissertation may be relevant, and products that may derive from its findings will be taken into account. Thirdly, the degree of innovation of the thesis will be highlighted. Finally, implementation and knowledge dissemination of the findings of the current dissertation will be provided.

\section{Relevance}

The current dissertation focuses on the cognitive mechanisms underlying the detrimental effects of feigning amnesia on offenders' actual memory for a crime. This is a relatively new and, for several reasons, challenging topic. In recent years, scholars have accepted the notion that victims involved in specific types of offences (e.g., sexual assaults) may have difficulty in providing a comprehensive account of what has took place. Might the same notion be applied to offenders? If so, which cognitive factors may undermine the completeness of perpetrators' statements? Given the various motivations that they may have to withhold the truth, the present thesis examines the consequences for memory when individuals feign crime-related amnesia, in order to understand and explain why and how this phenomenon does affect defendants' actual memory for an offence they committed.

Despite progress in legal psychological research, little is known about offenders' memory for a crime. Specifically, it is unclear what happens to memory for a criminal experience when defendants adopt deceptive strategies such as feigning amnesia. Although research on the malleability of memory (e.g., Loftus, 2005) is abundant in the literature, studies on the relationship between feigning amnesia and memory for a crime are scarce. Using a set of empirical studies, the current dissertation aims to gain insight in the all-to-human nature of offenders' memory for a crime.

\section{Target Population and Products}

According to some authors, the most common form of memory loss in a legal context is feigned crime-related amnesia (e.g., Cima et al., 2002). Take for instance the well-known case of Rudolf Hess (Picknett, Prince, \& Prioir, 2001). He claimed memory loss for his entire Third Reich period during the Nuremberg trial. Some prominent psychiatrists stated that his memory loss was genuine. However, when Hess discovered that, due to his amnesia, he could not respond to the allegations against him, he suddenly declared during one of the trial sessions that he had fooled the psychiatrists and feigned his amnesia. This illustrates that crime-related amnesia represents a 
serious concern for professionals working in criminal law. Clearly, findings from the current dissertation may be relevant for judges, prosecutors, lawyers, and police officers. Because memory loss for an offence has benefits to defendants, a nontrivial part of them feign complete or partial crime-related amnesia. Hence, it is important for legal professionals to know what perpetrators can remember from crimes they have committed. Offenders who confess to the police usually have good memory for their offences in court. But what if a defendant, similar to Rudolf Hess, initially feigns amnesia for an offence, but later gives up his role as a feigner? The results reported in Chapters 2 and 3 show that such individuals are still able to recollect large parts from their crime. The research reported in this dissertation also may be useful for police officers involved in interrogating suspects. The findings reported in Chapter 5 demonstrate that interviewing suspects repeatedly about one part of a crime might, via RIF, make other parts of the offence inaccessible. Therefore, it is recommended that police interrogations should not focus on specific aspects of the crime, but should deal with each and every element of the (alleged) crime.

\section{Innovation}

The aim of this dissertation was to examine which cognitive mechanisms might be considered the best explanation for the memory-undermining effect of feigning amnesia. The work presented in the current thesis is unique in the sense that all three hypotheses pertaining to detrimental effects of feigned amnesia on genuine memory for a crime were investigated. While in the last two decades the "lack of rehearsal" hypothesis has been crowned to be the most parsimonious explanation for the feigning amnesia effect (e.g., Christianson \& Bylin, 1999; Van Oorsouw \& Merckelbach, 2006), no research has focused on alternative accounts for this negative mnemonic phenomenon. The explanations examined here include not only lack of rehearsal, but also inner speech, source monitoring and implicit memory, and retrieval induced forgetting. While doing so, different approaches, methodologies, and techniques, were adopted to get a more complete picture pertaining to this crucial topic. For instance, a mock crime video (also reordered in point of view, see Chapter 4 and 5) was used to increase ecological validity, thereby bypassing more traditional crime stimuli (e.g., narrative stories). In Chapter 2 WhatsApp messages were used in an attempt at visually rehearsing the crime experience. In Chapter 4 the source monitoring confusion explanation was investigated by utilizing an implicit measure such as the aIAT, while in Chapter 5 a RIF procedure was adapted to the feigning amnesia for a crime paradigm. In closing, one could argue that the current dissertation contains a set of innovative studies. 


\section{Implementation and Knowledge Dissemination}

The studies comprising this dissertation have all been disseminated in several ways. The studies presented in Chapter 3 and 4 have been published in international peer-reviewed journals, while the studies in Chapter 2 and 5 are currently under review. Moreover, Chapter 1 and 6 will be used for a review article on crime-related amnesia. In addition, all the studies have been presented at several national and international conferences, which were attended by both scholars and legal practitioners. Finally, the main findings of the present dissertation have also been mentioned in lectures and courses for students - who will be future researchers, legal psychologists and practitioners. 



\section{Acknowledgments}

I would like to acknowledge all the people who have, in various ways, helped me to carry out my research, thereby contributing to my professional and personal growth. To begin with, my deepest gratitude goes to all of my three supervisors: I would like to thank Antonietta Curci, who has, in her own way, taught me to be passionate about research and how to make the first steps in academia - grazie mille, Antonietta; I would like to thank Marko Jelicic, who has been more than a mere promotor in this last year and who has always left his office's door open for me, providing me with advices, insights and guidance that will stay with me forever - hvala puno, Marko; Finally, I would like to thank Kim van Oorsouw, who has strongly believed in me. I would not be defending this dissertation at Maastricht University if it was not for her - van harte bedankt, Kim.

I want to thank to all of my colleagues and friends at the University of Bari. Notably, I would like to thank Tiziana for being always understanding and helping me out in the toughest period of this $\mathrm{PhD}$, the beginning. I would like to thank Franceschina and Grazia for the amusing, cheerful and sometimes miserable moments that we have had together. In the same vein, a owe a big "thank you" to all my colleagues and friends at Maastricht University: Each and every of you has made me feel at home, rendering the whole experience in Maastricht as the most remarkable journey of my entire life. Particularly, I would like to thank Harald and Henry for being encouraging and motivating especially in these last months. Finally, I would like to thank Leonardo who has not been only a colleague with whom I shared my lunch breaks, but who has also rapidly become a close and loyal friend.

I am thankful to my best evergreen-friends, Domenico, Enrico, and Francesco, who have invariably showed interest, devotion, and affection for the last fourteen years. Regardless of the distance, I have felt them close to me every single day.

Thank you to my buddy, my partner in crime, my biggest support, moja žena Irena, who has suddenly entered my life turning it upside down and enriching it. Thank you for all the patience, care, encouragement, laugher, and love you have been giving me. Ne postoje reči koje mogu da opišu koliko te volim. Uvek i zauvek.

Dulcis in fundo, ringrazio infinitamente la mia famiglia. Grazie ai miei genitori che mi hanno insegnato l'arte del vivere e del credere nei propri sogni. Tutto quello che oggi ho e che un domani conquisterò, lo devo a voi. Grazie a mia sorella, la ragione più grande per cui non ho mai mollato e a cui auguro il meglio dalla vita. 



\section{Curriculum Vitae}

Ivan Mangiulli was born on the $17^{\text {th }}$ of October 1989, in Bari, Italy. After having received his diploma from A. Scacchi High School, in 2008 he started studying Psychological Science and Techniques at the University of Bari A. Moro, Italy. In November 2011, he received the bachelor's diploma and, in the same year, he started the master in Clinical Psychology at the same university. In October 2013 he received the master's diploma, cum laude. While in the beginning of 2014 he started the $2^{\text {nd }}$ level master in Forensic Psychopathology and Neuropsychology at the University of Padua (Italy), in November 2014 he won a grant from the Italian Government that allowed him a 3year fellowship to start a $\mathrm{PhD}$ in psychology at the Department of Education, Psychology, Communication, University of Bari A. Moro. In May 2015, he got the $2^{\text {nd }}$ level master's diploma and he obtained the Psychologist Qualification from the Order of Psychologists of Puglia (Italy) in October 2015.

From November 2016 he was appointed as a PhD student also at the Faculty of Psychology and Neuroscience, Maastricht University. His PhD project on the cognitive mechanisms underlying the memory-undermining effect of feigning amnesia for a crime was supervised by Dr. Antonietta Curci in Bari, and Prof. dr. Marko Jelicic and Dr. Kim van Oorsouw in Maastricht. 


\section{List of Publications}

\section{Articles published in peer-reviewed journals}

1. Mangiulli, I., van Oorsouw, K., Curci, A., Merckelbach, H., Jelicic, M. (2018): Feigning amnesia moderately impairs memory for a mock crime video. Frontiers in Psychology, 9:625. doi:10.3389/fpsyg.2018.00625

2. Mangiulli, I., Lanciano, T., Jelicic, M., van Oorsouw, K., Battista, F., \& Curci, A. (2018). Can implicit measures detect source information in crime-related amnesia?. Memory, 26, 1019-1029. doi: 10.1080/09658211.2018.1441421

3. Lanciano, T., Soleti, E., Guglielmi, F., Mangiulli, I., \& Curci, A. (2016). Fifty shades of unsaid: Women's explicit and implicit attitudes towards sexual morality. Europe's Journal of Psychology, 12, 550-556. doi: 10.5964/ejop.v12i4.1124

4. Quarto, T., Blasi, G., Maddalena, C., Viscanti, G., Lanciano, T., Soleti, E., Mangiulli, I., ... \& Curci, A. (2016). Association between ability emotional intelligence and left insula during social judgment of facial emotions. PloS One, 11, e0148621. doi: 10.1371/journal.pone.0148621

\section{Manuscript under review:}

1. Mangiulli, I., Lanciano, T., Van Oorsouw, K., Jelicic, M., \& Curci, A. (2018). Do visual and verbal reminders of the crime reverse the memory-undermining effect of simulating amnesia?. Manuscript under review

2. Mangiulli, I., Van Oorsouw, K., Curci, A., \& Jelicic, M., (2018). Retrieval-Induced Forgetting in the Feigning Amnesia for a Crime Paradigm. Manuscript under review

\section{Books}

1. Mangiulli, I. (2016). La suggestionabilità interrogativa: contributo alla validazione della GSS su un campione italiano (Interrogative suggestibility: a contribution to the Italian GSS validation). Edizioni Accademiche Italiane, ISBN: 978-3-639-77998-1 


\section{Main Conference Contribution}

1. Mangiulli, I., van Oorsouw, K., Curci, A., \& Jelicic, M. (2018, June). Retrieval-Induce Forgetting in the Simulating Amnesia Paradigm. Poster presentation given at Sepex - Sepneca Aip experimental (joint conference), Madrid, Spain

2. Mangiulli, I., van Oorsouw, K., Curci, A., \& Jelicic, M. (2018, June). Retrieval-Induce Forgetting in the Simulating Amnesia Paradigm. Oral presentation given at European Association Psychology and Law conference (EAPL), Turku, Finland

3. Mangiulli, I., Lanciano, T., Jelicic, M., van Oorsouw, K., \& Curci, A. (2017, September). Can the IAT detect source information in crime-related amnesia?. Oral presentation given at Italian Psychology Association (IPA) - Experimental Psychology Section, Bari, Italy

4. Mangiulli, I., Lanciano, T., Jelicic, M., van Oorsouw, K., \& Curci, A. (2017, May). Can the IAT detect source information in crime-related amnesia?. Oral presentation given at European Association Psychology and Law conference (EAPL), Mechelen, Belgium

5. Mangiulli, I., \& Curci, A. (2016, September). Il ruolo della reiterazione nella simulazione di amnesia di reato. Oral presentation given at Italian Psychology Association (IPA) - Experimental Psychology Section, Rome, Italy

6. Mangiulli, I., Lanciano, T. \& Curci, A. (2015, September). Può l'assenza di reiterazione giustificare l'amnesia di un crimine? Uno studio sperimentale sulla simulazione di amnesia. Oral presentation given at Italian Psychology Association (IPA) - Experimental Psychology Section, Rovereto, Italy 


Cover designed by Sabrina Fiore 